\title{
Enzymes for Degradation of Energetic Materials and Demilitarization of Explosives Stockpiles \\ SERDP Annual (Interim) Report, 12/98
}

M. M. Shah, Ph.D.

January 1999

Prepared for

The U.S. Department of Energy

Under Contract DE-AC06-76RLO 1830

Pacific Northwest National Laboratory

Richland, Washington 99352 


\section{DISCLAIMER}

This report was prepared as an account of work sponsored by an agency of the United States Government. Neither the United States Government nor any agency thereof, nor any of their employees, make any warranty, express or implied, or assumes any legal liability or responsibility for the accuracy, completeness, or usefulness of any information, apparatus, product, or process disclosed, or represents that its use would not infringe privately owned rights. Reference herein to any specific commercial product, process, or service by trade name, trademark, manufacturer, or otherwise does not necessarily constitute or imply its endorsement, recommendation, or favoring by the United States Government or any agency thereof. The views and opinions of authors expressed herein do not necessarily state or reflect those of the United States Government or any agency thereof. 


\section{DISCLAIMER}

Portions of this document may be illegible in electronic image products. Images are produced from the best available original document. 


\section{Summary}

The current stockpile of energetic materials requiring disposal contains about half a million tons. Through 2001, over 2.1 million tons are expected to pass through the stockpile for disposal. Safe and environmentally acceptable methods for disposing of these materials are needed.

This project is developing safe, economical, and environmentally sound processes using biocatalysts (enzymes) to degrade energetic materials and to convert them into economically valuable products. Altemative methods for destroying these materials are hazardous, environmentally unacceptable, and expensive. These methods include buming, detonation, land and sea burial, treatment at high temperature and pressure, and treatment with harsh chemicals. Enzyme treatment operates at room temperature and atmospheric pressure in a water solution.

A series of experiments demonstrated the ability of redox enzymes from spinach (ferredoxin NADP oxidoreductase, and glutathione reductase), buttermilk (xanthine oxidase), and $E$. coli (oxyrase) to transform 2,4,6-trinitrotolune (TNT). All enzymes rapidly transformed TNT into a 4-hydroxylamino-2,6-dinitrotoluene intermediate. Hence, we expect that TNT degrading enzymes will be ubiquitous in nature and thus the scale of the process will not be limited from enzyme availability perspective. The subsequent fate of 4HADNT is currently under investigation. The rate of transformation icreased with increases in the concentration of both TNT and the enzyme.

The relevant process engineering parameters for scale-up were addressed using mathematical modelling of the process. Mathematical simulations were conducted for a proposed processing tank methodology for the enzymatic destruction of TNT. Two coupled rate equations contain terms for aqueous-phase transformation, solid-phase transformation, and solid TNT dissolution. Simulations showed that aqueous TNT concentrations rapidly became and remained low, limited by the relatively slow dissolution rate of solid TNT. They also showed that concentration versus time profiles contained a substantial initial period of linear decline. Sensitivity studies conducted for the operating parameters of the engineered tank showed that the time for 100 percent disappearance of the added TNT was a linear function of the total enzyme concentration and the initial solid TNT concentration for the particular values of the other input parameters describing the expected processing tank system. Based on work conducted thus far, the simulated disappearance times were short enough to indicate the feasibility of this methodology for TNT destruction. A news release of the potential enzymatic process for the degradation of explosives provided evidence for public acceptance of the technology. It received attention and interest from end users, defense contractors, media, scientific magazines, and regulatory agencies. The total circulation number for the coverage was 2.6 million.

Potential commercial applications of TNT derivatives were studied. Products include aromatic hydroxylamines, aminophenols, and mixtures of those products. The most promising products, in order, appear to be 1) antioxidants, 2) curing agents, 3) biocides/disinfectants, 4) monomers, and 5) pharmaceutical and agricultural chemicals. Flame retardants and azo dyes were also evaluated, however they require further chemical processing of the main products produced in the enzyme processes.

Sodium chlorite and potassium superoxide, powerful oxidizers, were also shown to be effective, safe treatments for hexahydro-1,3,5-trinitro-1,3,5-triazine (RDX) and octahydro-1,3,5,7-tetranitro-1,3,5,7tetrazocine (HMX). The small molecules can penetrate the microstructure of bulk explosives, allowing the destruction of explosive devices that cannot be safely disassembled for treatment. Nitrate and nitrite were the primary by products. 



\section{Acknowledgements}

This research was supported wholly by the U.S. Department of Defense, through the Strategic Environmental Research and Development Program (SDERP). 



\section{Contents}

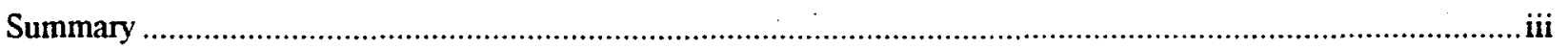

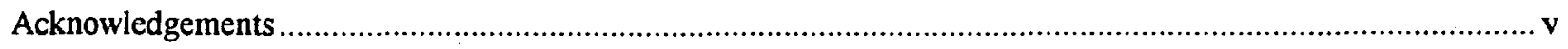

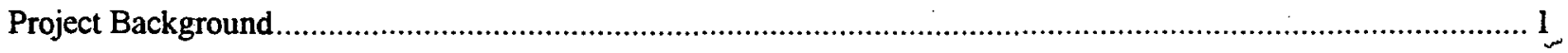

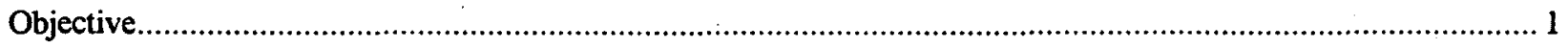

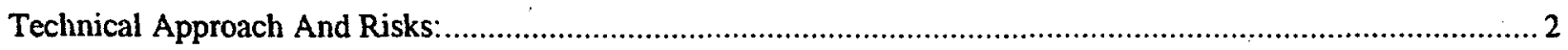

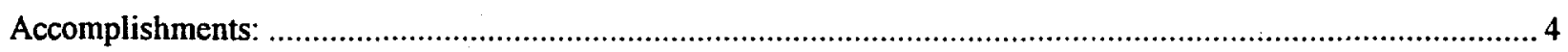

Appendix A - Transformation of 2,4,6-trinitrotoluene (TNT)

by Redox Enzymes from Spinach, Buttermilk, and $E$. coli............................................... A.l

Appendix B - Mathematical Simulation of Enzyme-Catalyzed TNT

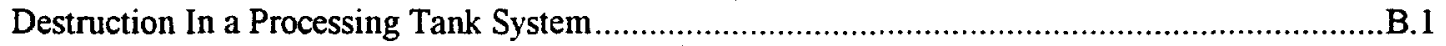

Appendix C - Potential Commercial Applications of Products from

Environmentally Sound and Safe Transformations of TNT ...........................................

Appendix D - Degradation of Octahydro-1,3,5,7-tetranitro-1,3,5,7-tetrazocine (HMX)

by Sodium Chlorite under Aqueous Conditions ........................................................... D.1

Appendix E - Degradation of Hexahydro-1,3,5-trinitro-1,3,5-triazine (RDX)

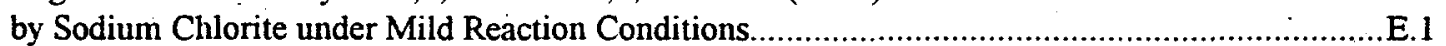

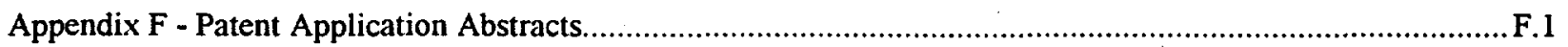




\title{
SERDP ANNUAL (INTERIM) REPORT, 12/98
}

\author{
(Project CP/1078/7)
}

December 16, 1998

Project Title: Enzymes for Degradation of Energetic Materials and Demilitarization of Explosives Stockpiles Agency: Department of Energy

Lab: Pacific Northwest National Laboratory

PI: Dr. Manish Shah

Thrust Area: Compliance

\section{Project Background}

The current stockpile of energetic materials requiring resource recovery or disposition (RRD) contains about 500,000 tons. Through 2001, over 1.2 million tons will pass through or reside in the RRD account. Safe and environmentally sound techniques are needed for disposal of energetic materials.

\section{Objective}

The objective of the current project is to develop a safe, economical and environmentally sound process using biocatalysts (enzymes) to degrade energetic materials, with an option of converting them into value added products. The proposed process can operate at room temperature and atmospheric pressure in the aqueous phase. The proposed technology is much different than microbial processes as it can tolerate high concentrations of explosives or solvents and will use catalysts with the highest activity per unit weight of the catalyst. The process does not employ open buming or open detonation to destroy energetic materials. It can stand by itself or augment and support other technologies for treating energetic materials. An enzyme based process will also provide the altemative of converting explosives into commercially valuable chemicals because the transformation process can be controlled to accumulate desired intermediates. The proposed technology will not release any air pollutants; the proposed enzyme technology will meet the regulations of Clean Air Act amendments, Resource Conservation and Recovery Act (RCRA) and Federal Facilities Compliance Act (FFCA). The development of enzyme technology is possible now because of recent developments in enzyme technology. Robust and active enzymes can now be developed that will withstand harsh reaction environments. These robust enzymes are developed by cross linking enzyme crystals. Altematively, inexpensive enzymes can be used as disposable catalysts in the same manner as their use by the detergent and food industries.

In our early work, we discovered that enzymes from spinach leaves could degrade the explosive tetryl. More detailed research and development efforts lead to the further discovery that enzymes from spinach leaves could also degrade TNT but not nitramine explosives such as RDX and HMX. The nitroreductase enzyme from spinach also reacted with 2,4,6-trinitrotoluene (TNT) and synthesized 4-hydroxylamino 2,6dinitrotoluene, which has potential uses in the production of antioxidants. This TNT conversion process could provide a zero-cost altemative for the disposal of unusable TNT stockpiles around the world. The rate of degradation of TNT by enzymes increased with increases in enzyme and TNT concentration. TNT was also degraded by enzymes above TNT's solubility limit of $100 \mathrm{ppm}$. Mathematical simulation studies suggested that the kinetics of the process are limited by the rate of dissolution of TNT. Mathematical simulation studies also suggested that insoluble TNT particles with diameters of $1 \mathrm{~mm}$ or less give the best kinetics of degradation. Our study also suggested that TNT degrading enzymes are probably ubiquitous in natural sources such as plants, dairy products, and microbial membranes. This is simply because these 
enzymes reduce biological molecules of higher redox potential and size in their natural function. This also explains why TNT is toxic to living organisms: high concentrations of TNT interfere with the natural functions of these enzymes.

To find enzymes that would degrade nitramine explosives, we decided to develop biomimetic processes. We discovered that the nitramine class of explosives could be treated more effectively using potassium superoxide. The mechanism used was similar to the natural defense system of humans, which produces superoxides to defend against environmental toxins or microorganism invasions. In addition to superoxide, we discovered that bleaching agents, such as sodium chlorite, could destroy RDX and HMX.

These results were very encouraging in our efforts to develop an environmentally benign digestion process for the destruction or conversion (in some situations) of explosives. We anticipate that we will have both enzymatic and biomimetic processes to achieve our objective. Based on this knowledge, we will seek out enzymes for degradation of RDX and HMX. We will look for enzymes that have redox potential or the ability to produce redox reactants similar to sodium chlorite, superoxide, or equivalent reactants. We will also investigate the degradation of metabolites of TNT formed by enzymatic processes. We would like to see if the metabolites are biodegradable by microorganisms. We will evaluate industrial options for 4hydroxylamine-2,6-dinitrotoluene, as it is relative easy to synthesize from TNT. Our preliminary market assessment with a consultant from Air Products Chemical Company suggested that it may be converted to an antioxidant and, potentially, other applications.

We now have a sound foundation for providing environmentally benign and safe methods for the synthesis and destruction of nitrocompounds at room temperature without heating and without the use of organic solvents. Unlike incineration, the PNNL biomimetic process based on potassium superoxide allows the destruction of explosives under mild reaction conditions. These emerging enzyme and biomimecic technologies provide an environmentally benign, safe, and cost-effective method for destroying explosives and other nitrocompounds.

\section{Technical Approach And Risks:}

The project is a joint effort between Pacific Northwest National Laboratory, Genencore Intemational, and the Demil Technology Office (Defense Ammunition Center) at Savanna, Illinois. The overall technical approach for the proposed research involves the developing enzymatic or equivalent biomimetic transformation of munitions such as TNT, RDX, and HMX in different forms (composition A, B, C, D, H-6, Tritonal) to intermediate products. The intermediate products, in some cases, are expected to have reduced or no toxicity and thus will be evaluated for their approval for disposal by the regulatory agencies. In other cases, the intermediates could be used as a feed stock in the chemical industry or degraded to carbon dioxide and water using microbial and chemical processes. We will evaluate the toxicity of the intermediate products and final products.

We have a biocatalyst that operates at room temperature and atmospheric condition in aqueous phase to degrade munitions. The first need for the project is an understanding of the kinetics and mass transport issues involved in explosive degradation by an enzymes under heterogeneous conditions. The conversion of explosives (for example, TNT) by an enzyme-catalyzed heterogeneous solid-liquid system is different from a normal heterogeneous catalytic system since the catalyst (enzyme) is in the aqueous system. The change in concentration of TNT will therefore require a TNT material balance. TNT is degraded both in solution and on the surface of explosive particles. The size and mixing of TNT particles could have dramatic effects on the kinetics of the process. Since the reaction is a surface reaction, the rate of reaction will be one of the boundary conditions for the differential equation. Additionally, the kinetics will have to account for the change in the surface area with the passage of time. The basic equation is a transient equation suitable for the 
moving boundary problem. Assuming a single TNT particle to be spherical with angular symmetry, the change in radius can be related to the velocity of the moving boundary. This equation, once solved for a single particle, can be integrated for the entire reactor volume to get the change in TNT concentration with time. Hence, the first task is to characterize the kinetics of the enzymatic process under heterogeneous conditions. We will determine the kinetics where explosives will be used in both dissolved and insoluble form. The rate limiting component for the heterogeneous catalysis will be identified. Ideally, one would like to dissolve explosive munitions by incubating them in an enzyme bath. Parameters that can be used to enhance the kinetics of the process will be exploited. This first task of assessing kinetics and mass transport of explosive degradation by enzymes will be done by mid year.

Ferredoxin NADP reductase enzyme (FNR) from spinach can reduce 2,4,6-trinitrophenylmethylnitramine (tetryl) and 2,4,6-trinitrotoluene (TNT). A number of other redox enzymes (glutathione reductase, xanthine oxidase) could also exhibit explosive degradation activity. These enzymes are ubiquitous in nature and thus can be obtained in large quantity. The rate of transformation is estimated to be about $7 \mu \mathrm{moles} / \mathrm{min} / \mathrm{mg}$ of the enzyme. For TNT in solution, the estimated treatment time for 1 liter of waste stream containing $440 \mu \mathrm{M}$ (100 ppm) of explosive TNT can be as low as 4 seconds for one gm of enzyme. This is a significant improvement over the traditional microbial processes, which would take anywhere from days to weeks or months for the degradation of explosives. A complete oxidation of the metabolites to carbon dioxide is more doable after removal or reduction of the nitro group present in energetic materials. Enzymatic processes also provide an altemative, the accumulation of intermediates of TNT metabolism, which can be of commercial value. We will be attempting to convert TNT into a chemical intermediate (hydroxylamine/phenol) which can be used in free radical based polymerization processes. The market value for such chemicals ranges from $\$ 2$ to $\$ 10$ per pound.

Explosives can be attacked by enzymes and enzyme mediators under either oxidizing or reducing conditions. Another important point to note here is that the size (less than one micron) of the enzyme molecule or its mediator (less than 100 angstroms) will be small, and they can penetrate the plastic explosive matrix. In addition, enzymes can be sprayed at remote locations where access is difficult or expensive with current technologies. Reactions of redox enzymes with nitroaromatic and nitramine explosives are summarized below.

\section{Reductive Attack}

A. Single- or two-electron reduction step process for the reduction of nitroaromatic explosives:

$$
\mathrm{RNO}_{2} \rightarrow \mathrm{RNO} \rightarrow \mathrm{RNHO} \rightarrow \mathrm{RNH}_{2}
$$

B. Newly discovered single-electron reduction step process for nitramine explosives:

$$
\mathrm{RN}-\mathrm{NO}_{2} \rightarrow\left[\mathrm{RN}^{-\mathrm{NO}_{2}}\right]^{-} \rightarrow \mathrm{RNH}+\mathrm{NO}_{2}^{-}
$$

or: Hydride-based reduction of nitroaromatic chemicals:

$$
\mathrm{RNO}_{2}+\mathrm{H}^{-} \rightarrow \mathrm{RH}+\mathrm{NO}_{2}
$$

\section{Oxidoreductive Attack}

This is a very innovative and unique approach with tremendous potential. Under this approach, enzymes will be used to generate reactive cation radicals, anion radicals, or oxygen radicals of widely differing redox potentials. As a result, the process could be applicable for the treatment of a number of structurally diverse energetic materials. In addition to nitroreductase enzymes, we will investigate the transformation of explosives by oxidative enzymes such as peroxidases. Peroxidase enzymes can catalyze both oxidative and reductive reactions. Peroxidases are available commercially in large quantity at a price of 250,000 million units of activity for $\$ 10$ (Enzymol, Intemational, Inc.). Peroxidases can produce highly powerful oxidant 
radicals, such as aromatic cation radicals and hydroxyl radicals, or highly reducing carboxylate anion radicals and superoxide anion radicals. They can oxidize (iodide, cyanide, and methoxyphenols) or reduce (carbon tetrachloride, cytochrome $c$, ferric iron, and nitrobluetetrazolium) molecules under different reaction conditions. Genencore Intemational, our collaborator, has several potential proprietary enzymes, which will be available to us. One of them, laccase, an oxidative enzyme, uses molecular oxygen (air) for catalyzing oxidative reactions. Overall, our strategy of enzyme selection is cost and availability driven.

We believe that the proposed line of research has high probability of success. It will certainly have niche in the treatment and conversion of explosives. The proposed enzyme technology can be viewed as a free-radical based process where enzymes are the free-radical generator. By selecting different combinations of enzymes, mediators, and reaction environments, one may change the redox potentials of free radicals. Such flexibility was never envisaged by any earlier biological or chemical process in aqueous phase process. Years ago, researchers at SRI Intemational found that RDX and HMX can be mineralized with light. The light based degradation is mediated by free radicals. The proposed technology will work similarly but will use enzymes as catalyst instead of light. White rot fungi have been shown to mineralize RDX and HMX; fungi use a freeradical based process to degrade recalcitrant chemicals. Unlike fungal or light-based systems, the proposed process will have the ability to control the free radical chemistry and process products, and could have significantly higher reaction rates.

Benefits of the proposed technology are many. Enzymes have the highest reactivity per unit weight of catalyst. The enzyme process operates under mild and safe conditions. The process can operate at room temperature, atmospheric pressure, and in aqueous phase. The process does not require any special equipment, hardware, or software and, thus, has very low capital cost. A mobile system can be designed without any major technical or cost hurdles. Enzymes can be produced at low cost and in large scale by enzyme manufacturers; enzyme production is a very attractive business opportunity as it creates a new market opportunity for oxidoreductive enzymes.

Special features of the proposed enzyme technology are

- excellent kinetics

- no special equipment hardware and thus low capital cost

- stability under harsh conditions (solvents, high concentration of explosives etc.)

- highest reactivity per unit weight of any catalyst

- simplicity of operation

- mobile system can be designed

- can be sprayed in remote location

- low operating cost

- can operate at room temperature and atmospheric pressure

- can be produced at low cost for large scale application.

\section{Accomplishments:}

Accomplishments to date include following publications, presentations, and patent submissions:

\section{Work Prior to SERDP Funding}

Shah, M. M. and J. C. Spain (1996), Reduction of the explosive tetryl by ferredoxin NADP from spinach, Biochem. Biophys. Res. Commun., 220, 563-568. 
M. M. Shah and J. A. Campbell (1997). Transformation of nitrobenzene by ferredoxin NADP oxidoreductase, Biochem. Biophys. Res. Commun., 241, 794-796.

M. M. Shah and J. A. Campbell(1998) Method for controlled reduction of nitroaromatics by enzymatic reactions of oxygen sensitive nitro reductase enzymes, US patent $\# 5,777,190$.

\section{Work Using Using SERDP Funding}

M. M. Shah, and K. A. Bennett, (1998) Transformation of 2,4,6-trinitrotoluene (TNT) by redox enzymes from spinach, buttermilk and E.coli, Biotechnology \&. Bioengineering. (Submitted).

M. M. Shah. (1998) Method of digesting an explosive nitrocompound using potassium superoxide, E1655 (patent pending).

M. M. Shah (1998) Method of reduction of nitroaromatics by enzymatic reaction with redox enzymes E1717 (patent pending).

M. M. Shah (1998) Method of digesting an explosive nitrocompound using sodium chlorite, E1730 (patent pending).

M. M.Shah, K. A. Bennett , G. P. Streile, and A. Chilakapati (1998) Environmentally benign digestion processes (EBDP) for disposal of energetic materials in demilitarization, NDIA. Global Demilitarization Symposium and Exhibition, Coeur d'Alene, ID. May 11-14. 1998. Event \#858.

M. M. Shah (1998) Enzymes for degradation of energetic materials under safe and environmentally benign conditions, Partners in Environmental Technology 98 Symposium, Sponsored by SERDP and ESTCP, Arlington, VA, December 1-3, 1998.

M. M. Shah (1998) Rapid degradation of explosives by chemical and biological methods at room temperature and atmospheric pressure under aqueous conditions, American Society of Microbiology General Meeting, May 1999 (submitted).

M. M. Shah and K. A. Bennett (1998) Destruction of explosives. 25th Environmental Symposium \& Exhibition, NDIA, Denver, CO, March 29-April 3, 1999 (submitted).

\section{Award Nominations}

R\&D 100 Award

Green Chemistry

\section{Coverage in Scientific magazines, TV, Radio, Newspapers, and Industrial Response to News Releases on Explosive Degrading Enzymes}

Arizona Department of Environmental Quality Freelancer in England pitching the story to New Scientist

British general science publication

Freelancer in Wisconsin

Researcher in Florida indicates at least one television station in that state aired the story Arcadian Ship Yard, Louisiana
Editor with a Chinese-language web site Environmental engineer for the Navy Research Triangle Institute in North Carolina Official with the Ohio state Environmental Protection Agency

Associated Press

Battelle World

Ben Franklin Technology Center 
BHP Minerals

Canadian Broadcasting Corp. current affairs show, recorded interview by phone

Canadian Chemical News

Canadian Chemical News (L'Actualite chimique canadienne)

Chem 13 News, a publication for chemistry

teachers

Chemical Engineering magazine

Chemical Engineering Progress

Chemical Process Alert - an online publication

Chemistry in Britain

Citizens for Safe Water (Wisconsin)

City Link (Ft. Lauderdale, Fla.)

Columbia Basin Herald (Moses Lake)

Daily World (Aberdeen)

Discovery Channel

Online DOE Pulse

Dyno Nobel

Eastside Joumal (Bellevue)

Editorial Office Silicon Valley, contributes reports

to Stem, a German and English language weekly

magazine with 7 million readership

Environmental and Scientific Consultants

GZA Inc.

Hercules, Inc.

Il Mundo, an economic weekly news magazine

published in Milan, Italy, for general interest

readers

Industrial Bioprocessing Technical Insights

INEEL official

Inside Energy

Inside R\&D

KCPQ Fox-TV - interview in lab KEPR and

KVEW television (Tri-Cities) interview broadcast $6 / 5$

$\mathrm{KOMO}$ radio (Seattle) live interview by phone
KONA radio (Pasco) 5:05 p.m. recorded

interview

National Examiner

Northwest Cable News, live interview by phone

Orenda Technologies,

Connecticut Outside magazine

Pantex officials

Pollution Engineering

R\&D Magazine - August issue

Science Daily, an online publication

Science Spectra

Scientific American

Seattle P-I

Seattle Times, editorial page

Skagit Valley Herald (Mount Vemon)

Soluciones Organicas S.A.

Special Devices Inc.

Step Three Inc.

Stone \& Webster Engineering Corporation (on

behalf of U.S. military)

Sunday London Times

Tampa (Fla.) Tribune

Technology Review (publication of MIT)

Television broadcast on KIRO television (Seattle), no interview

The Scientist

Thompson Associates of Califomia on film safety

improvement

Tri-City Herald

Tri-State Defender (Memphis, Tenn.)

United Press Intemational wire service

Walla Walla Union-Bulletin

Washington State University professor

Washington Times, Sunday edition

Waste Treatment Technology News

Water Environment Federation

Winegaard Co.

Wired magazine 


\section{Technical Abstract: Accomplishments for the Current Fiscal Year}

A series of experiments demonstrated the ability of redox enzymes from a variety of sources such as spinach (ferredoxin NADP oxidoreductase, and glutathione reductase), buttermilk (xanthine oxidase), and E. coli (oxyrase) to transform 2,4,6-trinitrotolune (TNT). Xanthine oxidase and xanthine rapidly transformed TNT into 4-hydroxylamino-2,6-dinitrotoluene. The rate of transformation increased with increases in the concentration of both TNT and the enzyme. The 4-hydroxylamino-2,6-dinitrotoluene was metabolized, but at a much slower rate. Ferredoxin NADP oxidoreductase operated in a similar manner, although its activity was degraded in aerobic conditions. Glutathione reductase and oxyrase also produced 4-hydroxylamino-2,6dinitrotoluene from TNT. Ferredoxin NDP oxidoreductase had the highest rate of TNT transformation; oxyrase had the lowest.

Mathematical simulations were conducted for a proposed processing tank methodology for the destruction of TNT via enzyme-catalyzed transformation in the aqueous and solid phases. Two coupled rate equations (derived for aqueous-phase and solid-phase TNT concentrations in the tank) contain terms for aqueousphase transformation, solid-phase transformation, and solid TNT dissolution. Simulations based on solution of these rate equations showed that aqueous TNT concentrations rapidly became and remained low, limited by the relatively slow dissolution rate of solid TNT. They also showed that concentration versus time profiles contained a substantial initial period of linear decline. Sensitivity studies conducted for the operating parameters of the engineered tank showed that the time for 100\% disappearance of the added TNT was a linear function of the total enzyme concentration and the initial solid TNT concentration for the particular values of the other input parameters describing the expected processing tank system. As expected, disappearance time varied directly with initial TNT concentration and initial particle size, and varied inversely with total enzyme concentration. Based on work conducted thus far, the simulated disappearance times were short enough to indicate the feasibility of this methodology for TNT destruction (except for cases with both large initial particle size and low total enzyme concentration). Several issues need to be resolved before mathematical simulations can be used to make firm judgements on the feasibility of the methodology, and to aid the design of the actual processing tank system and its operation:

- Several parameters lack precise definition.

- The model assumes linear equilibrium sorption of the enzyme on TNT particles; however saturation of enzyme-binding sites leads to non-linear activity.

- The model does not account for the temperature dependency of some parameters.

Potential commercial applications of TNT derivatives were studied. Products include aromatic hydroxylamines, aminophenols, and mixtures of those products. The most promising products, in order, appear to be 1) antioxidants, 2) curing agents, 3) biocides/disinfectants, 4) monomers, and 5) pharmaceutical and agricultural chemicals. Flame retardants and azo dyes were also evaluated, however they require further chemical processing of the main products produced in the enzyme processes. Further testing is required to give a definitive answer about the feasibility of commercial production of any of these products from the output of the enzymatic destruction of TNT.

Sodium chlorite was investigated to degrade hexahydro-1,3,5-trinitro-1,3,5-triazine (RDX) at room temperature and atmospheric pressure under aqueous conditions. The rate of degradation was directly related to the concentration of RDX and sodium chlorite and to the temperature. Nitrite and nitrate were primary byproducts of the reaction. Sodium chlorite eliminates RDX through oxidation under mild conditions; no acids, alkalis, or organic solvents are required.

A similar experiment provided similar results using sodium chlorite to treat octahydro-1,3,5,7-tetranitro1,3,5,7-tetrazocine ( $\mathrm{HMX})$.

The experimental efforts under this project led to three patent applications during the year: 
- Superoxides to destroy nito-bearing explosives

- Sodium chlorite to destroy nitro-bearing explosives

- Redox enzymes to reduce nitroaromatics.

The experiments are described in detail in the appendix along with abstracts of the patents. 


\section{APPENDIX A}

TRANSFORMATION OF 2,4,6-TRINITROTOLUENE (TNT) BY REDOX ENZYMES FROM SPINACH, BUTTERMILK, AND E. coli 


\section{Transformation of 2,4,6-trinitrotoluene (TNT) by Redox Enzymes from Spinach, Buttermilk, and E. coli}

\section{Summary}

Redox enzymes from a variety of sources such as spinach (ferredoxin NADP oxidoreductase, and glutathione reductase), buttermilk (xanthine oxidase), and E. coli (oxyrase) were able to transform 2,4,6-trinitrotolune (TNT). Reactions of TNT with ferredoxin NADP oxidoreductase and xanthine oxidase were characterized further. The rate of transformation of TNT was increased with increases in either enzyme or TNT concentration. The reduction of TNT led to the formation of one major intermediate, which was identified as 4-hydroxylamino-2,6-dinitrotoluene. We envisage a potential for development of an enzyme-based process for disposal of TNT present in stockpiles, soil, and water. We also envisage a potential for selective conversion of TNT to value-added products such as 4-hydroxylamino-2,6-dinitrotoluene and its derivatives.

\section{Introduction}

The current stockpile of energetic materials requiring resource recovery or disposition (RRD) is 449,308 tons. Through 2001, over 1.2 million tons will pass through or reside in the RRD account Joint Ordnance Commands Group; 1995). A totally different but significantly similar challenge exists in clean-up of the sites where soil and ground water are contaminated with TNT, RDX, HMX, and other nitro-based explosives. Hence, there is need for characterizing the reactions of explosives with naturally occurring enzymes, and a cost-effective technology to degrade these contaminants.

The transformation of TNT by microorganisms (Hughes et al., 1998; Hawari et al., 1998; Lewis, et al., 1997; Spain, 1995; Ederer, et al., 1997) and plants (Rivera et al., 1998) has been reported. In all cases, the first step in its transformation was the reduction of the nitro group. However, the final fate of TNT in bioremediation by microorganism or plants is not clear and only a small percentage of the TNT is generally mineralized (Rivera et al., 1998; Pucik et al., 1998; Hawari et al., 1998; Funk, et al., 1993; Boopathy, et al., 1994). The redox activity of enzymes such as dehydrogenases, reductases, and oxidases on nitroaromatic and nitroheterocyclic chemicals has been reported previously. These enzymes come from plants, aerobic and anaerobic bacteria, and animals (Spain, 1995; Oma and Mason, 1989; Anlezark et.al.,1992; Angermaier and Simon, 1983). However, there has been little investigation of the reactions of explosives with such naturally occurring enzymes. We have previously demonstrated the ability of ferredoxin NADP oxidoreductase from spinach to eliminate the nitramine nitro group and reduce the aromatic nitro group from the explosive 2,4,6trinitrophenylmethylnitramine (Shah and Spain, 1996).

The results reported here suggest that TNT reducing enzymes might be ubiquitous, and there may be a potential for development of an enzyme-based process for disposal of TNT present in stockpiles, soil, and water. We also envisage a potential for selective conversion of TNT to value-added products such as 4 hydroxylamino-2,6-dinitrotoluene and its derivatives.

\section{Materials And Methods}

\section{Chemicals}

Chemicals used for the research were 2,4,6- trinitrotoluene (Chem Service, Westchester, PA, USA), 4 hydroxyamino-2,6-dinitrotoluene and 2-hydroxyamino-4,6-dinitrotoluene (SRI International, Menlo Park, CA, USA), 4-amino-2,6-dinitrotoluene and 2-amino-4,6-dinitrotoluene (Radian Intemational, Austin, TX, USA), oxyrase from E. coli (Oxyrase, Inc., Mansfield, OH, USA), and high-performance liquid chromatography (HPLC) grade methanol (EM Science, Gibbstown, N], USA). Beta nicotinamide adenine 
dinucleotide phosphate (NADPH), ferredoxin NADP+ oxidoreductase EC 1.18.1.2 (F-0628) from spinach, xanthine oxidase EC 1.13.22 (X-1875) from buttermilk, glutathione reductase EC 1.6.4.2 (G-3011) from spinach, xanthine (X-4002), TRIZMA Base (T-8524), sodium EDTA, sodium lactate, and potassium phosphate were all purchased from Sigma (St. Louis, MO, USA).

\section{Analytical Methods}

A Hewlett Packard (Palo Alto, CA) 1090L HPLC with photodiode array UV-visible detector was used to identify and quantify TNT and its metabolites using the retention times and UV-visible spectra. The HPLC was controlled by a PC workstation with ChemStation software. Analytes were separated on a reverse-phase Altech Platinum C18 column ( $250 \mathrm{~mm}$ X $4.6 \mathrm{~mm}$ ID) with guard cartridge ( 5 micron, $100 \AA$ ) heated to $38^{\circ} \mathrm{C}$. An isocratic mobile phase of 50 percent methanol and 50 percent water (Milli-Q $\mathrm{H}_{2} \mathrm{O}$, Millipore, Co, Bedford, MA, USA) at $1.00 \mathrm{ml} \mathrm{min}{ }^{-1}$ was used. The absorbance of the column eluant was monitored at 230 nin.

\section{Experimental Methods}

All reactions were carried out at room temperature $\left(22^{\circ} \mathrm{O}\right)$. Reaction composition is described under each figure legend. The buffers used were $\mathrm{KH}_{2} \mathrm{PO}_{4}\left(\mathrm{pH}\right.$ 7.5), TRIZMA $(\mathrm{pH} 7.5), \mathrm{NaH}_{2} \mathrm{PO}_{4}$ with EDTA (pH 7.6), and TRIZMA with $\mathrm{Na}$ lactate ( $\mathrm{pH} 8.0$ ). Xanthine was prepared in $1 \mathrm{MNaOH}$, while the NADPH was prepared in buffer. A small volume of TNT was mixed with water and appropriate buffer in a target (2-ml) vial. The necessary reductant (xanthine for xanthine oxidase, NADPH for ferredoxin NADP+ reductase and glutathione reductase, Na lactate for oxyrase) was added to the vial. To initiate the reactions, the enzyme was added to the vial, and the solution was mixed. For specified reactions, the vials were flushed with a low nitrogen flow (<10 psi) for 10 to 30 seconds. A range of TNT and 4-HADNT standards from 10 to 100 $\mu \mathrm{g} / \mathrm{ml}$ were prepared, and the concentration of analyte in solution was calculated based on the calibration curves. TNT, HADNT, and ADNT were identified by comparison of their retention times and UV-VIS spectra with authentic standards.

\section{Results}

TNT was incubated in a phosphate buffer solution containing xanthine oxidase and xanthine. The degradation of TNT and its products was followed using HPLC. The kinetics of TNT transformation and product formation is shown in Figure 1. TNT was transformed rapidly into one major metabolite. The metabolite was identified as 4-hydroxylamino-2,6-dinitrotoluene based on its retention time and spectral comparison with the standard. Figure 2 compares spectra of 4-hydroxyamino-2,6-dinitrotoluene standard and the metabolite. No metabolites were detected in the absence of TNT or enzyme. As can be noticed in Figure 1 , the reduction of 4-hydroxylamino-2,6-dinitrotoluene was relatively slower than that of TNT. When the reaction sample was analyzed 2 days later, 4-hydroxylamino-2,6-dinitrotoluene was not detectable. Only a small amount of 4-amino-2,6-dinitrotoluene was detected $(<10 \%)$. However, further detailed research is needed to elucidate the transformation of the TNT intermediate 4-hydroxylamino-2,6-dinitrotoluene.

We further investigated the transformation of TNT by xanthine oxidase. Figure 3 shows the kinetics of TNT transformation at various concentrations of xanthine oxidase. As can be expected, the rate of transformation of TNT increases with increase in enzyme concentration. Figure 4 shows the dependence of the apparent initial rate of transformation of TNT by xanthine oxidase on TNT concentration. The rate of transformation of TNT by xanthine oxidase increased with an increase in TNT concentration. The reaction of xanthine oxidase with TNT did not require nitrogen flush and thus samples were not flushed with nitrogen. Xanthine oxidase is known to scavenge oxygen using xanthine as a reductant (White and White, 1997). 


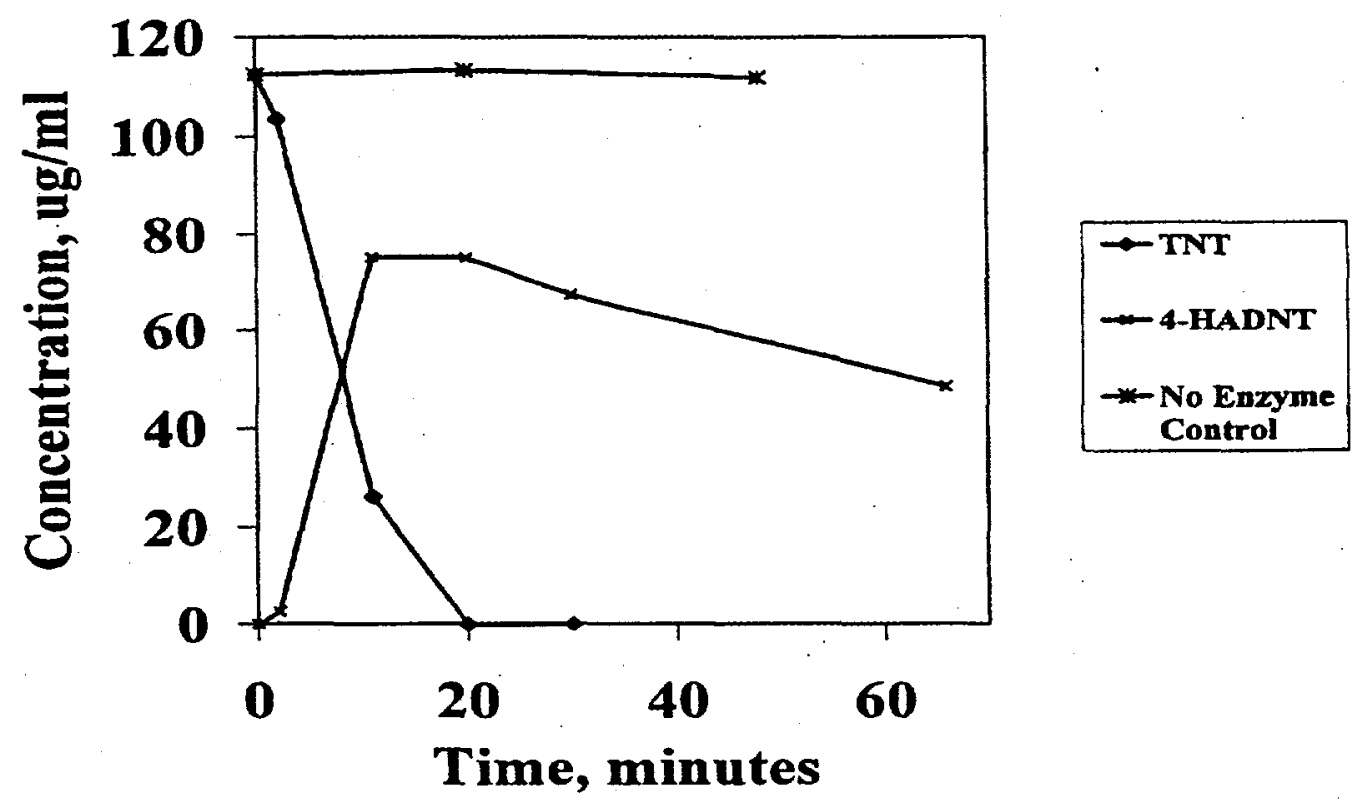

Figure 1. Metabolism of TNT catalyzed by by xanthine oxidase. The solution contained $10 \%$ (vol.) $\mathrm{CH}_{3} \mathrm{CN}$, $0.45 \mathrm{mM}$ TNT, $0.2 \mathrm{M} \mathrm{KH}_{2} \mathrm{PO}_{4}, 10 \mathrm{mM}$ xanthine, and $0.5 \mathrm{U} / \mathrm{ml}$ xanthine oxidase. Reaction mixtures were flushed with nitrogen gas for 30 seconds at the start of the reaction.

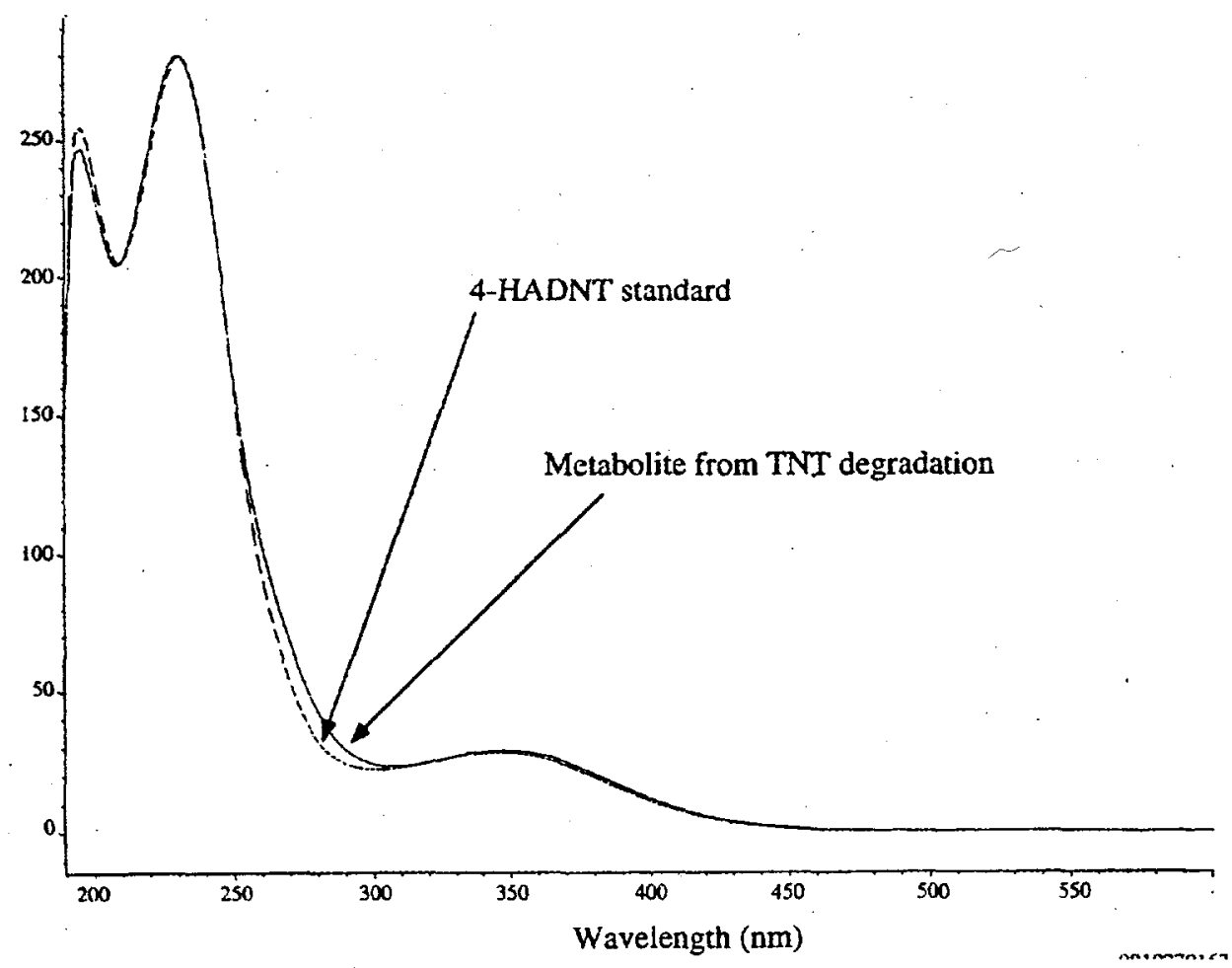

Figure 2. Spectral Comparison between 4-hydroxyamino-2,6-dinitrotoluene standard and the metabolite from the reaction mixture of TNT with ferredoxin NADP+ reductase. 


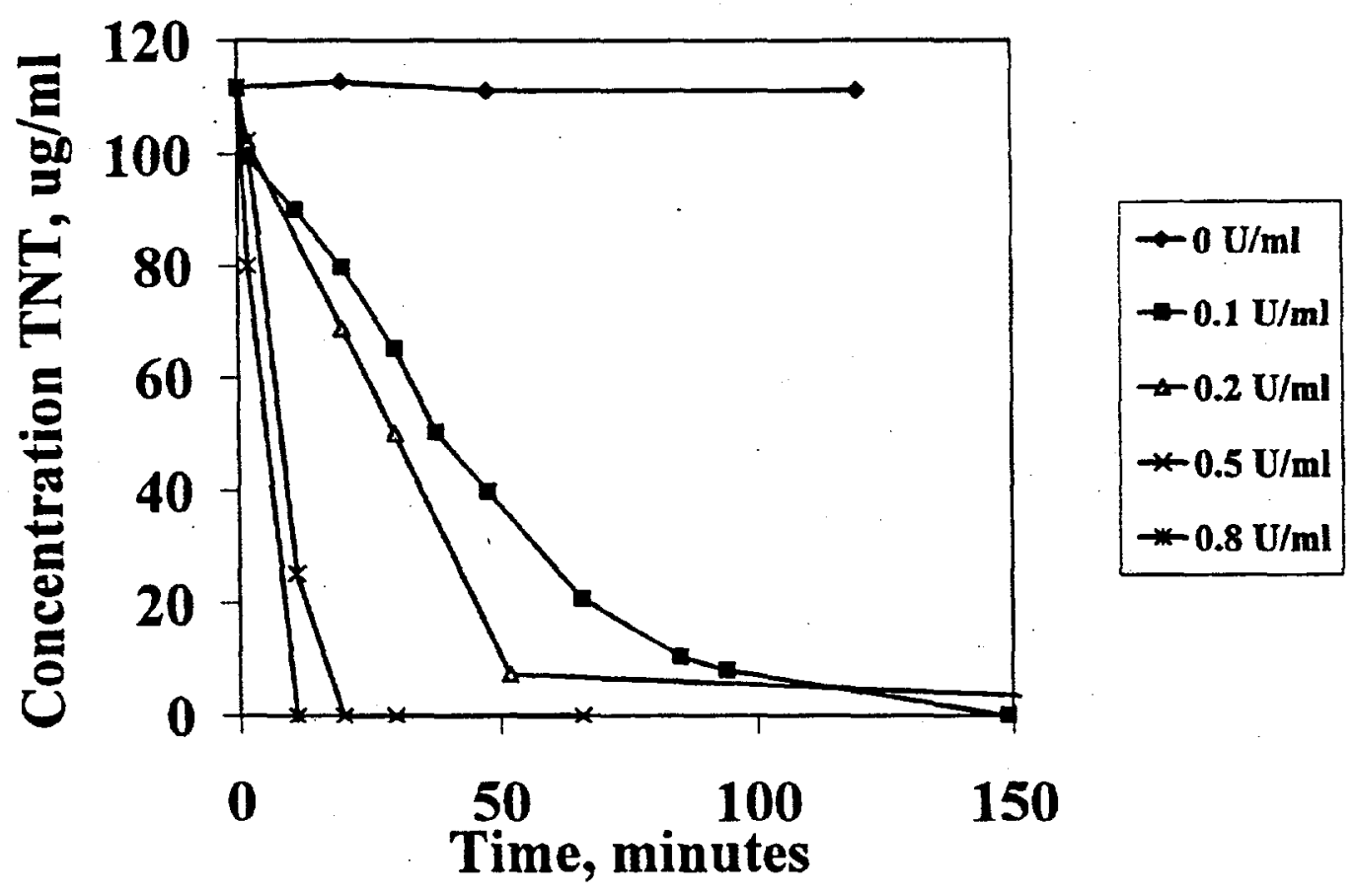

Figure 3. Kinetics of TNT degradation at various concentrations of xanthine oxidase. Solutions contained $10 \%$ (vol.) $\mathrm{CH}_{3} \mathrm{CN}, 0.45 \mathrm{mM}$ TNT, $0.2 \mathrm{M} \mathrm{KH}_{2} \mathrm{PO}_{4}(\mathrm{pH} 7.5) ; 10 \mathrm{mM}$ xanthine and varying amounts of xanthine oxidase. Reaction mixtures were not flushed with nitrogen.

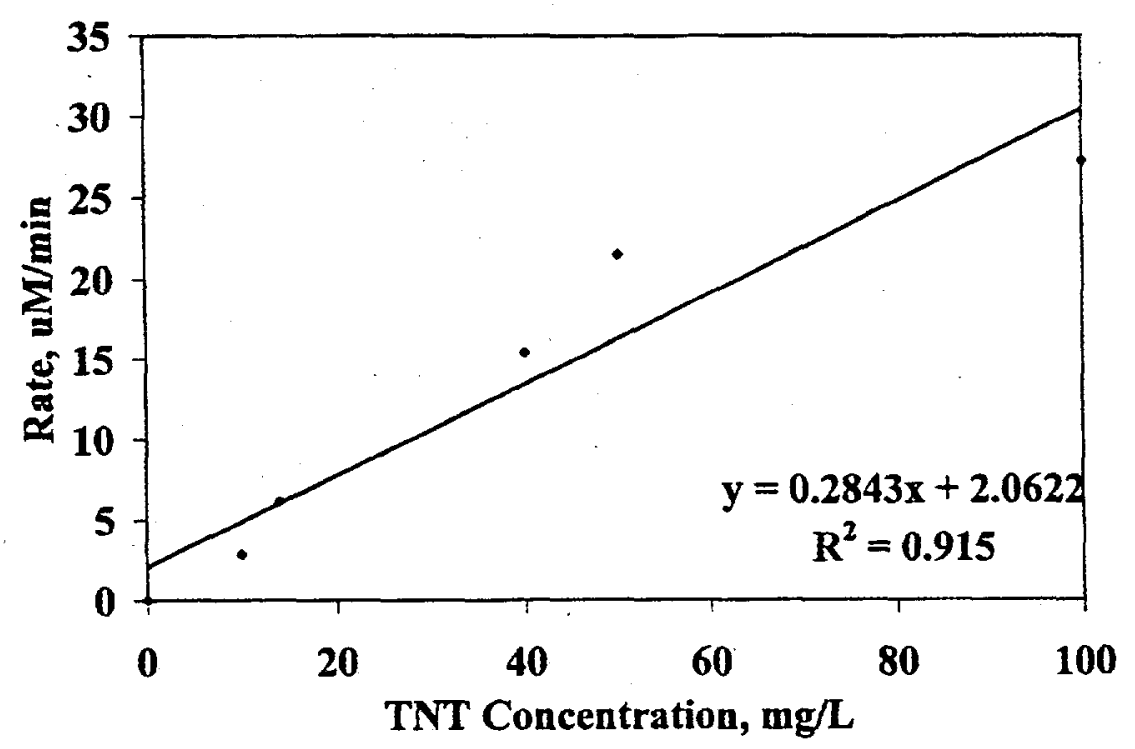

Figure 4. Dependence of TNT degradation rates on concentrations of TNT for xanthine oxidase system. The solution contained between $1-10 \%$ (vol.) $\mathrm{CH}_{3} \mathrm{CN}$ depending on TNT concentration, $0.2 \mathrm{M} \mathrm{KH}_{2} \mathrm{PO}_{4}, 10$ $\mathrm{mM}$ xanthine, $0.2 \mathrm{U} / \mathrm{ml}$ xanthine oxidase with increasing concentrations of TNT. Solutions were not flushed with nitrogen. 
We also characterized the reactions of ferredoxin NADP oxidoreductase (FNR) from spinach with TNT. As in the case of xanthine oxidase, the rate of transformation of TNT by enzyme increased with increase in either enzyme (Figure 5) or TNT concentrations (Figure 6). Again, as in the xanthine oxidase, the major intermediate of TNT transformation by ferredoxin NADP oxidoreductase was 4-hydroxylamino-2,6dinitrotoluene (data not shown). The reduction of TNT was inhibited if performed under aerobic conditions. This observation was similar to our finding for the reduction of tetryl by FNR (Shah and Spain, 1996). In case of oxygen sensitive nitroreductases such as ferredoxin NADP oxidoreductase (Oma and Mason, 1989), the reduction mechanism involves a single electron step process. It has been suggested that the nitroanion radical of the parent nitro compound is an intermediate. Under aerobic conditions, the radical is oxidized back to the parent nitro compound while molecular oxygen is reduced. Thus, a futile cycle is established in which there is no net reduction of the nitro compound but rather it serves as the free radical mediator. Although this experiment was performed by flushing nitrogen for 30 seconds at the beginning of experiment for its simplicity in doing experiment, we noticed that the continuous flushing of nitrogen in the vial increased the rate of transformation of TNT by at least a factor of 3 .

The reduction of TNT was also tested using glutathione reductase from spinach and oxyrase enzymes from E. coli. Oxyrase enzymes are E. coli membrane enzymes and are marketed by the manufacturer (Oxyrase Inc., $\mathrm{OH})$ for oxygen scavenging reactions. We found that both enzymes had TNT reducing activity, with 4hydroxylamino-2,6-dinitrotoluene as the intermediate product. Table 1 compares the relative rates of transformation of TNT by all four enzymes. Overall, ferredoxin NADP oxidoreductase enzyme was the fastest while oxyrase enzyme was the slowest. It is important to note that oxyrase enzymes used sodium lactate as reductant under nitrogen atmosphere and TNT served as an electron acceptor.

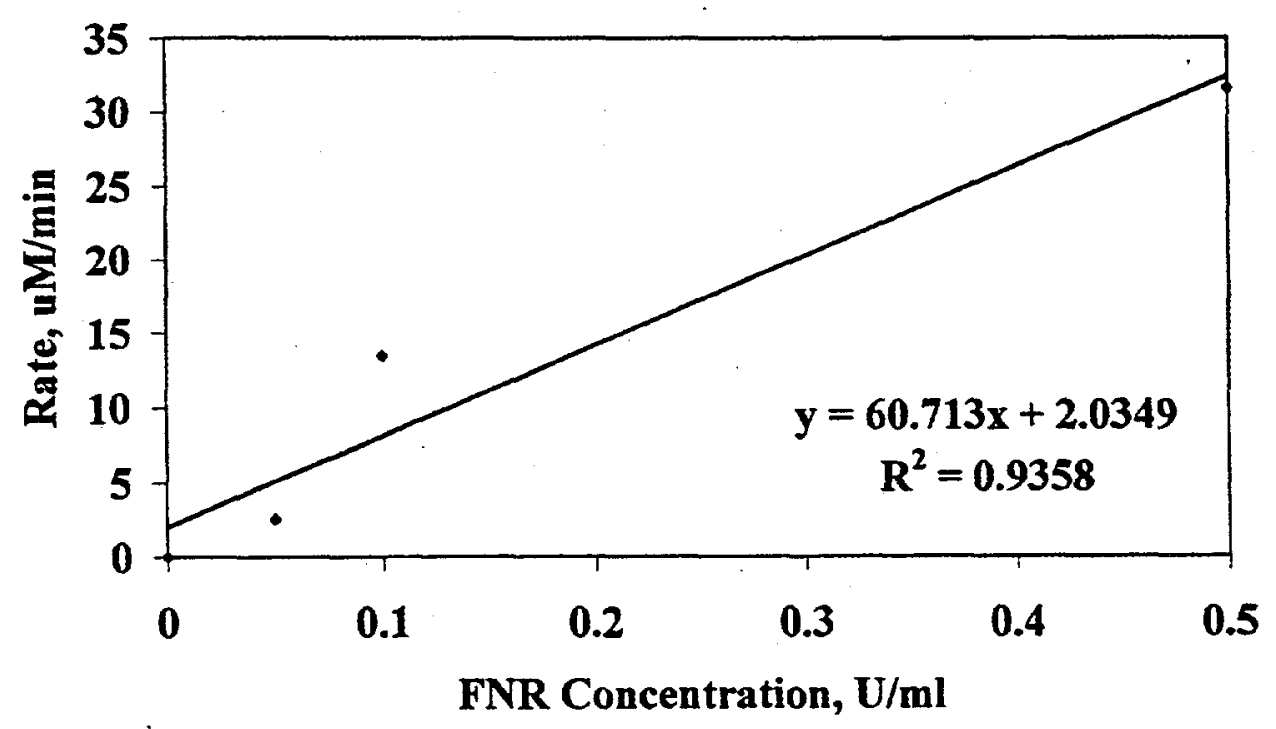

Figure 5. Dependence of TNT degradation rates on concentrations of ferredoxin NADP oxidoreductase (FNR). Solutions contained 10\% (vol.) $\mathrm{CH}_{3} \mathrm{CN}, 0.45 \mathrm{mM}$ TNT, $25 \mathrm{mM}$ TRIZMA (pH 7.5), $16 \mathrm{mM}$ $\mathrm{NADPH}$, and increasing amounts of FNR. Reaction mixtures were initially flushed with nitrogen flow for 30 seconds. 


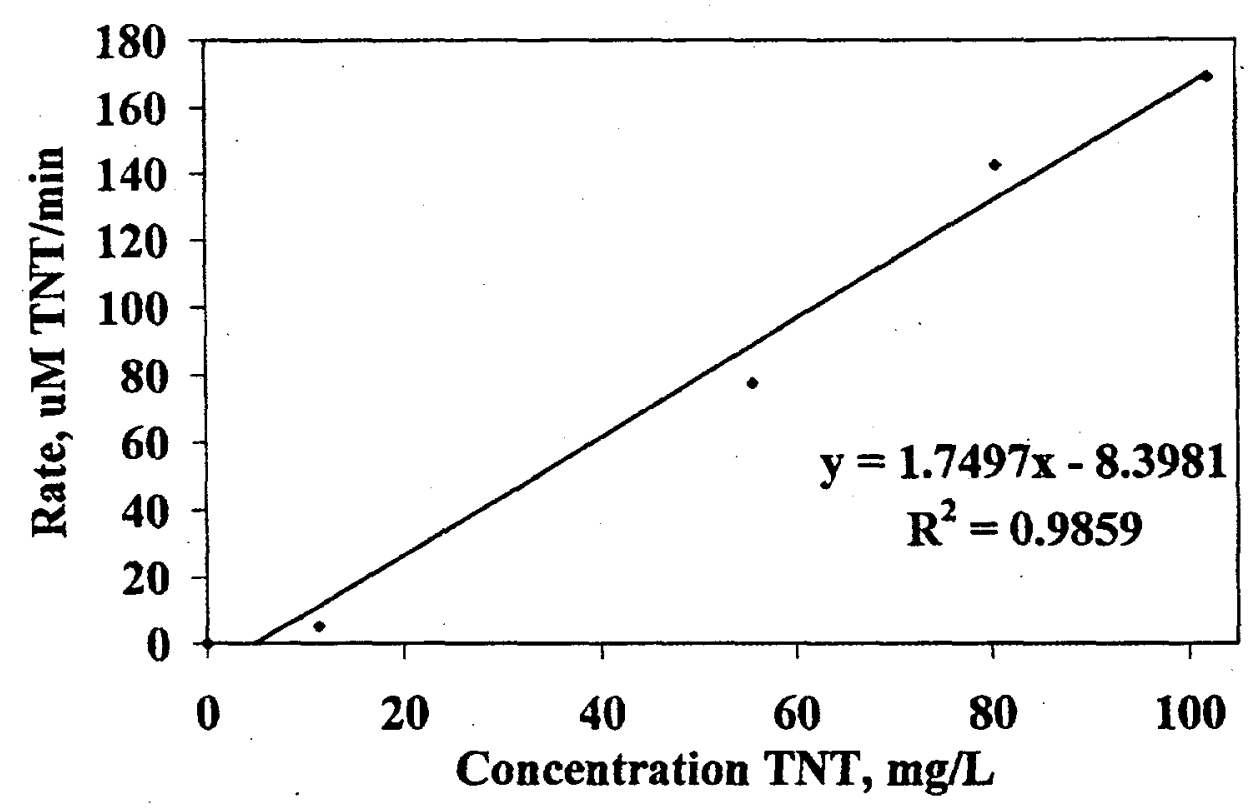

Figure 6. Dependence of TNT degradation rates on concentrations of TNT for FNR system. The solutions contained between $1-10 \%$ (vol.) $\mathrm{CH}_{3} \mathrm{CN}$ depending on TNT concentration, $25 \mathrm{mM}$ TRIZMA (pH 7.5), $0.53 \mathrm{U} / \mathrm{ml}$ FNR, $16 \mathrm{mM}$ NADPH with increasing concentrations of TNT. Solutions were initially flushed with nitrogen for 30 seconds.

Table 1. Relative Rates of Transformation of TNT by Different Redox Enzymes ${ }^{a}$

\begin{tabular}{|l|c|}
\hline \multicolumn{1}{|c|}{ Enzyme } & $\begin{array}{c}\text { TNT reduction rate } \\
\text { (nmoles/min/mg of } \\
\text { protein) }\end{array}$ \\
\hline Xanthine oxidase from buttermilk & $45 \pm 10$ \\
\hline Glutathione reductase from spinach leaves & $50 \pm 10$ \\
\hline $\begin{array}{l}\text { Ferredoxin NADP oxidoreductase } \\
\text { from spinach leaves }\end{array}$ & $1300 \pm 200$ \\
\hline Oxyrase from $E$.coli & $5 \pm 1$ \\
\hline
\end{tabular}

${ }^{\text {a }}$ Reaction mixture $(2 \mathrm{ml})$ contained appropriate buffer, enzyme, reductant and $0.45 \mathrm{mM}$ TNT. The concentrations of xanthine oxidase $(0.68 \mathrm{units} / \mathrm{mg}$ ), glutathione reductase $(200 \mathrm{units} / \mathrm{mg})$, oxyrase (1 unit/mg) and ferredoxin NADP oxidoreductase ( 4.3 units $/ \mathrm{mg}$ ) were $588 \square \mathrm{g} / \mathrm{ml}, 125 \mathrm{~g} / \mathrm{ml}, 9 \mathrm{mg} / \mathrm{ml}$ and $23.3 \mathrm{~g} / \mathrm{ml}$ respectively. In the reaction mixture containing xanthine oxidase, xanthine $(10 \mathrm{mM})$ was used as the reductant instead of the NADPH. For glutathione reductase and ferredoxin oxidoreductase system, NADPH $(16 \mathrm{mM})$ was used as the reductant. In the oxyrase system, sodium lactate $(21 \mathrm{mM})$ was used as reductant. The buffers for xanthine oxidase, glutathione reductase, oxyrase, and ferredoxin NADP oxidoreductase were potassium phosphate $(200 \mathrm{mM}, \mathrm{pH} 7.5)$, sodium phosphate (40 mM, pH 7.6) containing EDTA (1.4 mM), tris (17.5 mM, pH 8.3), and tris ( $36 \mathrm{mM}, \mathrm{pH} 7.5)$ respectively. All reactions samples were flushed with nitrogen continuously over the reaction period. The rates were calculated based on change in TNT concentration over ten minutes. 


\section{Discussion}

Our results demonstrate that TNT can be reduced by naturally occurring enzymes from plants (ferredoxin NADP oxidoreductase and glutathione reductase from spinach), dairy products (xanthine oxidase from buttermilk) and microorganisms (oxyrase enzyme from E. coli). In general, the transformation of TNT involves 4-hydroxylamino-2,6-dinitrotolune as a major intermediate. The further degradation of 4hydroxylamino-2,6-dinitrotolune was much slower than that of TNT. This is an important finding if this intermediate finds its way into industrial applications, especially for disposal of TNT stockpiles. Hughes et al.w (1998) studied the reduction of TNT by the anaerobic Clostridium acetobutylicum and found that two of three nitro groups of TNT were reduced to hydroxylamines. The reduced intermediate was rearranged to a phenolic product. The phenolic product was highly reactive with oxygen but also decomposed within a couple of days under strict anaerobic conditions. Thus, reduction of two nitro groups of TNT may not be attractive for conversion of TNT to candidate molecules for industrial applications. However, if only one nitro group of TNT is reduced to hydroxylamine intermediate and if that could be further transformed chemically through Bamberger rearrangement to make amino dinitrophenols, then the commercial potential is increased. Hence, future research is needed to evaluate the efficacy of the intermediate 4-hydroxylamino2,6-dinitrotoluene and its derivatives for industrial applications. Derivatives obtained from enzymatic transformations of TNT, such as hydroxylamines, aminophenols, and mixtures of these functional groups, have potential commercial applications. The monohydroxylamines appear to be the most economical products as they can be synthesized from TNT in a one step process. The potential applications for the TNT-based products include antioxidants, curing agents, monomers, biocides/disinfectants, flame retardants, azo dyes, pharmaceuticals, and agro chemicals. The flame retardant and azo dye applications require further chemical transformation of the TNT derivatives. Such processes could provide a "zero-cost" approach for disposal of stockpiles of TNT. Altematively, if enzymes could reduce TNT completely to 2,4dihydroxylamine-6-nitrotoluene, which would decompose itself as has been observed by Hughes et al. (1998) with $C$. acetobutylicum for anaerobic reduction of TNT. Further study is underway to determine if TNT metabolites formed after an enzymatic treatment could be mineralized to safe products like carbon dioxide and water.

The enzyme technology has many attractive features for treatment of TNT stockpiles or highly contaminated sites and sediments. For example, enzymes could offer better kinetics for degradation of TNT than microbial systems. Enzymes could also tolerate high concentrations of TNT. The process can be performed at room temperature, atmospheric pressure, and under water. Due to such simplicity of the process, enzyme technology could be implemented at relatively low capital cost. A mobile system can be designed without any major technical or cost hurdles. Further, TNT degrading enzymes can be used to wash equipment and floors in a manner similar to detergent enzymes for cleaning applications. Enzymes can be sprayed in remote locations; this feature is attractive for sites where contamination is on the surface. The enzyme process could provide a safe altemative to open buming or open detonation to destroy energetic materials. We envisage a potential for development of an enzyme-based process for disposal of TNT present in stockpiles, soil, and water. We also envisage a potential for selective conversion of TNT to value-added products such as 4 hydroxylamino-2,6-dinitrotoluene and its derivatives.

Although commercialization of enzyme based technologies is normally perceived as a difficult task, the enzyme market is close to one billion dollars annually. Enzymes are used in a cost-effective manner by detergent and food processing industries. The attractive feature of enzyme based processing is its simplicity, selectivity, and speed. Based on our results, we expect that TNT reducing enzymes are widespread even though TNT is not their native substrate. It is likely that large quantities of enzymes could be produced by enzyme manufacturers at low cost as a side product of their main stream enzyme products. Among all enzymes tested, oxyrase enzyme could transform TNT using low cost reductants such as glucose, lactic acid, and formic acid. However, there is still a significant need for research and development efforts to make enzyme technology viable at the commercial scale. It is also important to demonstrate that the metabolites of 
enzymatic transformation can indeed be mineralized to carbon dioxide and water rapidly and easily. In terms of conversion of TNT into value added products, it is important that the metabolite/s be tested for industrial applications. To increase the scope of the technology, there is also a need for finding enzymes for other common explosives.

\section{Acknowledgements}

This research was supported by the U. S. Department of Defense's Strategic Environmental Research and Development Program (SERDP). The authors would like to thank Shannon Roach for performing some of the HPLC analysis.

\section{Nomenclature}

$\begin{array}{ll}\text { 4-HADNT } & \text { 4-hydroxylamino-2,6-dinitrotoluene } \\ \text { 4-ADNT } & \text { 4-amino-2,6-dinitrotoluene } \\ \text { FNR } & \text { Ferredoxin NADP oxidoreductase } \\ \text { HMX } & \text { octahydro-1,3,5,7-tetranitro-1,3,5,7-tetrazocine } \\ \text { RDX } & \text { hexahydro-1,3,5-trinitro-1,3,5-triazine; } \\ \text { TNT } & \text { 2,4,6-trinitrotoluene; }\end{array}$

\section{References}

Angermaier, L., Simon, H. 1983. "On the reduction of aliphatic and aromatic nitro compounds by Clostridia: The role of ferredoxin and its stabilization". Hoppe-Sp Z. Physiol.Chem. 364: 961-975.

Anlezark, G. M., Melton, R. G., Sherwood, R. F., Coles, B., Friedlos, F., Knox Richard J. 1992. "The bioactivation of 5-(aziridin-1-yl)-2,4-dinitrobenzamide (CB1954): I. Purification and properties of a nitroreductase enzyme from Escherichia coli: A potential enzyme for antibody-directed enzyme prodrug therapy (ADEPT)." Biochem. Pharmacol. 44, 2289-2295.

Boopathy, R., Wilson, M., Montemagno, C. D., Manning, J. F. Jr, Kulpa, C. F.1994. "Biological transformation of 2,4,6-trinitrotoluene (TNT) by soil bacteria isolated from TNT-contaminated soil." Bioresour. Technol. 47: 19-24.

Ederer, M. M., Lewis, T. A., and Crawford, R. L. 1997. "2,4,6-trinitrotoluene (TNT) transformation by clostridia isolated from a munition-fed bioreactor: Comparison with non-adapted bacteria." J. Ind. Microbiol. Biotechnol. 18:82-88.

Funk, S., Robert, D. J., Crawford, D. L., Crawford, R. L. 1993. "Initial-phase optimization for bioremediation. of munition compound-contaminated soils." Appl. Enirinn. Microbiol. 59: 2171-2177.

Hawari, J., Halasz, A., Paquet, L., Zhou, E., Spencer, B., Ampleman, G., Thiboutot, S. 1998. "Characterization of metabolites in the biotransformation of 2,4,6-trinitrotoluene with anaerobic sludge: role of triaminotoluene." Appl. Eniminn. Micrabiol. 64(6): 2200-2206.

Hughes, J. B., Wang, C., Yesland, K., Richardson, A., Bhadra, R., Bennett, G., Rudolph, F. 1998. "Bamberger rearrangement during TNT metabolism by Clostridium acetobutylizum." Environ. Sai. Tecbnol. 32: 494500 .

Joint Ordnance Commands Group, Munitions Demil/Disposal Subgroup, 1995. Joint Demilitarization Study. Number 323. Washington, DC

Lewis, T. A., Ederer, M. M., Crawford, R. L. 1997. "Microbial transformation of 2,4,6-trinitrotoluene." J. Ind. Microbiol. Biotech. 18: 89-96. 
Oma, M. V. and Mason, R. P. 1989. "Correlation of kinetic parameters of nitroreductase enzymes with redox properties of nitroaromatic compounds". J. Biol. Chem. 21: 12379-12384.

Pucik, L. E., Zhang, C., Hughes, J. B. 1998. "Fate of TNT and its transformation products in mixed aerobic cultures." Bionemediation Journal. 2(1): 57-67.

Rivera, R, Medina, V. F., Larson, S. L., McCutcheon, S. C. 1998. "Phytotreatment of TNT-contaminated groundwater." J. Soil. Contam. 7(4): 511-529.

Shah, M. M., Spain J. C. 1996. "Reduction of the explosive tetryl by ferredoxin NADP oxidoreductase from spinach." Biochem. Biophys. Res. Commun. 220: 563-568.

Spain, J. C. 1995. Biodegradation of nitroaromatic compounds, $1^{\text {st }}$ ed. Vol 49. Planum Press, New York.

White, J. S., White D.L. 1997. Soure Book of Enoymes. CRC Press, New York. 


\section{APPENDIX B}

MATHEMATICAL SIMULATION OF ENZYME-CATALYZED TNT DESTRUCTION IN A PROCESSING TANK SYSTEM 


\title{
Mathematical Simulation of Enzyme-Catalyzed TNT Destruction In a Processing Tank System
}

\author{
Gary P. Streile, Ashok Chilakapati, and Manish M. Shah \\ Pacific Northwest National Laboratory, Richland, WA
}

\begin{abstract}
Mathematical simulations were conducted for a proposed processing tank methodology for the destruction of TNT via enzyme-catalyzed transformation in the aqueous and solid phases. Two coupled rate equations (derived for aqueous-phase and solid-phase TNT concentrations in the tank) contain terms for aqueousphase transformation (based on Michaelis-Menten kinetics), solid-phase transformation (based on equilibrium enzyme sorption to the TNT particles and subsequent TNT transformation into an aqueous-phase product), and solid TNT dissolution (based on a first-order rate expression referenced to the surface area of the shrinking TNT particles). Simulations based on solution of these rate equations showed that aqueous TNT concentrations rapidly became and remained low, limited by the relatively slow dissolution rate of solid TNT. They also showed that concentration versus time profiles contained a substantial initial period of linear decline. Sensitivity studies conducted for the operating parameters of the engineered tank showed that the time for $100 \%$ disappearance of the added TNT was a linear function of the total enzyme (FNR) concentration and the initial solid TNT concentration for the particular values of the other input parameters describing the expected processing tank system. As expected, disappearance time varied directly with initial TNT concentration and initial particle size, and varied inversely with total enzyme concentration. Based on work conducted thus far, the simulated disappearance times were short enough to indicate the feasibility of this methodology for TNT destruction (except for cases with both large initial particle size and low total enzyme concentration). Several issues are discussed related to further efforts needed before mathematical simulations can be used to make firm judgements on the feasibility of the methodology, and to aid the design of the actual processing tank system and its operation.
\end{abstract}

\section{Introduction}

As part of the demilitarization process, stockpiles of numerous types of explosives must be disposed of. The total projected amount of 2,4,6-trinitrotoluene (TNT) that may be subject to disposal is estimated at $8.5 \times 10^{6}$ $\mathrm{Ib}$ (Wheeler et al. 1995). Explosives are normally disposed of via incineration or eliminated by open buming or open detonation (Wheeler et al. 1995). However, efforts are currently underway to develop destruction methods that are more environmentally benign.

Biotransformation of TNT has been previously reported in the literature by many workers (e.g., see Boopathy et al. [1994] and the references cited therein). Furthermore, the literature also documents the transformation of TNT by enzymes extractéd from microorganisms (McCormick et al. 1976; Haidour and Ramos 1996), and the transformation of another nitroaromatic explosive (2,4,6-trinitrophenylmethyl-nitramine, known as tetryl) by an enzyme extracted from spinach (Shah and Spain 1996). Therefore, one type of altemative disposal method currently under study consists of enzymatic transformation of the explosive into nonhazardous/non-toxic byproducts. 
The enzyme studied by Shah and Spain (1996), ferredoxin NADP oxidoreductase (FNR), is an oxygen sensitive nitroreductase enzyme; and therefore catalyzes the release of the nitrite group from the tetryl aromatic ring. Experiments are currently underway to investigate the similar catalytic action of FNR on TNT. We currently believe that this enzyme may be able to catalyze the transformation of TNT as part of a multistep process that ultimately leads to desirable products such as aminophenols, azo initiators, and quatemary ammonium salts.

The mathematical modeling of chemical reaction kinetics is a well-developed discipline. Modeling of enzymecatalyzed reactions (Hill 1977; Benson 1982 pp. 652-658; van Santen and Niemantsverdriet 1995) commonly involves reaction rate expressions describing so-called Michaelis-Menten kinetics (Michaelis and Menten 1913). Laboratory experiments conducted by Shah and Spain (1996) show that the aqueous transformation of tetryl catalyzed by the enzyme FNR conforms to Michaelis-Menten kinetics.

Such transformations, when all chemical participants exist in one phase, are referred to as homogeneous catalysis reactions. However, chemical reactions can also be catalyzed on solid surfaces; which is referred to as heterogeneous catalysis. In engineered chemical processing reactors, the solid matrix is usually the catalyst. However, heterogeneous catalysis can also occur with aqueous-phase enzyme and a solid substrate (such as the TNT destruction methodology investigated in this effort). Figure 1 illustrates the different processes that could be part of an overall heterogeneous catalysis reaction. When developing a mathematical description of a heterogeneous catalysis reaction, it is important to first determine the proper conceptual picture for the particular system of interest (i.e., to determine which of the processes illustrated in Figure 1 are relevant and significant). Figure 2 illustrates different classes of possible mathematical models that can be applied to describe the solid-phase transformation reaction (based partly on which processes in Figure 1 are important).

This work reported in this paper focuses on the mathematical simulation of one proposed methodology for the enzymatic destruction of TNT. The destruction of solid-phase TNT is proposed to be carried out in a processing tank. The tank will contain an aqueous solution (including dissolved TNT and dissolved enzyme) and suspended solid TNT particles. It is assumed that transformation of both aqueous-phase TNT and solidphase TNT occurs, and that the solid-phase TNT transformation product is released into aqueous solution (rather than remaining as part of the solid particle). In addition to being transformed, solid-phase TNT is also assumed to dissolve into the aqueous solution. It is further assumed that the solid-phase TNT particles are non-porous (either because there are no pores, or because the pores are small compared to the aqueous-phase enzyme molecules, or because the pores are small enough that diffusion through them is extremely slow compared to either the solid-phase TNT dissolution or transformation). It is also assumed that the tank contents will be "well-stirred", meaning that concentrations of all substances in the tank can be assumed to be spatially uniform throughout the tank volume. In other words, the system under study is assumed to be a "batch reactor" system, otherwise known as a CSTR (constantly stirred tank reactor) system (Hill 1977, p. 269). Therefore, from a mathematical perspective, it is not necessary to model the transport of any substances in the system (e.g., due to processes such as advection or diffusion/dispersion).

The objectives of the mathematical simulations are to 1) determine if the TNT destruction rate in the processing tank will be fast enough to make this a feasible destruction methodology (given the expected range in operating parameters of the engineered system), and 2) investigate the sensitivity of the simulated destruction time to the values of the model input parameters (for the purposes of determining which parameters must be known to greater accuracies, and aiding in the choice desired operating conditions of actual processing tank). 


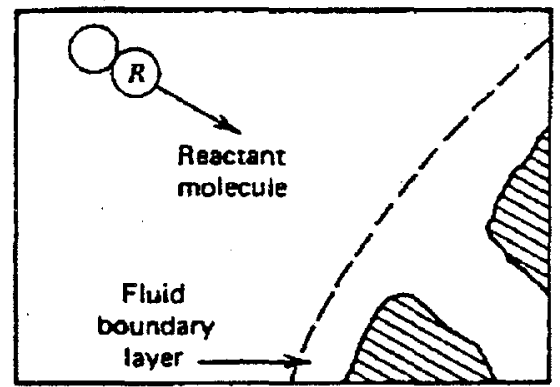

1. Mass transfer through external boundary layer

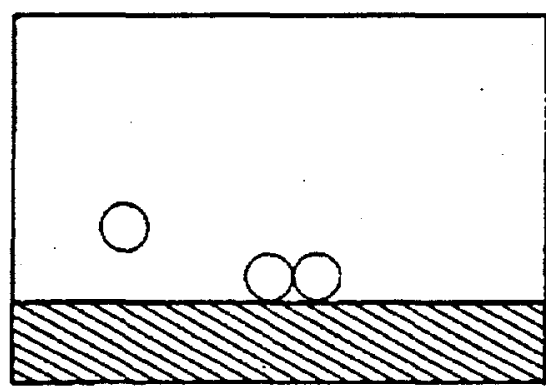

3. Chemisorption

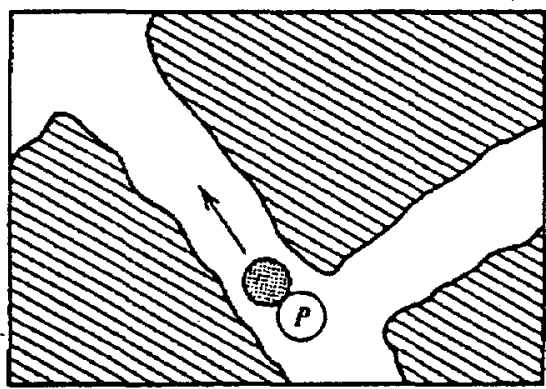

6. Diffusion of products out of pores

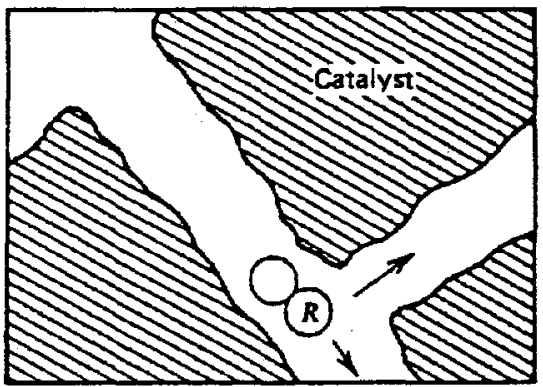

2. Diffusion into pores

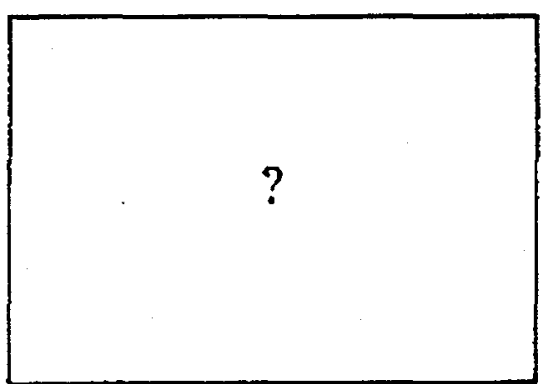

4,5 Reaction and desorption of products

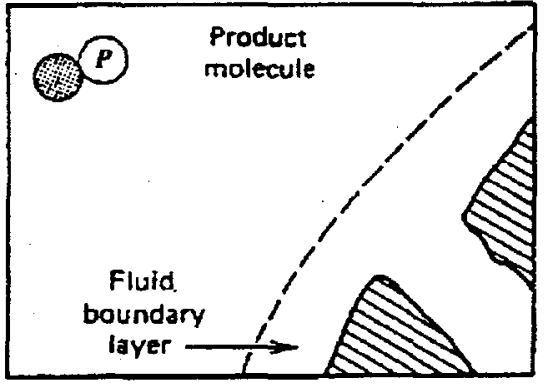

7. Mass transfer back to buik fluid

Figure 1. Schematic representation of potential processes involved in a heterogeneous catalytic reaction on a (porous) solid (after Figure 6.3 in Hill [1977], p. 179) 


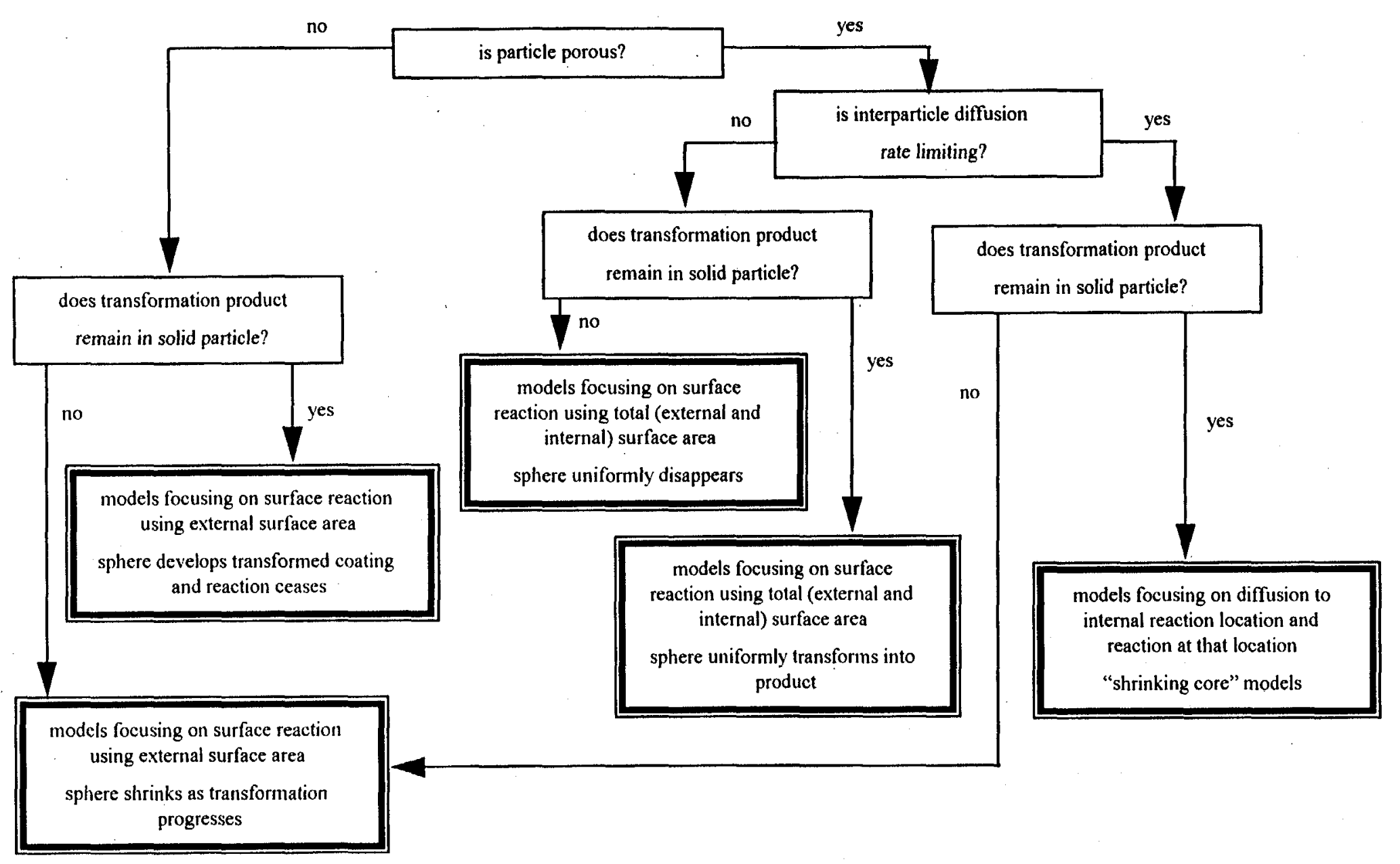

Figure 2. Categories of possible mathematical models for describing the kinetics of a heterogeneous catalysis reaction. Assumptions regarding the conceptual picture of the proposed methodology for solid-phase TNT destruction lead to a model in the category depicted in the lower left corner of the diagram 


\section{Overview of the Enzyme-Catalyzed TNT Transformation Reaction}

The proposed reaction scheme for the degradation of TNT (via nitroreductase enzymes) was developed based on previously obtained data related to aqueous-phase reactions involving the enzyme under consideration (Shah and Spain 1996). However, for the purpose of this overview, the reaction scheme will be presented in a general sense. The proposed scheme can be summarized in the following set of reactions.

$$
\begin{aligned}
& \mathrm{FNR}_{\mathrm{r}}+\mathrm{TNT} \rightarrow \mathrm{FNR}+\mathrm{P}+\text { others } \\
& \mathrm{FNR}+\mathrm{NADPH} \rightarrow \mathrm{FNR}_{\mathrm{r}}+\mathrm{NADP} \\
& \mathrm{NADP}+\mathrm{C}_{\mathrm{r}} \rightarrow \mathrm{NADPH}+\mathrm{C}
\end{aligned}
$$

In an initial series of steps (encompassed by reaction R1), the reduced form of the enzyme ferredoxin NADP oxidoreductase (abbreviated as $\mathrm{FNR}_{\mathrm{r}}$ ) reacts with TNT to ultimately produce the TNT transformation products (the main aromatic-ring product being abbreviated as $\mathrm{P}$ ), while at the same time releasing the oxidized form of the enzyme (abbreviated as FNR). The main transformation product of TNT is formed via reductive elimination of the nitro group attached to the aromatic ring. The first step in this process is the addition of a hydride ion [from FNR $R_{r}$ ] to the TNT aromatic ring to form a Meisenheimer complex. In reaction series R1, "others" refers to the eliminated nitro group.

In the next step (reaction R2), FNR reacts with the reduced form of the enzyme nicotinamide adenine dinucleotide phosphate (abbreviated as NADPH) to produce $F_{N R}$ again, as well as the oxidized form of NADPH (abbreviated as NADP). Because of this, the TNT transformation process never becomes limited by the disappearance of $F_{N R}$, as long as there is adequate NADPH in the system. Furthermore, because reaction $R 2$ is relatively fast, FNR is converted back to $F N R_{r}$ as quickly as it is produced. Once an FNR enzyme molecule is restored to its reduced state, it is free to participate in another TNT transformation reaction (reaction R1). Thus, the TNT transformation reaction proceeds in the forward direction without progressive consumption of $F N R_{r}$ (i.e., the total concentration of $F N R+F N R_{r}$ in the system remains constant, and $F N R_{r}$ is continually replenished). Therefore $F N R_{r}$ conforms to the classic definition of an enzyme in this process.

It is also worth noting that after NADPH is oxidized to NADP via the aforementioned reaction with FNR, the NADP is subsequently reduced again to NADPH via reaction with another reduced aqueous component of the system (abbreviated as $C_{r}$ ) (reaction R3). This reaction is also relatively fast. For this reason, the TNT transformation process never becomes limited by disappearance of NADPH either, as long as there is adequate $C_{r}$ in the system. To achieve this, the tank processing system is engineered so that $C_{r}$ is always present in great excess of the demand for a reducing agent for NADP in the TNT destruction process.

Now, if we sum reactions $R 1$ - R3 to get an expression of the overall reaction in the system we obtain

$$
\mathrm{FNR}_{\mathrm{r}}+\mathrm{TNT}+\mathrm{C}_{\mathrm{r}} \rightarrow \mathrm{FNR}_{\mathrm{r}}+\mathrm{P}+\text { others }+\mathrm{C}
$$

(where the FNRr component has been explicitly retained on both sides of the equation to highlight the fact that this reaction is catalyzed by FNRr). In the engineered tank system, the concentration of $\mathrm{Cr}$ is always relatively close to its initial value, and the concentration of $C$ is always relatively small. Because of all of these considerations, quantitative modeling of TNT disappearance in the tank processing system does not need to explicitly model the enzymes or the other aqueous components $\mathrm{Cr}$ and $\mathrm{C}$. That is, those components don't need to be considered as primary time-varying components of the model (which must be represented by 
separate rate equations in the set of coupled kinetic reaction equations that constitute the overall model). So, for all practical purposes, reaction R4 can be rewritten in the classic notation of enzyme-substrate theory. To do so, denote the FNRr enzyme by the symbol E and the TNT substrate by the letter $S$, and (without loss of generality) drop "others". from explicit inclusion in the equation. Considering that the enzyme-substrate interaction is actually a series of steps (as mentioned above), this enzyme-catalyzed transformation reaction can be expressed as:

$$
\begin{aligned}
& E+S \leftrightarrow E S \\
& E S \rightarrow E+P
\end{aligned}
$$

In reactions R5 and R6, ES represents an intermediate complex (e.g., related to the formation of the Meisenheimer complex described above). Note that reactions R5 and R6 also assume that the stoichiometry of the transformation reaction is such that one mole of substrate is transformed into one mole of main product (which is the case for aromatic ring TNT transformation product).

In the Theory section, a Michaelis-Menten type rate expression (appropriate to Reactions R5 and R6) will be derived to describe the transformation reaction of the aqueous-phase TNT. This choice was based the fact that data from experiments of aqueous-phase transformation of tetryl, catalyzed by the same enzyme, have been shown to conform to Michaelis-Menten kinetics (Shah and Spain 1996). However, because of the lack of certain data needed for an analogous theory for solid-phase substrate, a slightly different rate expression will be derived for the solid-phase TNT transformation. The basic approach of the derivation will be similar, though; which means that the overall mathematical form of the derived rate expressions will be similar.

\section{Theory}

The theory for describing the proposed TNT processing tank system consists of specifying a set of coupled kinetic reaction equations, which describe the physicochemical processes occurring (at any given location) at any time for each relevant component (in this case: aqueous-phase TNT and solid-phase TNT). The development of the mathematical forms of the equations used in the modeling is given below. In developing these equations, the idea was to express the final forms of these equations in terms of practical engineering operating parameters, previously measured constants, or well-defined thermodynamic parameters that could be obtained from the literature, whenever possible. Furthermore, the conceptual/mathematical model developed attempts to strike an appropriate balance between simplicity and complexity. The intent was to make the model complex enough to include some kind of description of all processes that are assumed to be significant. However, the intent was also to make this initial model reasonably simple (i.e., idealized) because of the current lack of specific experimental data to elucidate and quantify the mechanisms of some of the processes involved.

\subsection{Fundamental Relationships Between Certain Parameters}

At the time when the processing tank is set up, the conditions that can be chosen, a priori, include the size of the added TNT particles, the overall initial concentration $\left(C_{T_{s o}}\right)$ of solid-phase TNT in the processing tank solution, and the concentration of total enzyme added to the tank. This modeling efforts assumes that the solid-phase TNT particles can be represented by a collection of equivalent spherical pellets of uniform size. Thus, choosing the size of the TNT particles amounts to choosing the average initial radius, $r_{s o}$, of the equivalent spherical pellet. Choosing the initial particle radius and the overall initial TNT concentration determines the number density of particles in solution, $n_{s}$, according to the expression 


$$
n_{s}=\frac{C_{\text {Tso }}}{m_{\text {so }}}=\frac{C_{\text {Tso }}}{\rho_{s} V_{\text {so }}}=\frac{C_{\text {Tso }}}{\rho_{s}\left(\frac{4}{3} \pi r_{\text {so }}^{3}\right)}
$$

(The symbols in Equation 1, and elsewhere in the paper, are defined in the Notation section.)

This number density remains constant throughout the process because it is assumed that no additional particles of solid-phase TNT are added to the tank during the process, and that each particle only shrinks in radius as it loses mass to dissolution or transformation (i.e., the particles do not break up into a greater number of smaller particles, nor do they bind together into a fewer number of particles). Because of this assumption, the number density at any time during the process is also given by

$$
n_{s}=\frac{C_{T s}}{\rho_{s}\left(\frac{4}{3} \pi r_{s}^{3}\right)}
$$

Solving Equation 2 for the radius of the equivalent spherical pellet at any given time, and substituting Equation 1 into the resulting expression, gives a simple expression for the radius in terms of the concentration of solid-phase TNT at any given time

$$
r_{s}=r_{s o}\left(\frac{C_{T s}}{C_{T s o}}\right)^{1 / 3}
$$

Furthermore, for a collection of spheres of uniform radius, the volumetric surface area of solid-phase TNT in the tank (i.e., the total area of solid surface per volume of aqueous solution) at any time is given by

$$
A_{v}=n_{s}\left(4 \pi r_{s}^{2}\right)
$$

Substituting Equations 1 and 3 into Equation 4, and simplifying, we obtain

$$
A_{v}=\left(\frac{3 C_{T s o}^{1 / 3}}{\rho_{s} r_{s o}}\right) C_{T s}^{2 / 3}
$$

\subsection{Rate Equation for Aqueous-Phase TNT}

For the aqueous-phase substrate (TNT), the expression for the rate of change of the concentration is given by (in general form)

$$
\frac{\mathrm{dC}_{\mathrm{Taq}}}{\mathrm{dt}}=\left[\frac{\mathrm{dC}_{\mathrm{Taq}}}{\mathrm{dt}}\right]_{\text {trans-aq }}+\left[\frac{\mathrm{dC}_{\mathrm{Taq}}}{\mathrm{dt}}\right]_{\mathrm{dis}}
$$

In Equation 6, the first term on the right-hand side of the equation represents the change in concentration due to enzyme-catalyzed transformation of aqueous-phase TNT, and the second term on the right-hand side of the equation represents the change in concentration due to dissolution of solid-phase TNT. 


\subsubsection{The Aqueous-Phase TNT Transformation Term:}

In accordance with the general reaction description provided above, for the aqueous-phase transformation process, it is assumed that the aqueous enzyme molecule first forms a complex with the aqueous TNT substrate molecule. Then this complex is ultimately converted (in a series of steps) to an aqueous TNT degradation product, and the aqueous enzyme molecule is released. The classic Michaelis-Menten reaction scheme (presented in reaction equations R5 and R6), as well as the classic derivation of the rate expression, will be applied. The rate-controlling portion of this aqueous-phase transformation scheme can be expressed more specifically as:

$$
\begin{aligned}
& E(a q)+S(a q)<==>E S(a q) \\
& E S(a q) \cdots E(a q)+P(a q)
\end{aligned}
$$

Let $k_{122 q}$ and $k_{212 q}$ denote the forward and reverse rate constants for reaction $R 7$, respectively; and let $k_{232 q}$ denote the forward rate constant for reaction R8. Assuming classic Michaelis-Menten theory, reactions R7 and R8 are analyzed as if the system was in steady state; i.e., as if the concentrations of $E(a q)$ and $S(a q)$ were essentially constant in time. This would be approximately true for early times if the concentration of substrate was much higher than that of the enzyme and the complex. The resulting theory, applied to a system where the substrate concentration falls significantly as it is transformed into product, is therefore a quasi-steadystate theory.

The rate of production of product is given by

$$
\frac{\mathrm{d}[\mathrm{P}(\mathrm{aq})]}{\mathrm{dt}}=\mathrm{k}_{23 \mathrm{aq}}[\mathrm{ES}(\mathrm{aq})
$$

(In Equation 7, and subsequent equations, the square bracket notation denotes the molar concentration of the species within the bracket.) Because the concentrations of $E(\mathrm{aq})$ and $\mathrm{S}(\mathrm{aq})$ are assumed constant, the rate of production of $\mathrm{P}(\mathrm{aq})$ would be constant. According to Equation 7, this means that $[\mathrm{ES}(\mathrm{aq})]$ would be constant (i.e., ES(aq) exists in a steady state). In turn, this means that the rate of change of [ES(aq)] would be zero. Therefore

$$
\frac{d[E S(a q)]}{d t}=k_{12 a q}[E(a q)][S(a q)]-\left(k_{21 a q}+k_{23 a q}\right)[E S(a q)]=
$$

Note that it has not been assumed that reaction $\mathrm{R} 7$ is in equilibrium. Therefore, [ES(aq)] is not necessarily equal to the value that would be in equilibrium with $[\mathrm{E}(\mathrm{aq})]$ and $[\mathrm{S}(\mathrm{aq})]$. In general, it would be less than this because of the fact that reaction R8 is irreversibly removing ES(aq) from the system; and so [ES(aq)] would have to be lower than its equilibrium value in order for a net amount of $E(a q)$ and $S(a q)$ to be complexing at any time.

Rearranging Equation 8 to solve for $[\mathrm{ES}(\mathrm{aq})]$ gives

$$
[E S(a q)]=\frac{1}{K_{S a q}}[E(a q)][S(a q)
$$

where $\mathrm{K}_{\mathrm{Sa}}^{\prime}$, the strict molar Michaelis-Menten half-saturation constant for the aqueous phase, is given by 


$$
\mathrm{K}_{\mathrm{Saq}}^{\prime}=\frac{\mathrm{k}_{2 \mathrm{aq}}+\mathrm{k}_{23 \mathrm{aq}}}{\mathrm{k}_{12 \mathrm{aq}}}
$$

Now, because the total enzyme concentration in the system, $\left[\mathrm{E}_{\uparrow}\right]$, is constant over time

$$
[\mathrm{E}(\mathrm{aq})]=\left[\mathrm{E}_{\mathrm{t}}\right]-[\mathrm{ES}(\mathrm{aq})
$$

(Note that Equation 11 implicitly assumes that enzyme complexed with solid-phase TNT can be neglected. While this is not strictly true, accounting for this kind of coupling between the aqueous-phase and solidphase transformation would result in much more complicated terms in the rate expressions. This kind of coupling may be accounted for in later improvements in the model. However, this initial modeling effort assumes that the type of rate expression terms derived by considering the aqueous-phase and solid-phase transformations independently will suffice.)

Substituting Equation 11 into Equation 9, and solving for [ES(aq)] gives

$$
[E S(a q)]=\frac{\left[E_{t}\right][S(a q)]}{\left(K_{S a q}^{\prime}+[S(a q)]\right)}
$$

Now, substituting Equation 12 into Equation 7 gives

$$
\frac{d[P(a q)]}{d t}=k_{23 a q} \frac{\left[E_{t}\right][S(a q)]}{\left(K_{S a q}^{\prime}+[S(a q)]\right)}
$$

If we now assume that the substrate and complex concentrations decrease over time, Equation 13 can be used to predict the rate of production of product according to quasi-steady-state Michaelis-Menten kinetics. If we use the fact that the total molar concentration of substrate in the system is equal to the sum of [S(aq)] and $[\mathrm{ES}(\mathrm{aq})]$, along with the steady-state assumption for $\mathrm{ES}(\mathrm{aq})$, the rate of loss of substrate is given by

$$
\frac{\mathrm{d}[\mathrm{S}(\mathrm{aq})]}{\mathrm{dt}}=\frac{\mathrm{d}[\mathrm{S}(\mathrm{aq})]}{\mathrm{dt}}+\frac{\mathrm{d}[\mathrm{ES}(\mathrm{aq})]}{\mathrm{dt}}=-\frac{\mathrm{d}[\mathrm{P}(\mathrm{aq})]}{\mathrm{dt}}=-\mathrm{k}_{23 \mathrm{aq}} \frac{\left[\mathrm{E}_{\mathrm{t}}\right][\mathrm{S}(\mathrm{aq})]}{\left(\mathrm{K}_{\mathrm{Saq}}^{\prime}+[S(a q)]\right)}
$$

If $M_{S}$ is the molecular weight of the substrate, $M_{S}$ grams of substrate are transformed for every mole of substrate transformed. Using this fact, converting the molar concentrations of enzyme and substrate on the right-hand-side of Equation 14 to mass concentrations, and multiplying both sides of the equation by $M_{s}$, the first term in Equation 6 can be given by

$$
\left[\frac{\mathrm{dC}_{\mathrm{Taq}}}{\mathrm{dt}}\right]_{\text {trans-aq }}=-\mathrm{k}_{\text {maq }} \mathrm{C}_{\mathrm{et}}\left(\frac{\mathrm{C}_{\mathrm{Taq}}}{\mathrm{C}_{\mathrm{Taq}}+\mathrm{K}_{\mathrm{Taq}}}\right)
$$

where $k_{m a q}$, the maximum aqueous reaction rate constant for a given enzyme concentration, is given by

$$
\mathrm{k}_{\mathrm{maq}}=\left(\frac{\mathrm{M}_{\mathrm{S}}}{\mathrm{M}_{\mathrm{e}}}\right) \mathrm{k}_{23 \mathrm{aq}}
$$


and where $\mathrm{K}_{\text {Taq }}$, the aqueous Michaelis-Menten half-saturation constant, is given by

$$
\mathrm{K}_{\mathrm{Taq}}=\mathrm{M}_{\mathrm{S}} \mathrm{K}_{\mathrm{Saq}}^{\prime}=\mathrm{M}_{\mathrm{S}}\left(\frac{\mathrm{k}_{21 \mathrm{aq}}+\mathrm{k}_{23 \mathrm{aq}}}{\mathrm{k}_{12 \mathrm{aq}}}\right)
$$

(Note that the molecular weights of the substrate and enzyme $\left[\mathrm{M}_{s}\right.$ and $\mathrm{M}_{e}$, respectively] enter into Equations 16 and 17 because the classic Michaelis-Menten derivation uses molar concentrations while the present theory uses mass concentrations.)

\subsubsection{The Aqueous-Phase TNT Dissolution Term:}

Assuming a simple, first-order rate law for dissolution, the second term on the right-hand side of Equation 6 can be given by

$$
\left[\frac{\mathrm{dC}_{\mathrm{Taq}}}{\mathrm{dt}}\right]_{\mathrm{dis}}=\mathrm{k}_{\mathrm{dis}}\left(\mathrm{C}_{\mathrm{Taq}}^{\mathrm{sol}}-\mathrm{C}_{\mathrm{Taq}}\right)
$$

Of course, the overall rate of TNT dissolution depends on how much surface area of solid-phase TNT is exposed to a given amouint of solution in the processing tank. In other words, the rate of dissolution per "area of solid surface" is a more intrinsic property of the system than is the overall rate of dissolution. Furthermore, because the dissolved mass coming off of a given area of surface causes the aqueous-phase concentration to more quickly approach the aqueous solubility if that surface area is associated with a smaller volume of solution, the rate of dissolution per "area of solid surface per volume of solution" is an even more intrinsic property of the system. Therefore, it would be more rigorous to express the first-order dissolution rate coefficient, $k_{d i s}$, in Equation 18 as a function of the area of solid-phase TNT surface per volume of solution. We assume a linear dependence of the overall rate coefficient on TNT volumetric surface area. Furthermore, we assume that only a fraction, $f$, of the volumetric surface area of the TNT particle consists of TNT molecules that can dissolve, because part of the particle surface has adsorbed enzyme molecules on it (see the subsequent section on the solid-phase rate equation). Substituting the linear model of $k_{\text {dis }}$ into Equation 18 produces the revised rate expression

$$
\left[\frac{\mathrm{dC}_{\mathrm{Taq}}}{\mathrm{dt}}\right]_{\mathrm{dis}}=\mathrm{A}_{\mathrm{v}} \mathrm{fk}_{\mathrm{dis}}^{\prime}\left(\mathrm{C}_{\mathrm{Taq}}^{\mathrm{sol}}-\mathrm{C}_{\mathrm{Taq}}\right)
$$

By substituting Equation 5 into Equation 19, the dissolution rate term can be given by

$$
\left[\frac{\mathrm{dC}_{\mathrm{Taq}}}{\mathrm{dt}}\right]_{\mathrm{dis}}=\left(\frac{3 \mathrm{C}_{\mathrm{Ts}}^{1 / 3}}{\rho_{\mathrm{s}} \mathrm{r}_{\mathrm{so}}}\right) \mathrm{C}_{\mathrm{Ts}}^{2 / 3} \mathrm{fk}_{\mathrm{dis}}^{\prime}\left(\mathrm{C}_{\mathrm{Taq}}^{\mathrm{sol}}-\mathrm{C}_{\mathrm{Taq}}\right)
$$

\subsubsection{The Complete Aqueous-Phase TNT Rate Expression:}

Therefore, by substituting Equations 15 and 20 into Equation 6, the final expression for the rate of change of the concentration of aqueous-phase TNT is given by

$$
\frac{d C_{\mathrm{Taq}}}{\mathrm{dt}}=-k_{\mathrm{maq}} C_{\mathrm{et}}\left(\frac{\mathrm{C}_{\mathrm{Taq}}}{\mathrm{C}_{\mathrm{Taq}}+\mathrm{K}_{\mathrm{Taq}}}\right)+\left(\frac{3 \mathrm{C}_{\mathrm{Tso}}^{1 / 3}}{\rho_{\mathrm{s}} \mathrm{r}_{\mathrm{so}}}\right) \mathrm{C}_{\mathrm{Ts}}^{2 / 3} \mathrm{fk}_{\mathrm{dis}}^{\prime}\left(\mathrm{C}_{\mathrm{Taq}}^{\mathrm{sol}}-\mathrm{C}_{\mathrm{Taq}}\right)
$$




\subsection{Rate Equation for Solid-Phase TNT}

For the solid-phase substrate (TNT), the expression for the rate of change of the concentration is be given by (in general form)

$$
\frac{\mathrm{dC}_{\mathrm{Ts}}}{\mathrm{dt}}=\left[\frac{\mathrm{dC}_{\mathrm{Ts}}}{\mathrm{dt}}\right]_{\text {trans-s }}+\left[\frac{\mathrm{dC}_{\mathrm{Ts}}}{\mathrm{dt}}\right]_{\mathrm{dis}}
$$

In Equation 22, the first term on the right-hand side of the equation represents the change in concentration due to enzyme-catalyzed transformation of solid-phase TNT on the surface of the particle, and the second term on the right-hand side of the equation represents the change in concentration due to dissolution of solid-phase TNT.

Recall that it is assumed that the TNT particles are nonporous, and that once the solid-phase TNT is transformed on the surface, the transformation product is released into aqueous solution. Note that this latter assumption is commensurate with the fact that it is the reduction of $\mathrm{C}_{\mathrm{Ts}}$ from both processes (from Equation 22) that is used to determine the shrinking radius of the solid-phase particle (in Equation 3), and thereby the volumetric surface area of the particles (in Equation 5). Based on the these assumptions, an appropriate mathematical model for the solid-phase TNT transformation would fall into the category depicted in the lower left comer of the diagram in Figure 2.

\subsubsection{The Solid-Phase TNT Transformation Term:}

At this time, no specific experimental data exists to elucidate and quantify the $F_{N R}$ enzyme-catalyzed transformation of TNT on the solid-phase surface. Therefore, this modeling effort is based on the following hypothesized conceptualization of the solid-phase transformation. First, it is assumed that the process of TNT transformation on the surface is similar to that in solution. So, for the solid-phase transformation process, it is assumed that the aqueous enzyme molecule first forms a complex with a solid-phase TNT substrate molecule that resides on the outer surface of TNT particle. In other words, the first step in the process is a sorption reaction. Then this complex (between a substrate sorption site and an adsorbed enzyme molecule) is ultimately converted (in a series of steps) to an aqueous TNT degradation product, and the aqueous enzyme molecule is released.

It should be noted that to use a classic Michaelis-Menten rate expression for the first term in Equation 22 (derived through a process exactly like that presented in the previous section for the aqueous phase), we would need to have values of either the overall Michaelis-Menten maximum rate and half-saturation parameters, or of the more fundamental sorption and desorption rate constants. However, at this time, these data are not available. Hence, one additional idealizing assumption will be made: namely, that the adsorption/desorption processes are so fast relative to the subsequent transformation reaction, that the sorbed and aqueous forms of the enzyme can be considered to be in equilibrium with each other. With thisconceptualization, a reaction scheme similar to the classic Michaelis-Menten reaction scheme (presented in reaction equations R5 and R6), can be applied. The relevant portion of this solid-phase transformation scheme can be expressed more specifically as:

$$
\begin{aligned}
& \mathrm{E}(\mathrm{aq})+\mathrm{S}(\mathrm{s}) \leftrightarrow \mathrm{ES}(\mathrm{ad}) \\
& \mathrm{ES}(\mathrm{ad}) \rightarrow \mathrm{E}(\mathrm{aq})+\mathrm{P}(\mathrm{aq})
\end{aligned}
$$


(Note that reaction $\mathrm{R} 9$ is the sorption reaction.) Let $k_{12 s}$ and $k_{21 s}$ denote the adsorption and desorption rate constants for reaction $R 9$, respectively; and let $k_{23 s}$ denote the forward rate constant for reaction $R 10$.

Because reaction $\mathrm{R} 9$ is assumed to be in equilibrium, it must follow that

$$
k_{12 s}[E(a q)][S(s)]=k_{21 s}[E S(a d)
$$

Note that in Equation 23, [S(s)] does not refer to the total number of moles of solid-phase substrate per volume of solution, because not all of the TNT particle is available for participation in the surface reaction. Instead, much of the TNT is within the particle; and because the particle is assumed to be nonporous, it is not available for reaction. So, $[S(s)]$ refers only to the number of moles of "surface-site" TNT that does not have enzyme bound to it per volume of solution. Similarly, while [ES(ad)] might most properly be referred to as the number of moles of adsorbed enzyme-substrate complex per volume of solution, it is also numerically equal to the number of moles of "surface-site" TNT that has enzyme bound to it per volume of solution. Because of this, these two quantities are more closely associated with the particle surface area than with the particle volume or mass. This relationship will be shown more explicitly in the subsequent derivation. At this point, it is not necessary to define these variables any more rigorously, because subsequent derivation will show that these variables are only intermediate quantities in the present theory.

Rearranging Equation 23 to solve for [ES(ad)] gives

$$
[\mathrm{ES}(\mathrm{ad})]=\frac{\mathrm{k}_{12 \mathrm{~s}}}{\mathrm{k}_{21 \mathrm{~s}}}[\mathrm{E}(\mathrm{aq})][\mathrm{S}(\mathrm{s})
$$

Now, because the total enzyme concentration in the system, $\left[E_{t}\right]$, is constant over time

$$
[\mathrm{E}(\mathrm{aq})]=\left[\mathrm{E}_{\mathrm{t}}\right]-[\mathrm{ES}(\mathrm{ad})
$$

(Note that Equation 25 implicitly assumes that enzyme complexed with aqueous-phase TNT can be neglected. While this is not strictly true, accounting for this kind of coupling between the aqueous-phase and solid-phase transformation would result in much more complicated terms in the rate expressions. This kind of coupling may be accounted for in later improvements in the model. However, this initial modeling effort assumes that the type of rate expression terms derived by considering the aqueous-phase and solid-phase transformations independently will suffice.)

Substituting Equation 25 into Equation 24, solving for [ES(ad)], and dividing the numerator and denominator by $[\mathrm{S}(\mathrm{s})]$ gives

$$
[\mathrm{ES}(\mathrm{ad})]=\frac{\left[\mathrm{E}_{\mathrm{t}}\right][\mathrm{S}(\mathrm{s})]}{\left(\frac{\mathrm{k}_{21 \mathrm{~s}}}{\mathrm{k}_{12 \mathrm{~s}}}+[\mathrm{S}(\mathrm{s})]\right)}=\frac{\left[\mathrm{E}_{\mathrm{t}}\right]}{\left(1+\frac{\mathrm{k}_{21 \mathrm{~s}}}{\mathrm{k}_{12 \mathrm{~s}}[\mathrm{~S}(\mathrm{~s})]}\right)}
$$

At this point, it is worthwhile to examine how the quotient of parameters in the denominator of Equation 26 is related to parameters involved in the more common description of linear equilibrium sorption (i.e., a $\mathrm{K}_{d-}$ type description of sorption). First, note that the molar concentrations used thus far can be related to the more common mass concentrations used in a $K_{d}$ definition by the following expressions:

$$
[E S(\mathrm{ad})]=\mathrm{C}_{\mathrm{ead}} \frac{\mathrm{C}_{\mathrm{Ts}}}{\mathrm{M}_{\mathrm{e}}}
$$




$$
[E(\mathrm{aq})]=\frac{C_{e a q}}{M_{e}}
$$

Substituting Equations 27 and 28 into Equation 24, and rearranging, we obtain

$$
C_{\text {ead }}=\left(\frac{k_{12 s}[S(s)]}{k_{21 s} C_{T s}}\right) C_{\text {ea }}
$$

From the standard definition of the linear equilibrium sorption coefficient, along with some other fundamental relationships, we obtain

$$
C_{\text {ead }}=K_{d} C_{\text {eaq }}=K_{d}^{\prime} A_{g} C_{e a q}=\left(\frac{K_{d}^{\prime} A_{y}}{C_{T s}}\right) C_{e a}
$$

Equating the parenthetical quotients on the right-hand-sides of Equations 29 and 30 , it can be shown that

$$
\frac{k_{21 s}}{k_{12 s}[S(s)]}=\frac{1}{K_{d}^{\prime} A_{v}}
$$

Finally, substituting Equation 31 into Equation 26, we obtain

$$
[E S(a d)]=\frac{\left[E_{t}\right]}{\left(1+\frac{1}{K_{d}^{\prime} A_{v}}\right)}
$$

Now, according to reactions R9 and R10, expressions for the rates of change of the concentrations of the two species related to the solid substrate can be written as

$$
\frac{\mathrm{d}[\mathrm{S}(\mathrm{s})]}{\mathrm{dt}}=-\mathrm{k}_{12 \mathrm{~s}}[\mathrm{E}(\mathrm{aq})][\mathrm{S}(\mathrm{s})]+\mathrm{k}_{21 \mathrm{~s}}[\mathrm{ES}(\mathrm{ad})
$$

and

$$
\frac{\mathrm{d}[\mathrm{ES}(\mathrm{ad})]}{\mathrm{dt}}=\mathrm{k}_{12 \mathrm{~s}}[\mathrm{E}(\mathrm{aq})][\mathrm{S}(\mathrm{s})]-\mathrm{k}_{21 \mathrm{~s}}[\mathrm{ES}(\mathrm{ad})]-\mathrm{k}_{23 \mathrm{~s}}[\mathrm{ES}(\mathrm{ad})
$$

Note that the sum of $[\mathrm{S}(\mathrm{s})]$ and $[\mathrm{ES}(\mathrm{ad})]$ represents the total molar concentration of the solid "surface site" substrate, and that it is the rate of change of this total solid "surface site" substrate that can be directly related to the rate of change of solid TNT in the system $\left(\mathrm{C}_{\mathrm{Ts}}\right)$. Taking the time derivative of this total molar concentration ([S(s)] + [ES(ad)]) amounts to adding Equations 33 and 34. Doing so, and then substituting Equation 32 into the resulting equation, produces the following expression

$$
\frac{d}{d t}([S(s)]+[\operatorname{ES}(\mathrm{ad})])=-k_{23 s}[\operatorname{ES}(\mathrm{ad})]=-k_{23 s} \frac{\left[E_{t}\right]}{\left(1+\frac{1}{K_{d}^{\prime} A_{v}}\right)}
$$


Now, if $M_{s}$ is the molecular weight of the substrate, $M_{S}$ grams of substrate are transformed for every mole of "surface site" substrate transformed. Using this fact, converting the molar concentration of enzyme on the right-hand-side of Equation 35 to mass concentration, multiplying both sides of the equation by $\mathrm{M}_{s}$, and substituting Equation 5 (i.e., the explicit expression for $A_{v}$ ) into the resulting expression, Equation 35 becomes

$$
\frac{d C_{T s}}{d t}=-\left(k_{23 s} \frac{M_{S}}{M_{e}}\right) C_{e t}\left(\frac{1}{1+\left(\frac{\rho_{s} r_{s o}}{3 K_{d}^{\prime} C_{T s o}^{1 / 3}}\right) C_{T s}^{-2 / 3}}\right)
$$

By multiplying the numerator and denominator of Equation 36 by $\mathrm{C}_{\mathrm{Ts}}^{2 / 3}$, the first term in Equation 22 can be given by

$$
\left[\frac{\mathrm{d} \mathrm{C}_{\mathrm{Ts}}}{\mathrm{dt}}\right]_{\text {trans-s }}=-k_{\mathrm{rns}} \mathrm{C}_{\mathrm{et}}\left(\frac{\mathrm{C}_{\mathrm{Ts}}^{2 / 3}}{\mathrm{C}_{\mathrm{Ts}}^{2 / 3}+\left(\frac{\rho_{\mathrm{s}} \mathrm{r}_{\mathrm{s} 0}}{3 \mathrm{~K}_{\mathrm{d}}^{\prime} \mathrm{C}_{\mathrm{Ts} \mathrm{l}}^{1 / 3}}\right)}\right)
$$

where $\mathrm{k}_{\mathrm{ms}}$, the maximum solid-phase reaction rate constant for a given enzyme concentration, is given by

$$
\mathrm{k}_{\mathrm{ms}}=\left(\frac{\mathrm{M}_{\mathrm{S}}}{\mathrm{M}_{\mathrm{e}}}\right) \mathrm{k}_{23 \mathrm{~s}}
$$

Note that Equation 37 has the same general mathematical form as Equation 15; however, there are a few differences in specific parts of the expressions. One difference is that the substrate concentration in the Michaelis-Menten multiplicative term in Equation 15 is the actual aqueous-phase TNT concentration, while in Equation 37 it is the $2 / 3$ power of the solid-phase TNT concentration. This makes intuitive sense for the following reason. The actual solid-phase concentration depends on the solid TNT mass, which is directly proportional to the volume of the solid, which depends on the cube of the radius. However, the reaction really depends on the amount of TNT along the outer surface area of the solid TNT particle; and the surface area depends on the square of the radius. Hence $\mathrm{C}_{T s}^{2 / 3}$ is related to the total surface area per volume of solution, or, more specifically, to the solid "surface site" TNT concentration. The other difference is that Equation 15 has an actual Michaelis-Menten half-saturation constant in the denominator, while Equation 37 has a quotient of other parameters in the same position. This collection of parameters can be thought of as an "effective Michaelis-Menten half-saturation constant" for this surface transformation reaction.

\subsubsection{The Solid-Phase TNT Dissolution Term:}

Now, with regards to the rate of change of solid-phase TNT concentration due to dissolution (i.e., the second term on the right-hand side of Equation 22), the expression for this term is merely the inverse of the dissolution-related term for aqueous-phase TNT (in Equations 6 and 20). Specifically, the expression is

$$
\left[\frac{\mathrm{dC}_{\mathrm{Ts}}}{\mathrm{dt}}\right]_{\mathrm{dis}}=-\left(\frac{3 \mathrm{C}_{\mathrm{Tse}}^{\mathrm{l} / 3}}{\rho_{\mathrm{s}} \mathrm{r}_{\mathrm{so}}}\right) \mathrm{C}_{\mathrm{Ts}}^{2 / 3} \mathrm{fk}_{\mathrm{dis}}^{\prime}\left(\mathrm{C}_{\mathrm{Taq}}^{\mathrm{sol}}-\mathrm{C}_{\mathrm{Taq}}\right)
$$




\subsubsection{The Complete Solid-Phase TNT Rate Expression:}

Therefore, by substituting Equations 37 and 39 into Equation 22, the final expression for the rate of change of the concentration of aqueous-phase TNT is given by

$$
\frac{\mathrm{dC}_{\mathrm{Ts}}}{\mathrm{dt}}=-k_{\mathrm{ms}} \mathrm{C}_{\mathrm{et}}\left(\frac{\mathrm{C}_{\mathrm{Ts}}^{2 / 3}}{\mathrm{C}_{\mathrm{Ts}}^{2 / 3}+\left(\frac{\rho_{\mathrm{s}} r_{\mathrm{s} Q}}{3 \mathrm{~K}_{\mathrm{d}}^{\prime} C_{\mathrm{Tso}}^{1 / 3}}\right)}\right)-\left(\frac{3 \mathrm{C}_{\mathrm{Tso}}^{1 / 3}}{\rho_{\mathrm{s}} \mathrm{r}_{\mathrm{so}}}\right) \mathrm{C}_{\mathrm{Ts}}^{2 / 3} \mathrm{f} \mathrm{k}_{\mathrm{dis}}^{\prime}\left(\mathrm{C}_{\mathrm{Taq}}^{\mathrm{sol}}-\mathrm{C}_{\mathrm{Taq}}\right)
$$

\subsection{Rate Equation for Enzyme}

Because the total amount of enzyme remains constant in the system (i.e., the enzyme participates in the multistep transformation reaction process, but it not consumed by it), the expression for the rate of change of the total concentration of enzyme is given by

$$
\frac{\mathrm{d} \mathrm{C}_{\mathrm{et}}}{\mathrm{dt}}=0
$$

Therefore, it is not really necessary to explicitly include the enzyme concentration as one of the components of the reaction system that will be modeled during the TNT destruction process.

\section{Parameterizing the Coupled Set of Rate Equations}

It is assumed that the processing tank system is set up by first adding the solid-phase TNT to aqueous solution in the tank. As long as no enzyme has been added to the tank yet, TNT will dissolve into solution according to the controlling dissolution kinetics, and increase with time. The simulations assume that the tank solution reaches aqueous solubility with respect to TNT before enzyme is added. In other words, the initial condition for the aqueous-phase TNT concentration variable is the aqueous solubility. The initial condition for the solid-phase TNT concentration variable should be equal to the mass of TNT added to the tank, minus the mass of TNT that dissolved into solution, per volume of solution. However, because the aqueous solubility is so low compared to the desired initial TNT loading of the tank, a negligibly small fraction of the added solid-phase TNT will dissolve into the tank solution during the initial set up. So, for practical purposes, the initial condition for the solid-phase TNT concentration can be taken to be the added TNT mass per volume of solution.

The coupled set of rate equations (Equations 21 and 40) that must be solved (to simulate the concentrations of aqueous-phase and solid-phase TNT in the tank as functions of time) contain 11 parameters (other than the dependent concentration variables themselves). However, it should be noted that specific values for $f$ (the fraction of the volumetric surface area of TNT particles that contributes to dissolution) and $\mathrm{k}_{\mathrm{dis}}$ (the firstorder dissolution rate coefficient on a volumetric surface area basis) have not been found in the literature or determined by experiment to date. Because these two parameters only appear in the two equations as a product, a "lumped parameter" approach was taken (meaning that these two parameters were combined and treated a single "effective" parameter). Hence, to conduct a mathematical simulation, values must be chosen for the resulting 10 input parameters. Table 1 lists these model input parameters and divides them into two categories: 1) parameters whose values are either known with reasonable confidence for the purpose of these 
simulations, or that are operating parameters of the engineered tank system (which can be varied over some practical range), and 2) parameters whose values are based only on initial estimates. Values used for the parameters in these simulations were obtained as follows.

The aqueous solubility of TNT is a well defined thermodynamic property. However, it will vary with the composition of the aqueous solution that the solid TNT is dissolving into. For these simulations a value of $123 \mathrm{mg} \mathrm{L}^{-1}$ (taken from Layton et al. 1987) was used.

The initial solid-phase TNT concentration is one of the variable operating parameters of the engineered system. It has been discussed above in terms of initial conditions of the two simulation variables; however it also appears explicitly in the rate equations. A value near the center of the anticipated range of control was taken to be $0.1 \mathrm{~g} \mathrm{~cm}^{-3}$.

The initial total enzyme concentration is one of the variable operating parameters of the engineered system. The center of the anticipated range of control of this parameter was estimated by scaling up the experimental system used in the study of tetryl transfomation catalyzed by FNR reported by Shah and Spain (1996). A value in the middle of the range of total enzyme concentrations used by Shah and Spain (1996) was chosen, and this value was multiplied by the ratio of average initial concentration of solid TNT anticipated for the processing tank to average initial concentration of tetryl used by Shah and Spain (1996). These scaling procedure resulted in a value of approximately $1 \times 10^{-3} \mathrm{~g} \mathrm{~cm}^{-3}$.

Values for the maximum aqueous reaction rate constant, $k_{\text {maq }}$, and the aqueous half-saturation constant, $K_{\text {Taq, }}$ could be calculated from Equations 16 and 17 if the actual forward and reverse rate constants of the associated reactions were known. Altematively, the values of $k_{\text {naq }}$ and $K_{T a q}$ could be directly estimated by TNT transformation experiments with only aqueous-phase species. Unfortunately, none of this information is currently available. However, this type of experiment has been performed previously using aqueous-phase tetryl and the same enzyme (Shah and Spain 1996). So, for the initial modeling efforts, it is assumed that these values of $k_{\text {maq }}$ and $K_{T_{a q}}$ for tetryl could be used as estimates of $k_{\text {maq }}$ and $K_{T_{a q}}$ for TNT by correcting them for the difference in molecular weight of tetryl and TNT (see Equations 16 and 17). Shah and Spain (1996) directly report a value for $K_{\text {Taq. }}$. To obtain the value of $k_{\text {maq }}$ for tetryl, it was noted that the plateau value of the relative nitrite release rate shown in Figure 3 is essentially equal to the quotient of $k_{232 q}$ and the molecular weight of tetryl (along with some unit conversions needed to get all the quantities in equivalent units). Based on these calculations, it is assumed that $k_{\text {traq }}=2290 \mathrm{~d}^{-1}$ and $\mathrm{K}_{\mathrm{Taq}}=2.95 \times 10^{-5} \mathrm{~g} \mathrm{~cm}^{-3}$.

The density of solid TNT was taken to be $1.65 \mathrm{~g} \mathrm{~cm}^{-3}$ (taken from Layton et al. 1987).

The initial radius of the equivalent spherical TNT particles is one of the variable operating parameters of the engineered system. A value near the center of the anticipated range of control was taken to be $0.05 \mathrm{~cm}$.

Currently, no specific data are available for sorption of FNR enzyme onto solid-phase TNT. So, this initial modeling effort will estimate the linear equilibrium sorption coefficient on an areal basis using data of protein sorption onto another type of solid material. An initial search of the literature related to protein sorption revealed that the sorption models proposed therein tended to be more complex than the model proposed for these simulations. The models found in the literature contain numerous parameters, most of which could not be quantitatively parameterized for our system due to lack of specific prior experimental characterization. Therefore, work reported by Membrez et al. (1996), which expresses protein sorption in terms of a linear equilibrium sorption coefficient, wa used to estimate our input parameter even though the sorbent in their study (Blue Sepharose CL-6B) was porous, and no measurement was made of the specific surface area of the sorbent particles. The external specific surface area of the spherical particles was calculated from the reported particle diameter and particle density; and it was assumed that the intemal 
Table 1. Input Parameter Values and Ranges Used in the TNT Destruction Simulations

\begin{tabular}{|c|c|c|c|c|c|c|c|c|}
\hline $\begin{array}{l}\text { input } \\
\text { param. } \\
\text { number }\end{array}$ & $\begin{array}{c}\text { parameter } \\
\text { symbol }\end{array}$ & $\begin{array}{l}\text { parameter } \\
\text { description }\end{array}$ & units & $\begin{array}{l}\text { parameter } \\
\text { "central" value }\end{array}$ & \multicolumn{2}{|c|}{$\begin{array}{c}\text { parameter value range } \\
\text { low high }\end{array}$} & $\begin{array}{c}\text { type of } \\
\text { parameter }\end{array}$ & variation \\
\hline \multicolumn{9}{|c|}{ Irameters are either known with reasonable confidence for these simulations, or are variable operating parameters for the tank system } \\
\hline $\begin{array}{l}1 \\
2 \\
3 \\
4 \\
5 \\
6 \\
7\end{array}$ & $\begin{array}{l}\text { CTaq sol } \\
\text { CTso } \\
\text { Cet } \\
\text { kmaq } \\
\text { KTaq } \\
\text { ps } \\
\text { rso } \\
\end{array}$ & $\begin{array}{c}\text { TNT aqueous solubility } \\
\text { initial solid TNT concentration } \\
\text { total enzyme concentration } \\
\text { aqueous max. reaction rate constant } \\
\text { half-saturation constant } \\
\text { density of solid TNT particle } \\
\text { initial TNT particle radius } \\
\end{array}$ & $\begin{array}{c}\mathrm{g} / \mathrm{cm} 3 \\
\mathrm{~g} / \mathrm{cm} 3 \\
\mathrm{~g} / \mathrm{cm} 3 \\
1 / \mathrm{d} \\
\mathrm{g} / \mathrm{cm} 3 \\
\mathrm{~g} / \mathrm{cm} 3 \\
\mathrm{~cm} \\
\end{array}$ & $\begin{array}{l}1.230 \mathrm{E}-04 \\
0.1 \\
1.00 \mathrm{E}-03 \\
2.290 \mathrm{E}+03 \\
2.950 \mathrm{E}-05 \\
1.65 \\
0.05 \\
\end{array}$ & $\begin{array}{c}6.150 \mathrm{E}-05 \\
0.02 \\
7.00 \mathrm{E}-06 \\
1.145 \mathrm{E}+03 \\
1.475 \mathrm{E}-05 \\
1.485 \\
5.00 \mathrm{E}-04 \\
\end{array}$ & $\begin{array}{c}1.845 E-04 \\
0.2 \\
2.00 E-01 \\
3.435 E+03 \\
4.425 E-05 \\
1.815 \\
12.5 \\
\end{array}$ & $\begin{array}{l}\text { known } \\
\text { var. op. param. } \\
\text { var. op. param. } \\
\text { known } \dagger \\
\text { known } \dagger \\
\text { known } \\
\text { var. op. param. }\end{array}$ & $\begin{array}{l} \pm 50 \% \\
\pm 50 \% \\
\pm 50 \% \\
\pm 10 \%\end{array}$ \\
\hline \multicolumn{9}{|c|}{ parameter values are based only on initial rough estimates } \\
\hline $\begin{array}{c}8 \\
9 \\
10\end{array}$ & $\begin{array}{c}\mathrm{Kd}^{\prime} \\
\mathrm{f}^{*} \mathrm{kdis} \\
\mathrm{kms}\end{array}$ & $\begin{array}{l}\text { sorption coefficient on areal basis } \\
\text { effective dissolution rate constant } \\
\text { solid max. reaction rate constant }\end{array}$ & $\begin{array}{c}\mathrm{cm} \\
\mathrm{cm} / \mathrm{d} \\
1 / \mathrm{d}\end{array}$ & $\begin{array}{c}3 \\
1.26 \\
2.290 E+03\end{array}$ & $\begin{array}{c}0.3 \\
0.55 \\
1.145 \mathrm{E}+03\end{array}$ & $\begin{array}{c}30 \\
30.25 \\
3.435 \mathrm{E}+03\end{array}$ & $\begin{array}{l}\text { estimated } \\
\text { estimated } \\
\text { estimated }\end{array}$ & \\
\hline
\end{tabular}

t Note that the values for these parameters are assumed equal to the corresponding values for tetryl degradation catalyzed by the same enzyme

Chemical components in the simulations:

1 CTaq aqueous TNT concentration $\mathrm{g} / \mathrm{cm} 3$

2 CTs solid TNT concentration $\mathrm{g} / \mathrm{cm}^{3}$

initial value $=\mathrm{CTaq}$ sol

initial value $=\mathrm{CT}$ so 

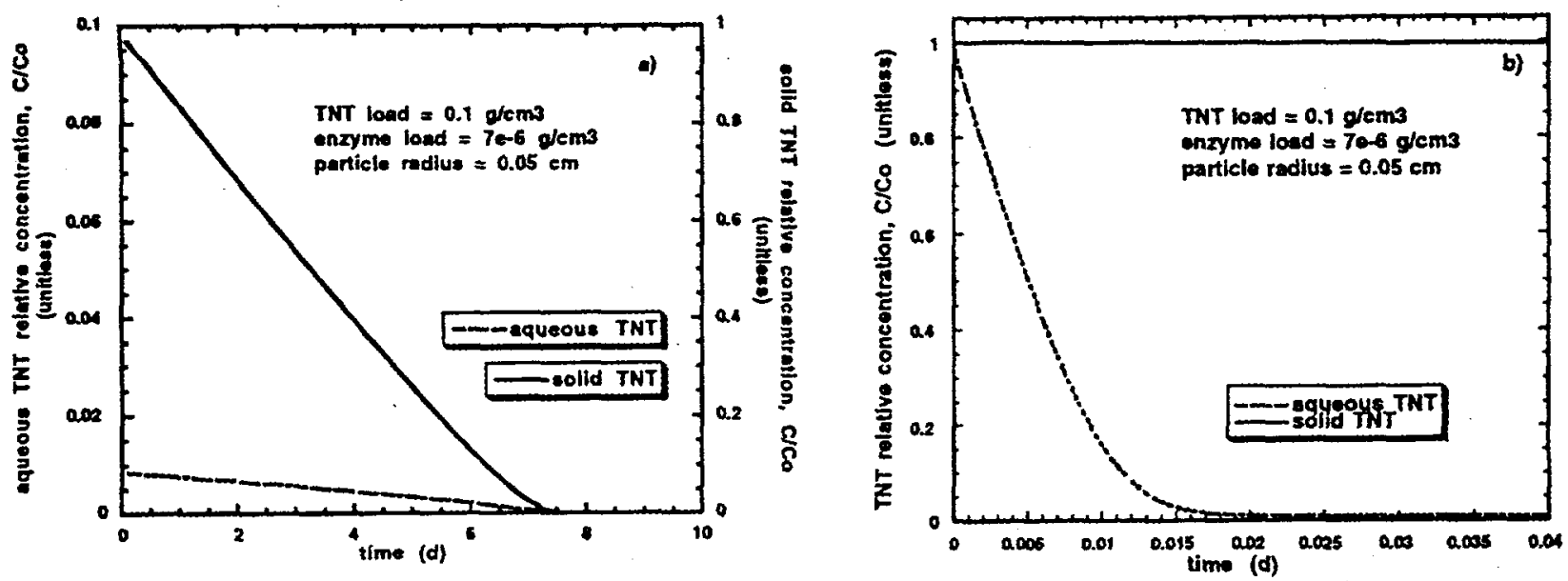

Figure 3. Aqueous-phase and solid-phase TNT relative concentrations as functions of time: a) full time scale of the simulation, and b) early times in the simulation. All input parameters set at "central" values (see Table 1) except total enzyme concentration.

specific surface area of the particles (available to the protein) was merely equal to three time the extemal specific surface area. Dividing the reported linear $K_{d}$ by the calculated specific surface area results in an estimated value for the linear equilibrium sorption coefficient on an areal basis of $3 \mathrm{~cm}$.

Similarly, no specific data are currently available for the effective dissolution rate constant. This parameter was estimated by first solving the simple first-order dissolution rate law (Equation 18) for $\mathrm{C}_{\mathrm{Taq}}$ as a function of time, assuming that dissolution of solid TNT was the only process occurring. The resulting expression was used to derive an expression for the overall dissolution rate constant, $k_{\text {dis }}$, as a function of the time it would take for the aqueous concentration to reach a value equal to $99 \%$ of the TNT aqueous solubility in a dissolution rate experiment. (Note that this point was chosen as essentially an indicator of saturation, because a first-order rate law predicts that $100 \%$ saturation would only be achieved after an infinite amount of time.) Engineering judgement was used to estimate that the aqueous solution initially in the processing tank might take approximately $1 \mathrm{~d}$ to come to complete saturation, given the average TNT initial particle radius and initial solid-phase concentration anticipated for the system. From this time value, a value for $k_{\text {dis }}$ was calculated; and subsequently (by dividing by the specific surface area of the assumed TNT particles, given by Equation 5) the value for the effective dissolution tate constant was estimated to be $1.26 \mathrm{~cm} \mathrm{~d}^{-1}$.

The maximum solid-phase reaction rate constant, $\mathrm{k}_{\mathrm{ms}}$, will, in general, have a value different from that appropriate to the aqueous-phase transformation process. However, in the absence of any specific experimental data for the surface transformation process, this modeling assumes that the surface transformation process is both qualitatively and quantitatively similar to the aqueous-phase transformation process. In other words $k_{\mathrm{ms}}$ is assumed to be equal to $\mathrm{k}_{\mathrm{m} 2 \mathrm{q}}$ (i.e., $2290 \mathrm{~d}^{-1}$ ). This is equivalent to assuming that $k_{23 s}$ is equal to $k_{2329}$.

Table 1 compiles the aforementioned values for the input parameters in the column labeled parameter "central" value. In addition, Table 1 also lists ranges for each of the parameters for use in mathematical simulations done for sensitivity analyses. Anticipated practical limits of engineering system operating parameters (initial solid TNT concentration, total enzyme concentration, and initial TNT particle radius) were used to set the ranges for these parameters. The ranges of variation assumed for the parameters assumed known with reasonable confidence represent ranges that should easily encompass the uncertainty in these 
values (with the caveat that the $k_{\text {maq }}$ and $K_{T_{2 q}}$ values are strictly applicable to tetryl rather than TNT). The ranges for the three parameters that are currently only based on initial estimates were chosen more arbitrarily. For the sorption coefficient on an areal basis, the range was chosen as an order of magnitude higher and lower than the central estimate. For the effective dissolution rate constant, the range was chosen to coincide with times to $100 \%$ saturation (in the initial processing tank setup with average values of particle radius and solid-phase concentration) between $1 \mathrm{hr}$ and $2 \mathrm{~d}$. For the maximum solid-phase reaction rate constant, the range was chosen to coincide with the range chosen for the maximum aqueous reaction rate constant.

\section{Results and Discussion}

The coupled set of rate equations (Equations 21 and 40) were solved using the RAFT (ReActive Flow and Transport) computer code, which was previously developed by one of the authors (Chilakapati 1995). The RAFT code is modular, so that arbitrary user specified reaction systems can be incorporated into it. RAFT capabilities include the solution of groundwater flow and solute transport problems; however, because the system under study in this work is a batch reactor, the RAFT simulation was set up in a mode that eliminates the unnecessary flow and transport calculations. A fourth-order Runge-Kutta solution algorithm was employed in RAFT to solve the coupled set of rate equations for these simulations.

Figure 3 a shows the simulated relative concentration versus time profiles for a run using a total enzyme concentration of $7 \times 10^{-6} \mathrm{~g} \mathrm{~cm}^{-3}$ and the central values for all of the remaining input parameters. (The relative concentration is the actual concentration divided by the initial concentration.) Both the aqueous TNT and solid TNT relative concentrations decrease monotonically with time, as expected. All TNT added to the system has been transformed by $7.7 \mathrm{~d}$. Note that the aqueous and solid TNT relative concentrations are plotted on axes with two different scales. This was done to improve the visibility of the curve because, by the first plotted time step, the aqueous TNT relative concentration had already dropped to a relatively low value of 0.0085 , and then gradually decreased until the solid TNT disappeared (after which it rapidly fell to zero).

The first plotted time step in Figure $3 \mathrm{a}$ occurs at $0.1 \mathrm{~d}$. To more clearly illustrate the early-time behavior of this simulated scenario, Figure $3 \mathrm{~b}$ shows the simulated relative concentration versus time profiles for times before $0.04 \mathrm{~d}$. The solid TNT relative concentration is, as expected, gradually falling off at a value of approximately 1 . The aqueous TNT relative concentration falls to a value of approximately 0.01 within 0.02 $\mathrm{d}$, and then enters the period of gradual decline that was depicted in Figure 3a.

This behavior is commensurate with what is expected based on the set of reaction equations, initial conditions, and specific parameter values. At the instant the simulation begins, the aqueous concentration is at its solubility (relative concentration of 1 ). Therefore, the dissolution term in the reaction equations predicts that no solid TNT would be dissolving at time $t=0$. However, the aqueous TNT can begin transforming (according to the transformation term in Equation 21) immediately. This reduces the aqueous TNT concentration, which in tum causes solid TNT to start to dissolve. As the aqueous TNT concentration falls, the difference between its value and the aqueous solubility increases; and so the dissolution rate increases (according to the dissolution term in Equation 21). The aqueous TNT concentration continues to fall rapidly until the rate at which solid TNT dissolves is essentially matching the rate at which aqueous TNT transforms. This is the point at which the gradual decline in aqueous TNT relative concentration begins. The fact that this point occurs so quickly is due to the fact that the aqueous transformation is rapid compared to the dissolution. In other words, for the particular choice of input parameter values used in this run, the amount of transformation occurring in the aqueous phase relatively small, and is essentially controlled by the relatively slow dissolution rate. It is also worthwhile noting that this run uses a low value of total enzyme concentration. So, the central value of the maximum aqueous reaction rate coefficient is high enough that the aqueous transformation is relatively fast even at the low end of its expected range in this simulated processing tank (given central values of the other parameters). 
Figures $4 \mathrm{a}$ and $4 \mathrm{~b}$ show two simulated solid TNT relative concentration versus time profiles for runs using a total enzyme concentration of $7 \times 10^{-6} \mathrm{~g} \mathrm{~cm}^{-3}$ and the central values for all of the remaining input parameters except initial solid TNT concentration. Figure $4 \mathrm{a}$ is a run with low initial solid TNT loading $\left(0.02 \mathrm{~g} \mathrm{~cm}^{-3}\right)$ and figure $4 \mathrm{~b}$ is a run with high initial solid TNT loading $\left(0.2 \mathrm{~g} \mathrm{~cm}^{-3}\right)$. Note that the curvatures of the two plots of solid TNT relative concentration are different. Both plots seem to fall off more or less linearly for a period of time, and then curve because rate of solid TNT disappearance decreases with time. However, the linear period of time is greater for run using a higher initial solid TNT loading. Note from the transformation tem in Equation 40 that, for a given maximum solid-phase reaction rate constant and total enzyme concentration, the decline of solid relative concentration would be approximately linear if the parenthetical tem involving $\mathrm{C}_{\mathrm{Ts}}$ were approximately constant. This term is closer to 1 , and relatively constant for a longer period of time, for higher values of $C_{T s}$ and $C_{T s o}$. For the values of input parameters in this run, the initial value of this term is 0.69 and 0.95 for Figures $4 \mathrm{a}$ and $4 \mathrm{~b}$ respectively. The curvature of the plot for a simulation run using the central value of $C_{\text {Tso }}$ (not shown) falls between the curvatures of plots shown in Figures $4 \mathrm{a}$ and $4 \mathrm{~b}$. So, the simulations indicate that for the particular choice of input parameter values assumed relevant to the processing tank, a substantial initial time period should exhibit relatively linear disappearance of the TNT.

Simulations were run to assess the sensitivity of the processing tank efficiency to variations in values of the operating parameters of the engineered system. The criterion used for comparison was the time required for $100 \%$ of the initially added TNT to be transformed (either in the aqueous or solid phase).
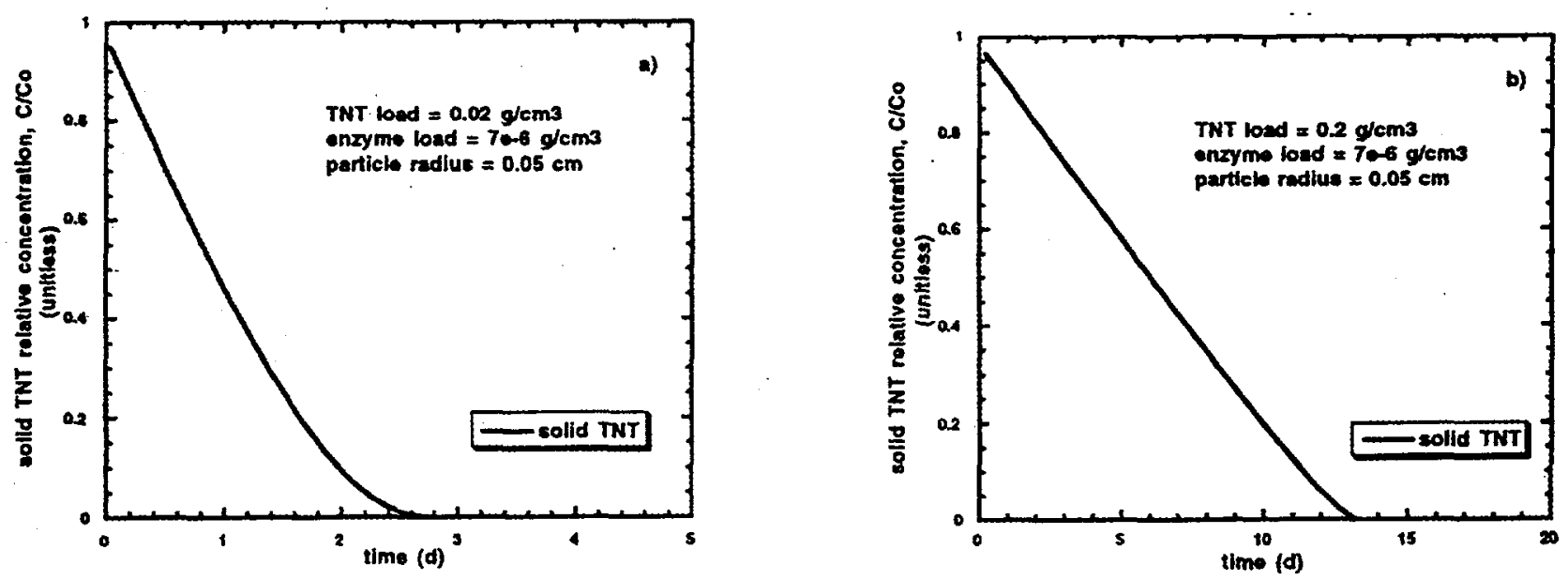

Figure 4. Solid-phase TNT relative concentration as a function of time: a) low initial solid-phase TNT concentration, and b) high initial solid-phase TNT concentration. All input parameters other than initial solid-phase TNT concentration set at "central" values (see Table 1) except total enzyme concentration. 
Figure 5 shows the results of the sensitivity study for total enzyme concentration. Runs were made with the total enzyme concentration ranging from $7 \times 10^{-6} \mathrm{~g} \mathrm{~cm}^{-3}$ to $0.2 \mathrm{~g} \mathrm{~cm}^{-3}$, and all other input parameters set at their central values. The plot of disappearance time versus total enzyme concentration is linear, on a log-log scale, over the entire range, and has a slope of -1 . This means that the disappearance time is inversely proportional to the enzyme concentration. According to the coupled rate equations (Equations 21 and 40), both transformation rate terms (which are the terms responsible for the actual disappearance of TNT from the system) are indeed linearly proportional to total enzyme concentration. Note that the disappearance time ranges from $7.7 \mathrm{~d}$ for low enzyme loading down to $2.75 \times 10^{-4} \mathrm{~d}(0.4 \mathrm{~min})$ for the high enzyme loading. The disappearance times for the higher enzyme loading are extremely fast. Whether these will actually be achieved in practice probably most strongly depends on whether the linear equilibrium sorption model used in the derivation of Equation 40 is valid for the higher enzyme concentrations. If not, disappearance times for the higher enzyme loadings will be somewhat longer than predicted by these simulations; although they will probably still be shorter than those predicted by the simulations using lower enzyme loadings (because the linear equilibrium sorption assumption is probably valid for these more dilute solutions). This concept is further discussed in the Conclusions section as part of a discussion on further efforts needed. However, in spite of this caveat, these simulations indicate that for achievable ranges of enzyme loading (and other parameters set at achievable or reasonable values) the TNT destruction in the tank could be carried out in a reasonably short period of time.

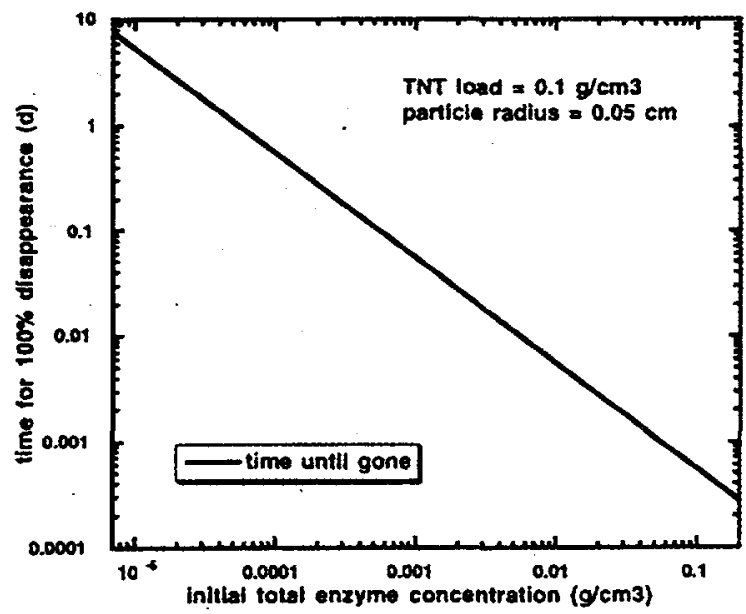

Figure 5. TNT disappearance time as a function of total enzyme concentration. All input parameters other than total enzyme concentration set at "central" values (see Table1).

Figure 6 shows the results of the sensitivity study for initial solid TNT concentration. Runs were made with the initial solid TNT concentration ranging from $0.02 \mathrm{~g} \mathrm{~cm}^{-3}$ to $0.2 \mathrm{~g} \mathrm{~cm}^{-3}$, and all other input parameters set at their central values except for the total enzyme concentration (which was set at the low value of $7 \times 10^{-6} \mathrm{~g}$ $\mathrm{cm}^{-3}$ ). The plot of disappearance time versus initial solid TNT concentration is also linear over the entire range investigated. However, the slope is not 1:1 (which would only be the slope if the overall TNT transformation rate was constant irrespective of the TNT concentration in the tank at any time).

Note that, if the plot had been extended by running additional simulations for lower values of initial solid TNT loading, it is expected that this linearity would not be maintained for the (uninvestigated) low end of the curve. This is clear because an extrapolation of the linear plot would cause it to cross zero at a negative initial TNT concentration; and it is clear that the disappearance time would approach zero as the initial TNT concentration approaches zero. As stated above, according to the coupled rate equations (Equations 21 and 40 ), the magnitude of the transformation terms are approximately constant only if the parenthetical terms in them involving the TNT concentrations are approximately constant (which occurs when these terms are 


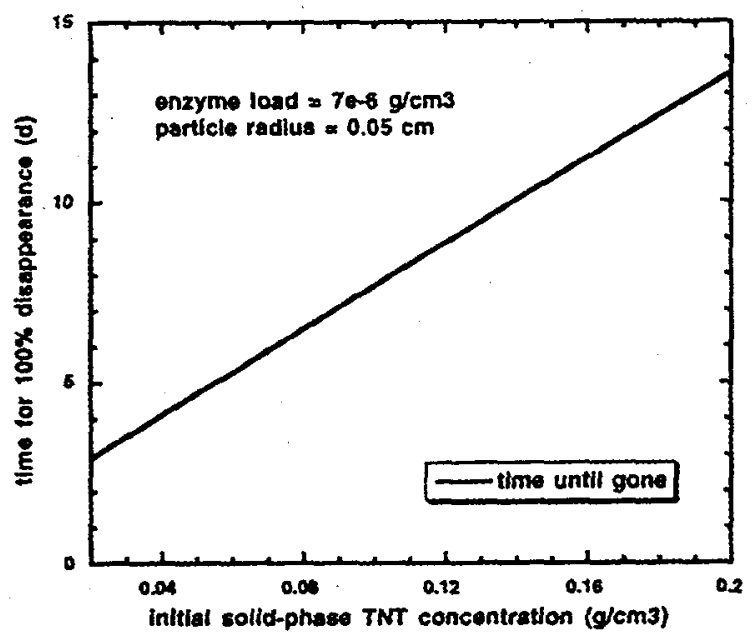

Figure 6. TNT disappearance time as a function of initial solid-phase TNT concentration. All iput parameters other than initial solid-phase TNT cocentration set at "central" values (see Table 1) except total enzyme concentration.

closer to 1). Figures $4 \mathrm{a}$ and $4 \mathrm{~b}$ have shown that this is case for a substantial initial time period (as discussed previously), but that eventually the TNT concentration falls to a small enough value that the parenthetical term changes fast enough to significantly effect the magnitude of the rate. When the initial solid TNT concentration itself is small enough that the parenthetical term in Equation 40 is already in the regime where it is changing rapidly as TNT disappears (i.e., in the uninvestigated region of the plot in Figure 6 where the initial TNT concentration would be lower than 0.02 ), the variation in disappearance time would thereby not be expected to be a linear function of the initial TNT concentration.

Figure 6 also shows that the disappearance times simulated for the range of expected TNT loadings are short enough that TNT destruction in the tank could be carried out in a reasonably short period of time. Adding more initially also increases the efficiency of the system in the long run because it takes less than $n$ times as long to treat $n$ times a much TNT if it is put in all at once rather than in $n$ separate batches.

Figures $7 \mathrm{a}$ and $7 \mathrm{~b}$ shows the results of the sensitivity study for initial TNT particle radius. Runs were made with the initial TNT particle radius ranging from $5 \times 10^{-4} \mathrm{~cm}$ to $12.5 \mathrm{~g} \mathrm{~cm}^{-3}$, and all other input parameters set at their central values except for the total enzyme concentration (which was set at the low value of $7 \times 10^{-6} \mathrm{~g}$ $\mathrm{cm}^{-3}$ for the runs in Figure $7 \mathrm{a}$ and at the high value of $0.2 \mathrm{~g} \mathrm{~cm}^{-3}$ for the runs of Figure $7 \mathrm{~b}$ ). It should be noted that all runs use the same initial solid TNT loading; which means that a smaller initial particle radius implies more particles in the system. This, in tum, means greater solid surface area per volume of solution for the runs with smaller initial particle radii. With more volumetric solid surface area, there is both faster solid-phase transformation and faster dissolution (followed by aqueous-phase transformation, which is primarily limited by the dissolution rate for the particular values of the other input parameters). Figures $7 \mathrm{a}$ and $7 \mathrm{~b}$ show that it is clearly better to use smaller particles. The disappearance time varies over two orders of magnitude for the range of candidate initial particle sizes. The simulations predict that large particles in systems with low enzyme loading may cause the TNT destruction to take a prohibitively long time. However, simulations indicate that TNT destruction can be accomplished in reasonable times for smaller initial particle sizes or high enzyme loadings (however, the same caveat stated above regarding runs with high enzyme loadings applies here).

Simulations were also run to assess the sensitivity of the processing tank efficiency to uncertainties in some of the other input parameters (which are not operating parameters of the engineered system). Again, the 

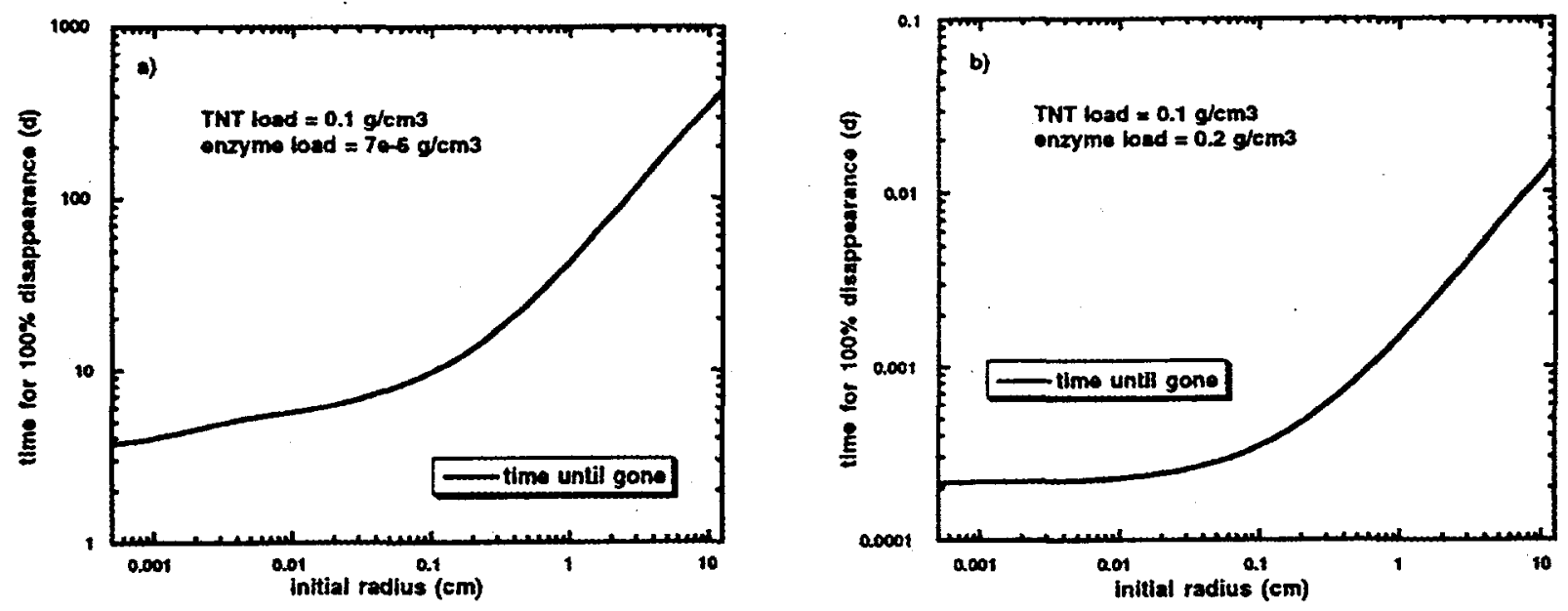

Figure 7. TNT disappearance time as a function of initial particle radius: a) for low enzyme loading in the processing tank, and b) for high enzyme loading in the processing tank. All input parameters other than initial particle radius set at "central" values (see Table 1) except total enzyme concentration.

criterion used for comparison was the time required for $100 \%$ of the initially added TNT to be transformed (either in the aqueous or solid phase).

Figure 8 shows the results of the sensitivity study for maximum reaction rate constants. As stated previously (in the section on parameterizing the rate equations), the "central" values used for both the aqueous and the solid-phase maximum reaction rate constants were assumed equal to the measured value for the aqueous maximum reaction rate constant for tetryl. Because of this, the equations implemented for this problem in the current version of the RAFT code use only a single reaction parameter for these two reaction rate constants. So, for the sensitivity study summarized in Figure 8, the values of both of these constants were varied concurrently. (This restriction will be removed from future versions of the specific simulation code). In

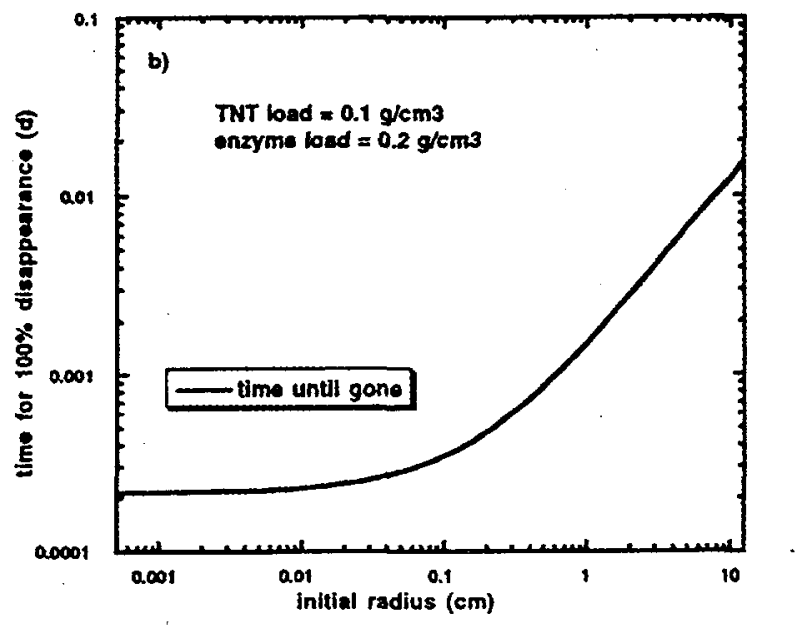

Figure 8. TNT disappearance time as a function of the aqueous and solid-phase maximum reaction rate constants (varied concurrently). All input parameters other than aqueous and solid-phase maximum reaction rate constants set at "central" values (see Table 1) except total enzyme concentration. 
Figure 8 , the disappearance time is exactly inversely proportional to the rate constant (i.e., it is equal to a constant times the (rate constant) ${ }^{-1}$ ). This is as expected because Equations 21 and 40 show that both transformation rate terms (which are the tems responsible for the actual disappearance of TNT from the system) are indeed linearly proportional to the reaction rate constants.

Figure 9 shows the results of the sensitivity study for the aqueous half-saturation constant. Note that the disappearance time was not at all affected by the variation in the half-saturation constant (for the $\pm 50 \%$ variation studied, and for the particular choices of values for all of the other parameters). Recall that Figures $3 \mathrm{a}$ and $3 \mathrm{~b}$ illustrated how, for our scenario, the aqueous concentration very quickly falls to a relatively steady, but gradually declining, low value. So, for most of the simulation, the aqueous TNT concentration is so small compared to the half-saturation constant that the parenthetical term in the first term in Equation 21 is clearly different from 1; and so the aqueous transformation term in Equation 21 should be affected by a change in $\mathrm{K}_{\mathrm{Taq}}$. However, simulated concentration versus time curves for aqueous and solid-phase TNT (not shown) illustrate that the relatively steady value that the aqueous concentration achieves is somewhat higher for higher values of the aqueous half-saturation constant. This increase in aqueous TNT concentration is just enough to compensate for the increase in $\mathrm{K}_{\mathrm{Taq}}$, which is further evidence that it is the low dissolution rate that is ultimately limiting the amount of TNT that gets transformed in the aqueous phase. In other words, because dissolution is so slow, a variation in $\mathrm{K}_{\mathrm{T}_{2 q}}$, merely alters the aqueous concentration during the simulation, and does not ultimately change the time for 100\% disappearance. (Note however, that the value of $\mathrm{K}_{\mathrm{T} a \mathrm{q}}$ would, in general, affect the disappearance time, as long as the dissolution rate was high enough.)

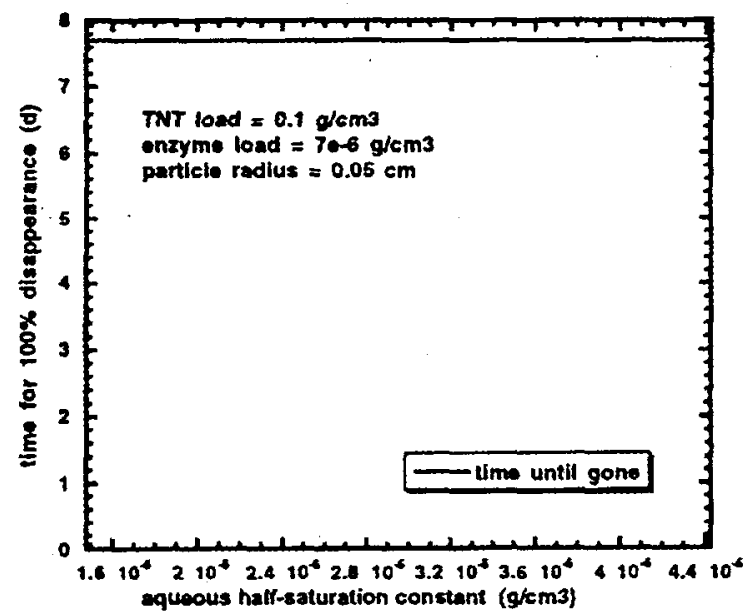

Figure 9. TNT disappearance time as a function of the aqueous half-saturation constant. All input parameters other than aqueous half-saturation constant set at "central" values (see Table 1) except total enzyme concentration

Figure 10 shows the results of the sensitivity study for the linear sorption coefficient on an areal basis. As expected from the mathematical form of Equation 40 , as this sorption coefficient increases, the time for $100 \%$ disappearance decreases. A higher value for the sorption coefficient means that more of the enzyme is sorbed relative to that in solution. This allows faster loss of the solid-phase TNT. In Figure 10, note that as the value of the sorption coefficient increases beyond a certain value, its effect on the disappearance time diminishes. This is expected because for high values of the sorption coefficient, the Michaelis-Menten-like term in Equation 40 is essentially equal to 1, and remains that way until $C_{T s}$ falls enough to become comparable to the parenthetical expression in the denominator of this term. What this means in terms of the expected efficiency of the tank processing system is as follows. If the actual value of the sorption coefficient 


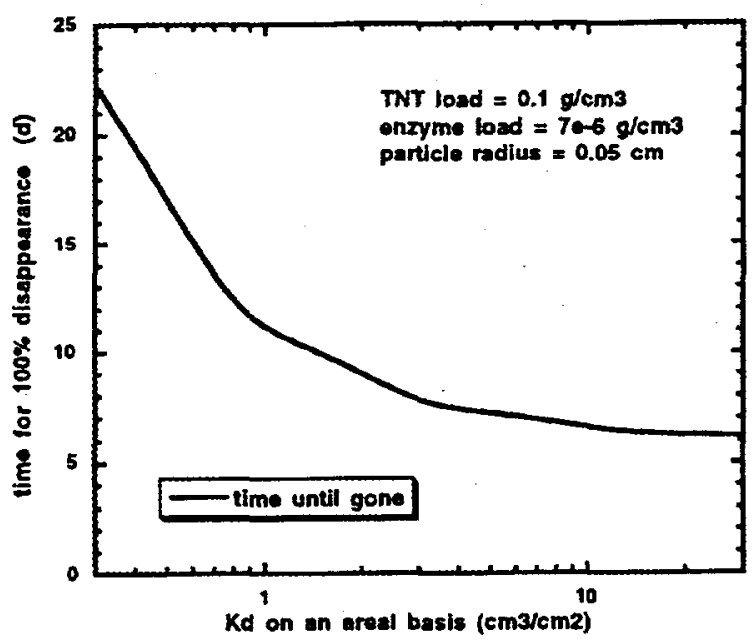

Figure 10. TNT disappearance time as a function of the linear equilibrium sorption coefficient on an areal basis. All input parameters other than linear equilibrium sorption coefficient on an areal basis set at "central" values (see Table 1) except total enzyme concentration.

is greater than the initial estimate we have made here, the actual disappearance time may not be very different from what we simulate using "central values" (because disappearance time is not strongly affected by the sorption coefficient in this region of values). However, if the actual value of the sorption coefficient is less than the initial estimate we have made here, it may take significantly longer to actually destroy the TNT than predicted by our "central value' simulation (because disappearance time is strongly affected by the sorption coefficient in this region of values).

Figure 11 shows the results of the sensitivity study for the effective dissolution rate constant. The range of values studied (i.e., $0.126 \mathrm{~cm} \mathrm{~d}^{-1}$ through $126 \mathrm{~cm} \mathrm{~d}^{-1}$ ) corresponds to a range of times (from $10 \mathrm{~d}$ through 15 $\mathrm{min}$ ) that it would take the solid TNT particles in the "central value" scenario to dissolve into the processing tank solution and raise the aqueous TNT concentration to $99 \%$ of its aqueous solubility if no transformation was taking place. As expected, as the dissolution rate constant increases, the time for $100 \%$ disappearance decreases. However, Figure 10 shows that for values smaller than our "central value" of $1.26 \mathrm{~cm} \mathrm{~d}^{-1}$, the disappearance time is not strongly affected by the dissolution rate constant. This is because, throughout this lower regime of dissolution rate values, the dissolution rate is so low that it is the solid-phase TNT transformation that really controls how long it takes to destroy the TNT in the tank. However, if the actual value of the effective dissolution rate constant is greater than the initial estimate we have made here, the TNT destruction efficiency of the processing tank could be significantly improved over what is simulated by our "central value" scenario (because the dissolution rate would no longer be limiting the amount of TNT that could be transformed in the aqueous phase). 


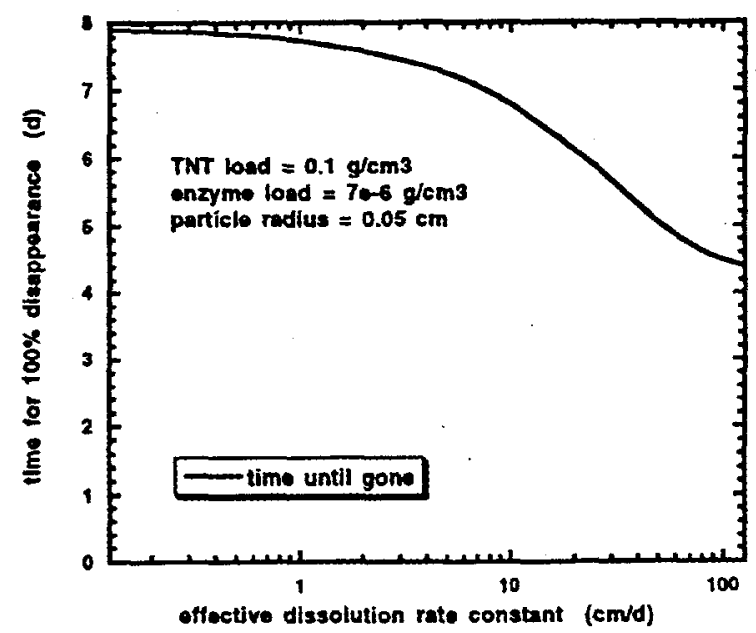

Figure 11. TNT disappearance time as a function of the effective dissolution rate constant. All input parameters other than effective dissolution rate constant set at "central" values (see Table 1) except total enzyme concentration.

\section{Conclusions and Needed Future Efforts}

The results of simulations tun thus far (which have analyzed realistic ranges in the values of operating parameters of the engineered system) indicate that TNT can be enzymatically transformed quickly enough in the tank reactor to make this methodology a feasible option for TNT destruction. However, it should be noted that further efforts are needed before a firm conclusion can be reached regarding the feasibility of the methodology based on mathematical simulation, and before mathematical simulations can be used to aid in the design of the actual processing tank system and its operation. These further efforts consist of the following activities.

- The values of certain parameters must be determined more accurately. Parameters for which this detemination is most needed are: the maximum solid-phase reaction rate constant, the linear equilibrium sorption coefficient on an areal basis, and the effective dissolution rate constant. However, because the values for the maximum aqueous reaction rate constant and the aqueous half-saturation constant were assumed equal to those experimentally determined for tetryl, it would also be beneficial to examine the accuracy of these values more closely. Improved values for these parameters might be obtained by a more extensive literature search, or certainly by conducting appropriately designed laboratory experiments using TNT and FNR.

- The model derivation assumes linear equilibrium sorption of the enzyme to the TNT particles for the entire range of potential enzyme loading: Sorption of solutes from dilute solution is often found to be described by a linear isotherm. However, as the aqueous concentration of the sorbate increases, sorption often is seen to be nonlinear because the finite number of sorption sites on the solid surface becomes saturated. Ultimately, the amount sorbed as a function of the aqueous concentration may reach a plateau (i.e., a Langmuir type sorption isotherm). Commensurate with the objective that the processing tank system transforms TNT as quickly as possible, potential enzyme concentrations in the tank will be high (up to $0.2 \mathrm{~g}$ enzyme per mL of tank solution, or greater). This is easily high enough to bring the linear sorption isotherm assumption into question. Therefore, further effort is needed to either verify the linear equilibrium sorption assumption, or to determine a more appropriate sorption model (and then to modify the overall TNT simulation model 
accordingty). This verification/determination might be accomplished by a more extensive literature search, or certainly by conducting laboratory sorption experiments with TNT and FNR.

- When deriving the transformation rate term for a particular phase of TNT, the present mathematical formulations assume that enzyme complexed with the other phase of TNT may be neglected when calculating the enzyme mass balance. Clearly a more complicated model can be derived that accounts for enzyme partitioning between aqueous, aqueous complex, and solid complex when writing the expression for total enzyme concentration in each transformation term derivation. The net effect of including this coupling would be to reduce the transformations rates from what are calculated by the present model. However, note that because the expected values of the input parameters cause the aqueous TNT concentration to be very low, and cause most of the transformation to occur on the solid phase, the effect of neglecting the contribution of aqueous complex in the derivation of the solid-phase transformation term should be negligible. The relative change in the aqueous phase transformation rate would be greater; however, because the effective dissolution rate is so small compared to the transformation rates, the amount processed by aqueous phase transformation is more controlled by dissolution. However, if the values used for the input parameters change as a result of further efforts to improve their accuracy, modifying the model in the respect described here may be more strongly justified.

- Additional simulations need (or may need) to be nun for the following reasons: 1) if the values used for the input parameters change as a result of further efforts to improve their accuracy, 2) to complete a full sensitivity study of all relevant parameters (including ones that are not engineering operating parameters), and 3 ) if the mathematical model is revised.

- The current model does not explicitly account for the fact that numerous input parameters are actually functions of temperature (e.g., aqueous solubility, maximum aqueous reaction rate constant, aqueous halfsaturation constant, maximum solid-phase reaction rate constant, linear equilibrium sorption coefficient on an areal basis, and effective dissolution rate constant). Currently, the values used for these parameters represent values for "ambient" temperature. Further effort is required to determine the temperature dependence of these parameters (either via a more extensive literature search, estimation using thermodynamic theory, or direct experimental measurement). Additional simulations should then be run to study the sensitivity of the tank processing efficiency to temperature.

\section{Notation}

$\mathrm{A}_{\mathrm{g}}$ gravimetric surface area of solid-phase TNT particles [ $\mathrm{cm}^{2}$ of solid-phase TNT surface / $\mathrm{g}$ of solid]

$A_{v}$ volumetric surface area of solid-phase TNT in the tank [ $\mathrm{cm}^{2}$ of solid-phase TNT surface $/ \mathrm{cm}^{3}$ solution]

$C_{\text {et }}$ total concentration of enzyme (in all forms) [g enzyme $/ \mathrm{cm}^{3}$ solution]

$\mathrm{C}_{\mathrm{P}}$ concentration of generic product [g product $/ \mathrm{cm}^{3}$ solution]

$C_{s}$ concentration of generic substrate [g substrate $/ \mathrm{cm}^{3}$ solution]

Cead concentration of sorbed enzyme [g enzyme / $\mathrm{g}$ solid TNT]

Ceaq concentration of aqueous-phase enzyme [g enzyme $/ \mathrm{cm}^{3}$ solution]

$\mathrm{C}_{\mathrm{Taq}}$ concentration of aqueous-phase TNT $\left[\mathrm{g}\right.$ TNT $/ \mathrm{cm}^{3}$ solution]

$\mathrm{C}_{\text {Taq }}^{\text {sol }}$ aqueous solubility of TNT $\left[\mathrm{g}\right.$ TNT $/ \mathrm{cm}^{3}$ solution]

$\mathrm{C}_{\mathrm{Ts}}$ concentration of solid-phase TNT [g TNT $/ \mathrm{cm}^{3}$ solution]

$\mathrm{C}_{\mathrm{Ts}}$ initial concentration of solid-phase TNT [ $\mathrm{g}$ TNT $/ \mathrm{cm}^{3}$ solution]

f fraction of the volumetric surface area of TNT particles that contributes to dissolution [unitless]

$k_{12}$ forward rate constant for generic enzyme-substrate complexation reaction $\left[\mathrm{cm}^{3} / \mathrm{mol}\right.$ d] 
$k_{12 a q}$ forward rate constant for aqueous-phase enzyme-substrate complexation reaction $\left[\mathrm{cm}^{3} / \mathrm{mol} \mathrm{d}\right]$

$k_{12 s}$ forward rate constant for solid-phase enzyme-substrate complexation reaction $\left[\mathrm{cm}^{3} / \mathrm{mol} \mathrm{d}\right]$

$\mathrm{k}_{21}$ reverse rate constant for generic enzyme-substrate complexation reaction [1/d]

$k_{212 q} \quad$ reverse rate constant for aqueous-phase enzyme-substrate complexation reaction [1/ $\left.d\right]$

$k_{21 s}$ reverse rate constant for solid-phase enzyme-substrate complexation reaction [1/d]

$k_{23}$ forward rate constant for generic transformation reaction [1/d]

$k_{232 q}$ forward rate constant for aqueous-phase transformation reaction [1 / d]

$\mathrm{k}_{23 \mathrm{~s}}$ forward rate constant for solid-phase transformation reaction [1/d]

$\mathrm{k}_{\mathrm{dis}}$ overall first-order dissolution rate coefficient for TNT [1/d]

$\mathrm{k}_{\text {dis }}$

is first-order dissolution rate coefficient for TNT on a volumetric surface area basis

$\left[1 /\left((d)\left(\mathrm{cm}^{2}\right.\right.\right.$ of solid-phase TNT surface $/ \mathrm{cm}^{3}$ solution $\left.\left.)\right)\right]$

$k_{\mathrm{m}}$ maximum reaction rate constant for generic substrate transformation [1/d]

$\mathrm{k}_{\mathrm{maq}}$ maximum reaction rate constant for TNT transformation in the aqueous phase [1/d]

$k_{m s}$ maximum reaction rate constant for TNT transformation on the surface of the solid phase $[1 / d]$

$K_{d}$ linear equilibrium sorption coefficient for the enzyme, on a "per mass of solid" basis [cm]

$\mathrm{K}$ linear equilibrium sorption coefficient for the enzyme, on a "per area of solid surface" basis [cm]

Ks Michaelis-Menten half-sanuration constant for generic substrate

[g substrate $/ \mathrm{cm}^{3}$ solution]

$\mathrm{K}_{\mathrm{Taq}} \quad$ Michaelis-Menten half-saturation constant for aqueous-phase TNT

[g TNT $/ \mathrm{cm}^{3}$ solution]

$m_{s o}$ initial mass of a single equivalent sphere of solid-phase TNT

[g TNT / equivalent sphere of TNT] .

$\mathrm{M}_{\mathrm{e}}$ molecular weight of the enzyme $[\mathrm{g} / \mathrm{mol}]$

Ms molecular weight of the substrate $[\mathrm{g} / \mathrm{mol}]$

$n_{s}$ number density of solid-phase TNT particles in solution

[equivalent spheres of TNT / $\mathrm{cm}^{3}$ solution]

$r_{s}$ radius of equivalent sphere of solid-phase TNT. [cm]

$r_{\text {so }}$ initial radius of equivalent sphere of solid-phase TNT $[\mathrm{cm}]$

$\mathrm{t}$ time [d]

$V_{\text {so }}$ initial volume of a single equivalent sphere of solid-phase TNT

$\left[\mathrm{cm}^{3}\right.$ TNT / equivalent sphere of TNT]

$\rho_{\mathrm{s}}$ mass density of solid-phase TNT $\left[\mathrm{g}\right.$ TNT $/ \mathrm{cm}^{3}$ TNT]

[E(aq)] molar concentration of the aqueous enzyme $\left[\mathrm{mol} / \mathrm{cm}^{3}\right.$ solution]

[ES(ad)] molar concentration of the sorbed enzyme-substrate complex (i.e., of the solid "surface site"

substrate that has enzyme bound to it) [ $\mathrm{mol} / \mathrm{cm}^{3}$ solution]

$[E S(a q)]$ molar concentration of the aqueous enzyme-substrate complex [mol $/ \mathrm{cm}^{3}$ solution]

[Et] molar concentration of the total enzyme (in all forms) [ $\mathrm{mol} / \mathrm{cm}^{3}$ solution]

$\mathrm{P}(\mathrm{aq})]$ molar concentration of the aqueous product [mol $/ \mathrm{cm}^{3}$ solution]

[S(aq)] molar concentration of the aqueous substrate $\left[\mathrm{mol} / \mathrm{cm}^{3}\right.$ solution]

$[\mathrm{S}(\mathrm{s})]$ molar concentration of the solid "surface site" substrate that does not have enzyme bound to it [mol $/ \mathrm{cm}^{3}$ solution]

\section{References}

Benson, S. W. 1982. The Fotındations of Chemical Kinetics. Robert E. Krieger Publishing Company. Malabar, FL. 
Boopathy, R., C. F. Kulpa, J. Manning, and C. D. Montemango. 1994. "Biotransformation of 2,4,6trinitrotoluene (TNT) by co-metabolism with various co-substrates: A laboratory-scale study." Bioresource Technol. 47:205-208.

Chilakapati, A. 1995. RAFT .- A Simulator for the ReActive Flow and Transport of Grounduater Contaminants. PNL10636. Pacific Northwest National Laboratory, Richland, WA.

Haidour, A., and J. L. Ramos. 1996. "Identification of products resulting from the biological reductions of 2,4,6-trinitrotoluene, 2,4-dinitrotoluene, and 2,6-dinitrotoluene by Pseidomonas sp." Environ. Sci. Technol. 30:2365-2370.

Hill, C. G. 1977. An Introduction to Chemical Engineering Kinetics and Reactor Design. John Wiley \& Sons. New York, NY. pp. 227-231.

McCormick, N. G., F. E. Feeherry, and H. S. Levinson. 1976. "Microbial transformation of 2,4,6trinitrotoluene and other nitroaromatic compounds." Appl. Entiron. Microbiol. 31:949-958.

Layton, D., B Mallon, W. Mitchell, L. Hall, R. Fish, L. Perry, G. Snyder, K. Bogen, W. Malloch, C. Ham, and P. Dowd. 1987. Data Base assessment of the Health and Environmental Effects of Conventional Weapons Demilitarization: Explosives and Their Co-contaminants. Final Report, U. S. Army Purchase Order 83 PP 3818. Lawrence Livermore National Laboratory. Livermore, CA..

Membrez, J., P. P. Infelta, and A. Renken. 1996. "Use of the Laplace transform technique for simple kinetic parameters evaluation. Application to the adsorption of a protein on porous beads." Chem. Engng. Sia. 51(19):4489-4498.

Michaelis, L., and M. Menten. 1913. Biochem. Z. 49:333.

Shah, M., and J. Spain. 1996. "Elimination of nitrite from the explosive 2,4,6-trinitrophenylmethylnitramine (tetryl) catalyzed by ferredoxin NADP oxidoreductase from spinach." Biochem. and Biophys. Research Commun. 220:563-568.

van Santen, R. A., and J. W. Niemantsverdriet. 1995. Chemical Kinetics and Catalysis. Plenum Press. New York, NY.pp. 43-58

Wheeler, J. et al. 1995. Joint Demilitarizution Study. Joint Ordnance Commanders Group, Munitions Demil, Disposal Subgroup. Washington, DC. 


\section{APPENDIX C}

POTENTIAL COMMERCIAL APPLICATIONS OF PRODUCTS FROM ENVIRONMENTALLY SOUND AND SAFE TRANSFORMATIONS OF TNT 


\title{
Potential Commercial Applications of Products from Environmentally Sound and Safe Transformations of TNT
}

\author{
Manish M. Shah \\ Pacific Northwest National Laboratory \\ Larry Plonsker \\ Chemical Network Associates
}

\section{Summary}

This study is aimed at identifying potential applications for derivatives obtained from enzymatic transformations of TNT. The potential products include aromatic hydroxylamines, aminophenols and mixtures of these functional groups. The monohydroxylamines appear to be the most economical products from the transforamtion.

The potential applications for the TNT-based products include the following functional areas:

- Antioxidants

- Curing Agents

- Monomers

- Biocides/Disinfectants

- Flame Retardants

- Azo Dyes

- Pharmeceutical and Agro Chemicals

The flame retardant and azo dye applications require further chemical transfomation of the TNT derivatives.

A brief market summary of each area is provided. Efficacy tests for the areas are discussed and where applicable, specific test laboratories are identified. In a few cases, i.e. curing agents and azo dyes, in-house lab tests are recommended. In all cases, it is recommended that PNNL find partners to carry the evaluation further, once significant activity is verified. In the case of monomers and pharmaceutical and agricultural chemicals, it is suggested that an interested company in these business areas carry out the initial evaluations.

\section{Introduction}

It is my understanding that there are approximately 100 million pounds of TNT (2,4,6-trinitrotoluene) in various locations throughout the United States that must be disposed of in a safe and environmentally sound manner. The Pacific Northwest National Laboratories (PNNL) have developed an enzymatic process that can convert one or more nitro groups on the aromatic ring to an hydroxylamine function. The change in 
structure essentially removes the explosive potential of the molecule. The question then becomes, does the hydroxylamine or derivatives have commercial value, such that there is an economic incentive to carry out the process at the various TNT storage sites?

\section{Objective}

The objective of the present brief study is to identify the areas where the products from the PNNL process can potentially find use. In addition, this study will attempt to outline tests that can be run to check for activity in these areas. Finally, we will recommend approaches to get definitive evaluations and identify companies with which to work, towards the commercialization of the PNNL process, including any further transformations and the viable applications.

\section{Scope of the Process}

The flow diagram attached as figure 1, summarizes the potential products from the PNNL process. It is my understanding that the structures shown in the diagram have not all been proven but that there is a strong likelihood that they are correct.

As can be seen from the diagram, the possible products include the monohydroxylamines designated as HAM-p and HAM-o, representing the two possible hydroxylamines from the transformation of an ortho or the para nitro group. It appears that the monohydroxylamines are formed rapidly and can be the most economical of the possible transformation products.

The remaining nitro groups can also be further reacted to form the dihydroxylamine, DHAM-op and/or DHAM-oo. Altematively, the monohydroxylamines can be rearranged to the aminophenols, AMPH-pm and AMPH-ox.

The dihydroxylamines can likely be partially rearranged to form either the hydroxylamine aminophenols, HAMAMPH-ox and/or HAMAMPH-px or completely to the diaminophenols, DAMDH-op and/or DAMDH-OO.

The formation of trihydroxylamines from TNT has not been considered. However, it appears that biodegradation of TNT with Clostridium Acetobutylicum can lead to the triamine, possibly through the hydroxylamine. The attached papers by Hughes, Rudolph and Bennett summarizes some of their work. Rudolph said, in a telephone contact, that they can get triamines from this system. Hughes also told me that they can run their biotransformations in the presence of gaseous hydrogen. This may be the agent for direct reduction of the hydroxylamine or perhaps the nitroso intermediate. It is not clear to me where their work stands today as the papers discuss the formation of the hydroxylamines and their subsequent Bamberger rearrangement to the hydroxy amine.

\section{Alternate Chemical Routes}

The enzymatic approach offers a safe and environmentally sound way to trainsform the nitro groups on the aromatic ring. The key to removing the explosive danger of the molecule is the reduction of the nitro groups. There are many well established chemical routes for the reduction of aromatic nitro groups to amines. For example, metal hydrides as well as catalytic hydrogenations are both effective. The latter is the favored commercial route to aromatic amines.

A potentially clean chemical route to the hydroxylamines may be possible. It is known that nitrobenzene can be converted to phenylhydroxylamine by the action of zinc dust in water (Kamm, Org. Syntheses, Coll. Vol. 


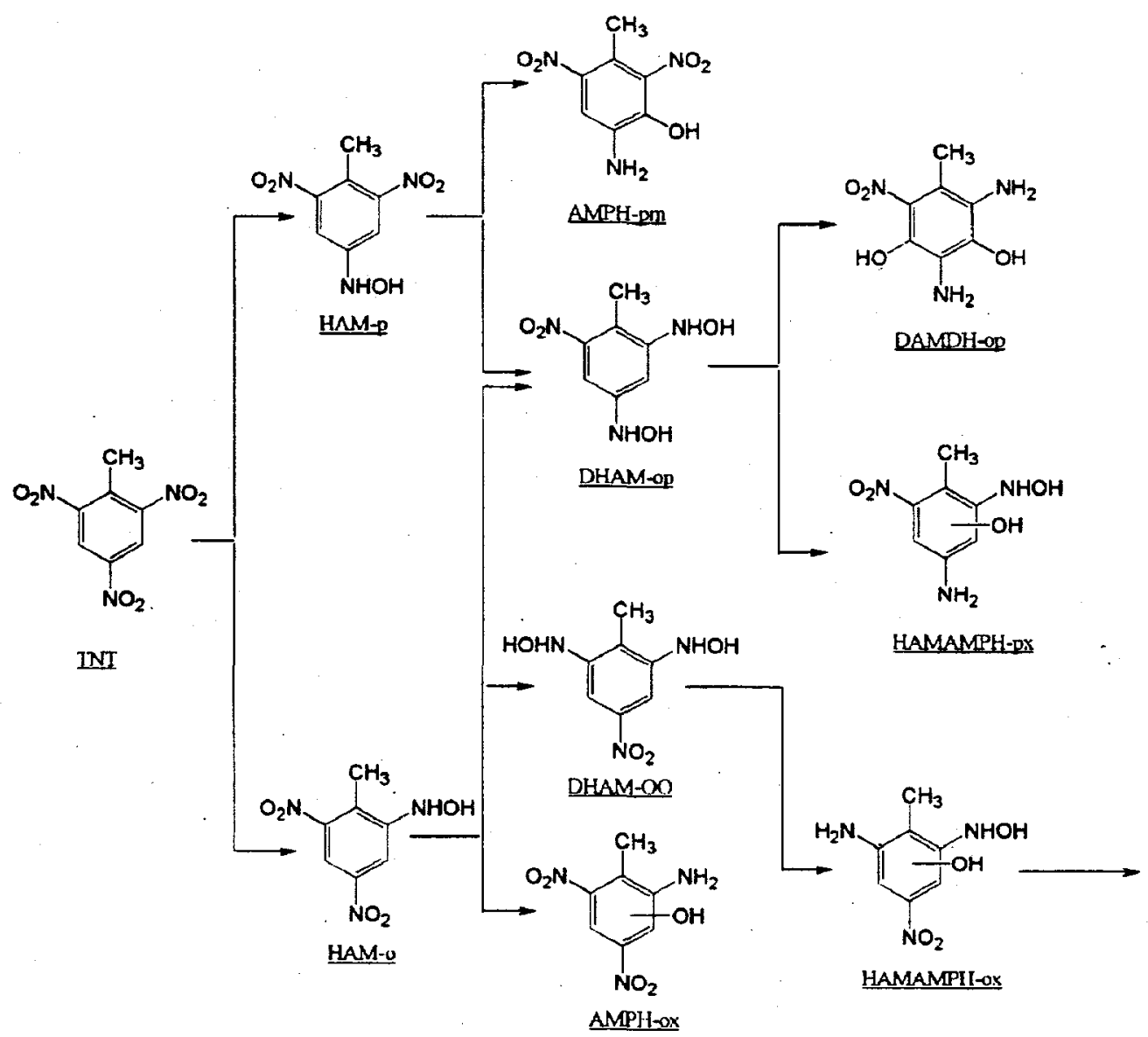<smiles>Cc1c(N)c(O)c([N+](=O)[O-])c(O)c1N</smiles>

DAMDH -0

Figure 1. Potential reactions in the production of commercially viable products from TNT.

$I, 445,1941)$. It is interesting that there was an earlier report of the zinc dust reduction by Bamberger in 1884 (Ber. 27, 1348, 1548 (1884)). This is a relatively innocuous approach to the hydroxylamines and the zinc should be recyclable. However, it is not known if this chemistry can work safely with TNT or at all. A small scale test should be run.

It is also known that 2,4-dinitrotoluene can be reduced to the corresponding diamino compound by the action of iron filings and $\mathrm{HCl}$ (Org. Syntheses, Coll. Vol.II, 160, 1943). The acid does cause a little more concern about disposal but the chemistry likely works on TNT. I do not know if TNT can be safely reacted with these reagents.

\section{Economics}

What is the potential price of any of the products listed in figure 1? At this stage of the development, we have no idea what the process costs are for carrying out the PNNL transformation. This is an area that will need more attention as the project moves further along.

It is my understanding that the stockpiles of TNT are in many locations and that they cannot be consolidated in any one area. Therefore, all processing will have to be without the benefit of scale. In addition, the process is carried out in dilute aqueous solutions which require large reactors relative to the quantity produced. Product recovery from the dilute solutions will be a costly step that could involve solvent extraction and 
distillation. These factors will hurt the economics but we are not sure of the overall impact since the effectiveness part of the economics is not known.

For this project to succeed commercially, the products must be at least as cost effective as those on the market today. Certainly, environmental considerations go into the calculation of cost effectiveness. But, as is the case in all new product areas, there has to be a compelling reason for a user to change from what they know to a relatively unknown entity.

\section{Commercial Potential}

Of what commercial value are the products using the PNNL route? I am not aware of commercial uses for any of the products shown in figure 1 . However, the functional groups suggest some potential applications, and these application areas are identified below. It should be emphasized that any potential application area will have to be proven from a performance perspective as well as from an economic, toxicity and environmental one. The commercialization of a new product is an expensive and complicated undertaking and it is recommended that we find an industrial partner to carry out the major part of this endeavor. However, before undertaking expensive toxicity and environmental testing, we need to establish that the products are effective and that there is a reasonable chance that they have commercial value.

Because the amount of product is limited by the availability of TNT to process, we are only considering specialty application areas. One can consider making TNT to make more of the desired derivative but the economics of such a process would not likely be attractive.

\section{Antioxidant}

Hydroxylamines have been reported to be antioxidant stabilizers in plastics. Ciba Geigy has at least 2 patents (US 4,612,393 and US 4,691,015) claiming hydroxylamines as part of a stabilizer system against the high temperature degradation of a polyolefin. There is reason to believe that the hydroxylamines HAM-o and HAM-p could be antioxidants. It is also possible that the DHAM and perhaps the AMPH could also be active.

We have emphasized the potential use of these products as antioxidants in plastics. If they are effective in this application, it is strongly recommended that effectiveness be tested in lubricants and rubber.

\section{Markets}

The market size for antioxidants in plastics in the US was about $40 \mathrm{MM}$ pounds, worth about $\$ 170 \mathrm{MM}$ in 1997. (Overall, the US market represents about $25 \%$ of the world market for plastic additives.) This is a large and attractive market. There are many products and companies that compete for this business. The major company in this business is Ciba Geigy. Their Irganox 1010 and 1076 hindered phenolic antioxidants are the predominant products used in plastics. Other effective products are Ethanox 330, sold by Albemarle, for use mainly in polypropylene and the Mark phenolic antioxidants sold by Witco. Antioxidants are used at less than $1 \mathrm{wt} . \%$, and closer to $0.1 \mathrm{wt} \%$ in the plastic.

\section{Testing}

Tests for antioxidant effectiveness in plastics involve formulating the candidate in an unstabilized polymer resin. A standard test to determine if the HAM products, or any other ones, are effective antioxidants is the ASTM D3895, Copper-Induced Oxidative Induction Time of Polyolefins by Thermal Analysis. This test is performed in a differential scanning calorimeter (DSC). The plastic is heated to $200^{\circ} \mathrm{C}$ in an inert atmosphere. The atmosphere is then switched to oxygen and the time to decompose the plastic, the oxidative 
induction time (OIT), is determined. Comparison with known antioxidants or the base resin itself will give an indication of the effectiveness of the product as an antioxidant.

A testing laboratory that will nun the ASTM D3895 test is Polyhedron Laboratories, 10626 Kinghurst St., Houston, TX 77099, telephone (281) 879-8600. The price per sample tested is $\$ 155$. A minimum of $100 \mathrm{mg}$ is required. The e-mail message from this laboratory is attached.

It is my recommendation that we test the simplest HAM product(s) at 2 concentrations, 0.1 and 0.5 wt. \%. The testing lab may have other recommendations. A comparison against the unstabilized base resin and a known antioxidant stabilized system would be advantageous. However, the testing laboratory might have enough experience with this test to be able to determine if these products have any significant antioxidant activity. It is also suggested that ASTM D3895 tests be run on any of the derivatives isolated in the process development program.

\section{Curing Agent}

Curing agents or chain extenders are generally used in polyurethane and epoxy systems. This allows the use of these polymers as liquids until needed. Thus, in a reaction injection molding (RIM) system, the prepolymer and curing agent are rapidly fed into a mold and cured in place. The product must not only be reactive with the polyurethane prepolymer, but must do it at a rate such that the polymer can fill the mold entirely before being hardened in place. Thus, rates of reaction are the key to an effective curing agent.

\section{Market}

The market for curing agents are in the multimillions of pounds. The major suppliers of these materials are Albemarle and Air Products, Conap and UOP. The products used are mainly aromatic diamines. The Albemarle product is diethyltoluenediamine.

\section{Testing}

I am not aware of any laboratories that will test for effectiveness as a polyurethane or epoxy curing agent. There are laboratory tests that can be run to determine if any of the TNT derivatives can be effective curing agents. For example, a standard cast elastomer prepolymer can be mixed with the candidate curing agent in a container. If the mixture cures to a hard block, it is effective. If a gel is formed, it is likely not a good curing agent. If the curing agent is promising, additional testing could be done to determine the effect of the curing agent on the properties of a molded test coupon.

Samples of a standard cast elastomer prepolymer should be available from the major suppliers, Uniroyal, Air Products or Bayer. Any of these companies would make a good partner for the further testing and development of the product. Some literature from Uniroyal and Albemarle are attached.

Products that could be tested for this application include the AMPH, HAMAMPH and, if isolatable, the DAMDH products.

\section{Monomers}

The hydrolysis products from the hydroxylamines are difunctional aromatics, i.e., aminophenols. These materials can be polymerized with difunctional reactants, such as a dicarboxylic acid, to form polymeric materials. The scope of such chemistry is very broad and it would be difficult to predict if polymers made from such a system would have any commercial value. One can visualize making polymers in the laboratory, 
but the evaluation of the product is very difficult. It is suggested that PNNL approach a sophisticated polymer producer, such as Dow, Shell, Uniroyal or Bayer, to help in the evaluation of the potential of TNT di- or polyfunctional derivatives as specialty monomers. Altematively, a specialty monomer company like Advanced Monomer Supply (215 860-7783), might be interested in looking at these products. Since the quantity of the TNT derivatives is limited, perhaps the specialty monomer company would make a better partner as they would require lower volumes than their larger counterparts.

Candidate products are the AMPH, HAMAMPH and, if isolatable, the DAMDH products.

\section{Biocide/Disinfectant}

Biocides are used in applications varying from retarding algae growth in paints and preventing food spoilage. Many commercial products contain phenolic and nitrogen functional groups, e.g. nitroparaffins, quatemary ammonium salts, pentachlorophenol and hydantoins. The products that we can produce from TNT have many of these functional groups and may have biocidal properties. Of course, the question of whether these products are safe enough to be used in these applications needs to be determined.

\section{Markets}

The total market in the US for biocides in 1998 will be about \$2MMM. There are many large volume products based on sodium bromide and halogens or halogen producing compounds. The opportunity for a new product based on a derivative of TNT will have the problem of overcoming the long history that users have with existing products. Therefore, we do not expect that the TNT derivatives will attract large volume uses, if indeed, the products are effective.

\section{Testing}

There are some basic tests to determine bacteriological efficacy. These are the Minimum Inhibitory Concentration (MIC) and the Use Dilution Test. The MIC determines the lowest concentration of the test agent inhibiting visible growth. The Use Dilution Test determines the effectiveness of disinfectants and sterilants against designated organisms. These tests can be purchased from Bioscience Labs and Microbiology Services. Their literature is attached. These labs can also advise on the best test protocols.

Products recommended for testing include all that are economicaly feasible form the system, particularly those soluble in water.

\section{Flame Retardants}

It is not likely that any of the structures shown in figure 1 will function as a flame retardant for plastics. To get to a structure that could resemble a flame retardant would require derivitization of one or more of the candidate products. There is a need today for flame retardants that do not contain halogen. The nonhalogenated products offered today are not considered to be as effective as the halogenated ones and also effect the plastic adversely. The emphasis on the non-halogenated products has been on phosphorus containing molecules. It is therefore suggested that phosphorus derivatives of products such as HAM or AMPH be prepared and tested as candidate flame retardants.

\section{Markets}

The market for flame retardants for plastics was about $183 \mathrm{MM}$ lbs in the US in 1997. The dollar value is estimated at $\$ 700 \mathrm{MM}$. The predominant products are based on brominated aromatic compounds. The major suppliers of the brominated flame retardants for plastics are Great Lakes Chemical and Albemarle Corp. The 
major phosphorus-based products are triphenylphosphate (TPP) and resorcinol diphosphate (RDP). These products are supplied by FMC, AKZO and Albright and Wilson.

The brominated flame retardants are used at the relatively high loading of $15-20 \mathrm{wt} \%$. However, they can be used at lower levels if the co-additive antimony trioxide is used. The phosphorus flame retardants are used at higher loadings to gain the same level of effectiveness.

\section{Derivatives for Evaluation}

There are several routes to incorporate phosphorus into the molecule. One approach is suggested in figure 2. The ester interchange suggested with triethylphosphate results in byproduct ethanol, an easy compound to recover and recycle. The objective is to incorporate as much phosphorus into the molecule as possible. Therefore, it may be desirable to run a less than stoichiometric exchange such that less than three ethanols are exchanged. This approach can lead to a library of phosphates that can be tested for efficacy. If some efficacy is found, the most active molecule can be isolated.

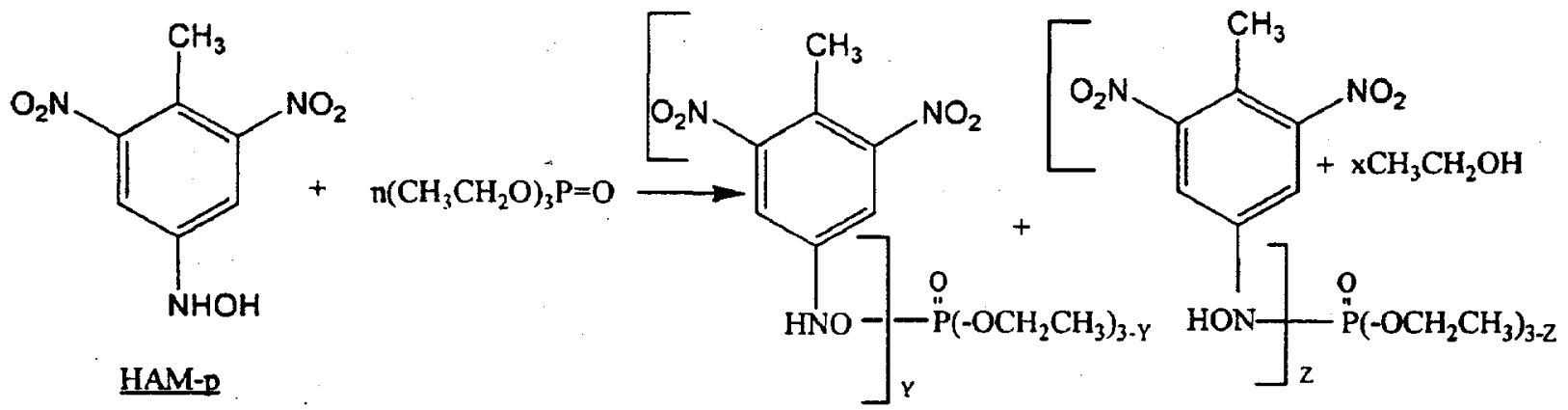<smiles>CCOP(=O)(OCC)O[P+](=O)[O-]</smiles>

Figure 2. Phosphorus incorporation routes.

\section{Testing}

There are several possible tests to determine if the derivatives are effective as a flame retardant. The tests all involve blending in a concentration of candidate material into a base resin and forming an appropriate shape for testing. Two tests are suggested for evaluating candidates, the UL-94 and the LOI test (ASTM D2863). The former involves igniting the $1 / 8$ " or $1 / 16$ " coupon in a bunsen burner. A Vo rating means the plastic will not bum. There are other classifications for lower efficacy. The LOI test is the limiting oxygen index, which determines the lowest concentration of oxygen required to burn the coupon. 
The above tests can be purchased from Omega Point Laboratories (800 966-5253) and Govmark Organization (516 293-8944). Copies of some of their literature are attached. Interestingly, the Carderock Division, Naval Surface Warfare Center, provides technical service in fire protection and does joint R\&D with industry and other government labs. They also run some of the tests described above. Some of their literature is attached.

If this approach is followed, it is suggested that the HAM products be converted to a phosphorus derivative, using triethylphosphate, and then tested.

\section{AZO DYES}

Aromatic amines are intermediates for the preparation of azo dyes. The aromatic amines are diazotized and then coupled with another activated aromatic. The AMPH derivatives are probably the best candidates to consider for diazotization.

\section{Markets}

The synthetic dye market is very large and complex, with many different types of products for use on different substrates. More than $300 \mathrm{MM}$ lbs of synthetic dyes are consumed annually in the US. The azo dyes probably represent $5-10 \%$ of this total. The azo dyes are expensive and cost in the range of $\$ 5-10 / \mathrm{lb}$.

The major companies producing azo dyes in the US are Ciba Geigy, Crompton \& Knowles and BASF.

\section{Testing}

It is difficult to assess the viability of a new azo dye without knowing a great deal about the current products and needs of the industry. This is true for all the suggested uses. However, the chemistry of preparing an azo dye can be tested in the lab. The first step is to prepare the diazonium compound from an aromatic amine such as AMPH. This is done by reacting the amine with sodium nitrite and acid, as shown in figure 3 . Once formed, the diazonium salt is then coupled with an activated aromatic, such as a toluidine. The resulting azo compound should be a colored material under the appropriate $\mathrm{pH}$ conditions.<smiles></smiles>

\section{AMPH-PM}

Figure 3. Azo dye production from AMPH. 
It is known that polynitroanilines are the most reactive in diazo forming reactions. Phenolics are the least reactive. In the AMPH compounds, both functional groups are present. I speculate that the 2 nitro groups will predominate and that the diazo reactivity will be high.

If the dye formation chemistry seems to work with the AMPH products, it is suggested that one or more of the companies mentioned above be contacted to determine their interest in pursuing this lead.

\section{OTHER}

I suggest that the intermediates be tested for pharmacological and agrochemical activity. From the functional groups present on the molecule, one can speculate that the molecules will have activity against organisms, insects and perhaps humans. The commercial potential in any of these areas will depend on the human toxicity of the products. It is suggested that PNNL provide samples of TNT products to pharmaceutical and agricultural chemical companies that are interested in testing new molecules.

Some $\mathrm{LD}_{50}$, Ames Test and/or other measures of toxicity should be done to determine the safety of these products. Some of this has been done according to Joe Hughes at Rice. Hughes is active in transforming TNT and is one of the authors of the paper attached. George Bennett is collaborating in this work and is doing Ames and other toxicity testing.

\section{Conclusions}

We have identified seven functional areas where derivatives of TNT might possibly find application. These application areas represent uses where the volume requirements can be within the limitations of the supply of TNT. Two of these areas, flame retardants and azo dyes require further chemical processing of the main products. We therefore suggest that these areas rank at the bottom of the priority list as far as evaluation attractiveness is concemed.

Of the remaining five areas, I would rank them in the following order:

- Antioxidants

- Curing Agents

- Biocides/Disinfectants

- Monomers

- Other (Phamaceutical and Agricultural Chemicals).

The above ranking implies that PNNL can do an evaluation and determine some measure of performance in their own lab or contracting out some simple test work. The lowest ranking areas can be tested simultaneously by providing samples to others for their testing, as suggested in the summary of these areas.

Accepting the above, the first requirement is that isolated and identified samples of the key products of the enzymatic transformation be obtained. How much material will depend on the amount of testing and the test requirements. Additional amounts will be required if PNNL chooses to have products evaluated by others for monomer, pharmaceutical or agricultural chemical applications. 
Will the products have activity in the areas suggested? We are not in a position to know the answer to this question at this time. It is suspected that there will be activity but whether of not it is adequate enough to have commercial value is the real question. Also, the toxicity of the products may preclude their application in some of the above areas. There is only one way to know the answer and that is to begin testing the products. 


\section{APPENDIX D}

DEGRADATION OF OCTAHYDRO-1,3,5,7-TETRANITRO-1,3,5,7-TETRAZOCINE (HMX) BY SODIUM CHLORITE UNDER AQUEOUS CONDITIONS 


\title{
Degradation of Octahydro-1,3,5,7-tetranitro-1,3,5,7-tetrazocine (HMX) by Sodium Chlorite under Aqueous Conditions
}

\author{
Manish M. Shah \\ Pacific Northwest National Laboratory \\ Shannon K. Roach \\ Pacific Northwest National Laboratory
}

\section{Summary}

Sodium chlorite degraded octahydro-1,3,5,7-tetranitro-1,3,5,7-tetrazocine $(\mathrm{HMX})$ at $70^{\circ} \mathrm{C}$ and atmospheric pressure under aqueous conditions. By increasing the concentration of sodium chlorite, the rate of HMX degradation increased. Additionally, a rise in reaction temperature significantly increased the rate of $\mathrm{HMX}$ degradation. This method could be an environmentally benign, cost-effective altemative the currently used techologies in the disposal of nitramine explosives.

\section{Introduction}

The recent shift away from arms production and towards diarmament by the leading military powers in our world has led to a need for environmentally safe methods of disposing of these weapons. Aging stockpiles of a variety of chemical explosives including RDX, HMX, TNT, PBX etc., as well as their metabolites, have built up considerably around the globe, with possibly 10,000 sites where resource recovery or disposition (RRD) technology is needed. It is estimated that the current stockpile of these energetic materials weighs 449 , 308 tons and that through 2001, over 1.2 million tons will pass through or reside in it (Joint Ordnance Commands Group; 1995).

At one time, destruction of these contaminates involved incineration, open buming, or open detonation which proved to further the problem by being cost-inhibiting and/or contaminating the environment with harmful explosive residue. Additionally, nitroaromatic compunds that are widely used in the manufacture of dyes, pharmaceuticals, pesticides, and explosives have contributed to the overall contamination of our environment. Many nitro-based compounds and their by-products and degradation products form polar contaminates with relatively high water solubilities. These contaminates are believed to be potentially mutagenic and carcinogenic (K. Spiegel 1997). As a result, technology is now required to address the problem of contaminated sites where soil, sediments and ground water have been polluted with nitro-based compounds. Environmentally friendly, cost-effective techologies are needed to address the problems of the disposal of stockpiled energetic materials and the clean-up of our nitro-based compound contaminated environment.

Previously we have reported on the degradation of the explosive hexahydro-1,3,5-trinitro-1,3,5-triazine (RDX) by sodium chlorite at room temperature $\left(22-24^{\circ} \mathrm{C}\right)$, atmospheric pressure and in aqueous conditions. Using the same methods, we have also found that the energetic compound octahydro-1,3,5,7-tetranitro1,3,5,7-tetrazocine ( $\mathrm{HMX})$ is degraded by sodium chlorite, yet requires conditions above room temperature $\left(22-24^{\circ} \mathrm{C}\right)$. Concurrent with the RDX method previously reported, this chlorite based technology is environmentally friendly and safe, offers potential economic benefits, and can be easily implemented over incineration, open burning, open detonation and other technologies available today. 


\section{Materials and Methods}

\section{Chemicals}

The chemicals used in this study were octahydro-1,3,5,7-tetranitro-13,5,7-tetrazocine (HMX) (Chem Service, West Chester, PA) and sodium chlorite (Aldrich Chemical Company, Milwaukee, WI). HPLC grade methyl alcohol (Sigma Chemical Co., St. Louis MO) was also used.

\section{Analytical Methods}

A Hewlett Packard (Palo Alto, CA) 1090L HPLC with a photodiode array UV-visible detector was used to identify and quantify the HMX in solution using the retention times and the UV-visible spectra of the peaks. The detector was sampling at $230 \mathrm{~nm}$ and $254 \mathrm{~nm}$ with a reference at $550 \mathrm{~nm}$. Separation was performed using an Alltech Platinum C18 reverse phase column $(250 \mathrm{~mm} \times 4.6 \mathrm{~mm})$ as well as an Alltech Platinum C18 guard column (100 $\AA, 5$ micron) heated to $38^{\circ} \mathrm{C}$. The isocratic mobile phase consisted of 50 percent methanol and 50 percent Milli-Q water (Millipore Co., Bedford, MA) flowing at a rate of $1.0 \mathrm{ml}^{\text {minute }}{ }^{-1}$. The sample injection volume was $30 \mu \mathrm{l}$. A PC workstation with ChemStation software controlled the HPLC.

\section{Experimental Methods}

All experiments involved the mixing of HMX solutions with sodium chlorite under varying experimental conditions. All reactions were performed at nomal atmospheric pressure and under aqueous conditions. The effects of changes in temperature and sodium chlorite concentration on HMX degradation were studied. The concentration of HMX was monitored by HPLC. Calibration curves using HMX standards were generated for each experiment and used to calculate the concentration of HMX in solution. Additionally, control samples, containing only the explosive and water, were prepared for each trial and subjected to the same environmental conditions as the experimental vials.

A stock solution of $\mathrm{HMX}\left(1000 \mu \mathrm{g} \mathrm{ml}^{-1}\right.$ in acetonitrile, with water) was used in all experiments. The appropriate amount of HMX stock solution was first added to the reaction vials $(2 \mathrm{ml})$ containing water. Then, suitable amounts of sodium chlorite crystals were added directly to the HMX solutions. For experiments at temperatures above room temperature $\left(22-24^{\circ} \mathrm{C}\right)$, an environmentally controlled incubator (VWR Scientific Co., Philadelphia, PA) was used to bring up and maintain the desired temperatures of the reaction vials.

\section{Results}

To investigate the degradation of HMXX by sodium chlorite, sodium chlorite crystals were added to the HMX solution in water at room temperature $\left(22-24^{\circ} \mathrm{O}\right)$. The concentration of HMC in solution was monitored over 24 hours but HMX was not degraded. We also noticed that the HMX was not as miscible in sodium chlorite solutions as RDX had been. In our previously reported study with RDX and sodium chlorite, we found that temperature was major factor in the degradation of the explosive. Therefore; we incubated the same initial concentrations of $\mathrm{HMX}$ and salt at $70^{\circ} \mathrm{C}$ and monitored the $\mathrm{HMX}$ concentration over a seven-hour period. Figure 1 shows the change in HMX concentration over seven hours. The concentration of HMX decreased significantly over time when treated with sodium chlorite and incubated at $70^{\circ} \mathrm{C}$. In fact after only one hour of sodium chlorite treatment, the HMX concentration had decreased by $93 \%$. However, the concentration of the control sample (containing only $\mathrm{HMX}$ and water) did not change significantly over the same period of time. 


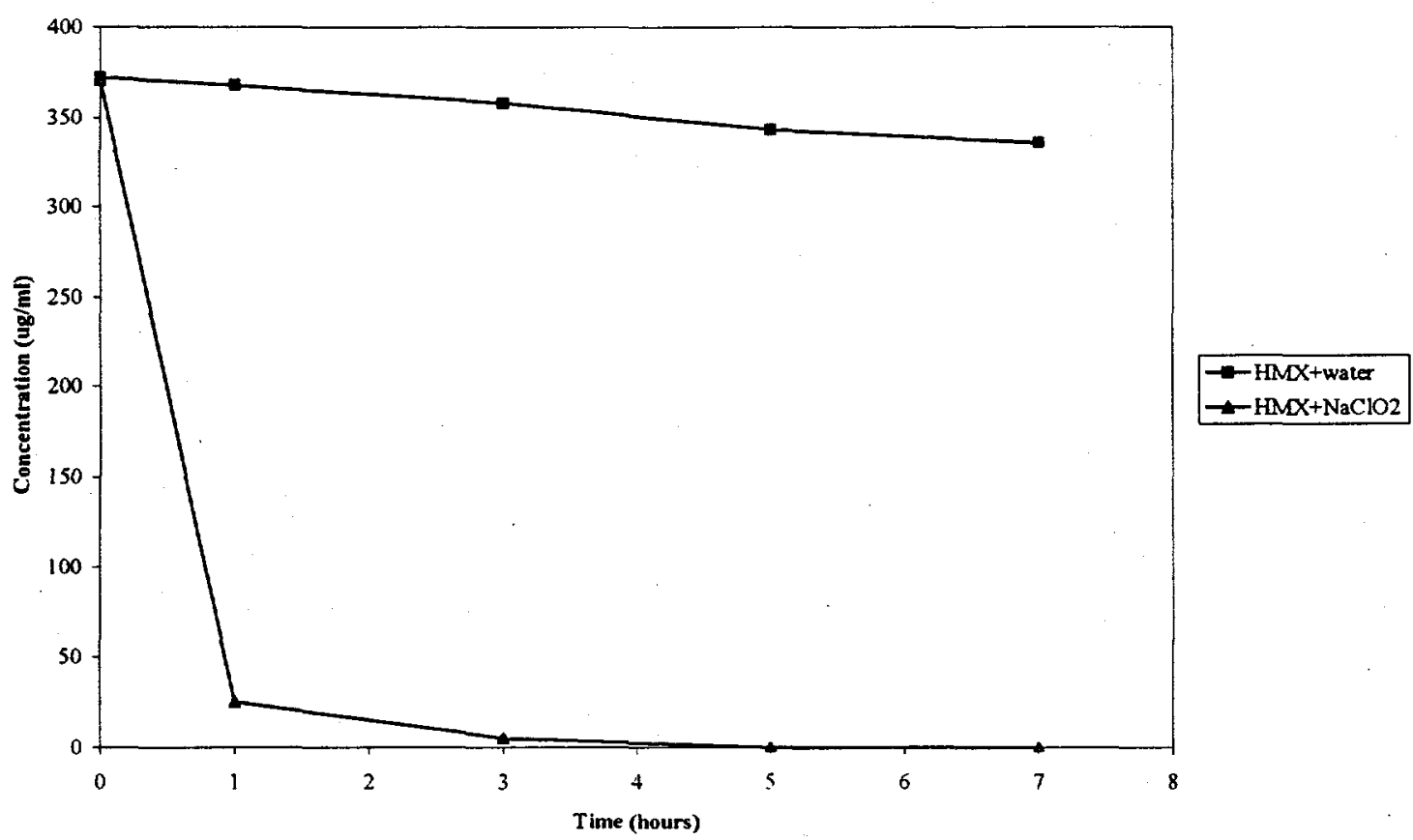

Figure 1: Kinetics of HMX degradation by sodium chlorite. Solutions contained final concentrations of $200 \mu \mathrm{g} \mathrm{ml}^{-1}$ of $\mathrm{HMX}$ and $100 \mathrm{mg} \mathrm{m}^{-1} \mathrm{NaClO}_{2}$ in water $(\mathbf{\Delta})$. The reaction was performed at $70^{\circ} \mathrm{C}$ and at atmospheric pressure in a $2 \mathrm{ml}$ reaction vial. The control sample contained only HMX and water $(\square)$. The total volume of the reaction mixtures was $1 \mathrm{ml}$.

We also evaluated the effects of varying the initial concentration of sodium chlorite on HMX degradation at $70^{\circ} \mathrm{C}$ in aqueous conditions. We found that the rate of HMX degradation was increased with increases in the concentration of sodium chlorite. Table 1 compares the rate of $\mathrm{HMX}$ degradation at various concentrations of sodium chlorite. The rate increased with increasing concentrations of sodium chlorite, but decreased between $0.898 \mathrm{M}$ and $1.1 \mathrm{M}$. The decline in rate between these two molarities is probably because at such high concentrations of sodium chlorite, the availability of $\mathrm{HMX}$ may be the rate-limiting factor, due to the initial high HMX degradation rates. It is important to note that the rate numbers were calculated based on changes in HMX concentration over a period of one hour. Thus, the estimated rate shown here is an average rate but not an initial rate. As a whole, the average rate of degradation of HMX increased with increases in sodium chlorite. 
Table 1. Rates of HMX Degradation by Different Concentrations of $\mathrm{NaClO}_{2}$ at $70^{\circ} \mathrm{C}^{2}$

\begin{tabular}{|c|c|}
\hline $\mathrm{NaClO}_{2}$ Concentration (M) & Average Rate ${ }^{\mathrm{b}} \mathrm{mg} / \mathrm{L} / \mathrm{hr}$ \\
\hline $\begin{array}{l}0.11 \\
0.23 \\
0.45 \\
0.67 \\
0.89 \\
1.10\end{array}$ & $\begin{array}{l}6.82 \\
62.02 \\
96.20 \\
161.90 \\
211.77 \\
180.46\end{array}$ \\
\hline
\end{tabular}

2Each sample contained final concentrations of $200 \mu \mathrm{g} \mathrm{ml}^{-1} \mathrm{HMX}$ and varying amounts of $\mathrm{NaClO}_{2}$ in water incubated at $70^{\circ} \mathrm{C}$ at atmospheric pressure. The total volume of the reaction mixtures was $1 \mathrm{ml}$.

bRates were calculated using the concentration of HMX remaining 1 hour after addition of the sodium chlorite.

\section{Discussion}

The energetic characteristics of explosive HMX were eliminated as a result of its treatment with sodium chlorite. The process was perfomed under mild conditions, lacking acid, base or organic solvents, at relatively low temperatures $\left(70^{\circ} \mathrm{C}\right)$, and required no expensive reaction chamber. Therefore, the process is environmentally benign, energy efficient, and cost-effective.

Current technologies proposed for the disposal of nitro-based compounds involve the use of microoganisms O.Hughes et.al. 1998; C. Huang 1998; S. Nicklin et.al. 1998), zero-valent iron (J. Singh et.al. 1998), photolysis with UV and ozone (P. Bose et.al. 1998a, 1998b), and chemical reagents including hydrazine and BNAH (1benzyl-1,4-dihydronicotinamide) (R.D. Chapman et.al. 1998), molten salt, base hydrolysis, and organic solvents (DMSO-dimethylsulphoxide), among others. These processes are relatively less cost-effective, either due to high temperatures needed for processing, the use of organic solvents, or expensive reaction chambers. Moreover, microbial technology cannot be used directly for the destruction of explosive stockpiles, as they cannot tolerate a high concentration of explosives. As a result, these techonologies pose a difficult design problem in building mobile systems at thousands of sites.

The proposed sodium chlorite technology has effectively degraded RDX and HMX under mild conditions. We have reported previously that RDX was degraded at room temperature, with degradation rates increasing with increaseing temperatures. Our $\mathrm{HMX}$ trials showed that temperatures above $22-24^{\circ} \mathrm{C}$ were needed in order to initiate the oxidative activity of sodium chlorite on the HMX molecule. It was also found that HMX was not as miscible in sodium chlorite solutions as RDX was. These characteristics of HMX are likely related to the fact that HMX is more stable than RDX and has a higher explosion termperature test value than RDX (U.S. Army). Although temperature has proven to be a limiting factor in the degradation of HMX by sodium chlorite, a reaction temperature of $70^{\circ} \mathrm{C}$ is still relatively low compared to the temperature required for other processes such as supercritical water oxidation, base hydrolysis, and molten salt processes.

The sodium chlorite based process overcomes many of the limitations found in current explosive degradation technology and maintains the silent features of bioprocessing. The primary attractive features of chlorite based processing are simplicity and speed, and a mobile systern can be designed without any major technical or cost hurdles. 
Chlorite solutions have many applications as cleaning and antimicrobial agents in food processing and in other industries. They can be used to wash equipment and floors at sites where nitroamine compounds are handled on a day-to-day basis, and can be sprayed in remote locations. These features are very attractive for certain sites where contamination is present on the surfaces and there is a safety risk involved with human exposure. Additionally, the chlorite technology does not release any air pollutants and will meet the regulations in the clean air act amendments, RDRA and FFCA. Sodium chlorite is a well-known oxidizer and is widely applicable to the destruction of all nitramine class explosives and compounds. The applications of this technology could be useful in the treatment of explosive stockpiles, unexploded ordance sites, and in the clean up of explosive contaminated groundwater, soil, and sediments. Other oxidizers or bleaching agents should be evaluated as mediums in the destruction of energetic materials.

\section{Acknowledgements}

Our project is funded by the SERDP program of the U.S. Department of Defense.

\section{Nomenclature}

HMX---Octahydro-1,3,5,7-tetranitro-1,3,5,7-tetrazocine

RDX---Hexahydro-1,3,5-trinitro-1,3,5-triazine

$\mathrm{NaClO}_{2}$---sodium chlorite

\section{References}

Bose, P., Glaze, W.H., Maddox, D.S. 1998a. "Degradation of RDX by various advanced oxidation processes: I. Reaction rates." Water Res., 32(4), 997-1004.

Bose, P., Glaze, W.H., Maddox, D.S. 1998b. "Degradation of RDX by various advanced oxidation processes: II. Organic byproducts." Water Res., 32(4), 1005-1018.

Chapman, R.D., O'Brien, R.A., Kondracki, P.A. 1995. Novel reagents for $\mathrm{N}-\mathrm{NO}_{2}$ scission. product insert. National Technical Information Service, Springfield, Virginia.

Coleman, N.V., Nelson, D.R., Duxbury, T. 1998. "Aerobic biodegradation of hexahydro-1,3,5-trinitro1,3,5-triazine (RDX) as a nitrogen source by a Rhodococcus sp., strain DN22." Soil Biol. Biochem., $30(8 / 9), 1158-1167$.

Huang, C. 1998. The anaerobic biodegradation of the high explosive octahydro-1,3,5,7-tetranitro-1,3,5,7tetrazocine (HMX) by and extremely thermophilic anaerobe Caldicellulosiruptor owensensis. $\mathrm{Ph}$.D. Dissertation, University of California, Los Angeles.

Hughes, J., Bennett, G. 1998. Anaerobic biodegradation of 2.4,6-trinitrotoluene and other nitroaromatic compounds by Clostridium acetobutylicum. National Center for Environmental Research \& Quality Assurance.

Joint Ordnance Commands Group, Munitions Demil/Disposal Subgroup, 1995. Joint Demilitarization Study. Number 323. Washington D.C.

Nicklin, S., Bruce, N.C., French, C.E., Travis, E.R., Basran, A. 1998. "Biodegradation of RDX explosives by cell-free enzymic extract from Rhodococcus rhodochrous 1 ly." PCT Int. Appl. $26 \mathrm{pp}$.

Singh, J., Comfort, S.D., Shea, P.J. 1998. "Remediating RDX contaminated water and soil using zerovalent iron" J. Environ. Qual. 27 (5), 1240-1245. 
Spiegel, K., Welsch, T. 1997. "Monitoring degradation processes of explosives by HPLX analysis with UV-and amperometric detection." Fresenius' J. Anal. Chem. 357(3), 33-337.

U. S. Army. "Explosives and Ammunition." Chapter 13 in AMC REG 385-100, Safety Manual, United States Army Materiel Command, Alexandria, Virginia. 


\section{APPENDIX E}

DEGRADATION OF HEXAHYDRO-1,3,5-TRINITRO-1,3,5-TRIAZINE (RDX) BY SODIUM CHLORITE UNDER MILD REACTION CONDITIONS 


\title{
Degradation of Hexahydro-1,3,5-trinitro-1,3,5-triazine (RDX) by Sodium Chlorite under Mild Reaction Conditions
}

\author{
Manish M. Shah \\ Pacific Northwest National Laboratory \\ Shannon K. Roach \\ Pacific Northwest National Laboratory
}

\section{Summary}

Sodium chlorite degraded hexahydro-1,3,5-trinitro-1,3,5-triazine (RDX) at room temperature $\left(22-24^{\circ} \mathrm{C}\right)$ and atmospheric pressure under aqueous conditions. By increasing the concentration of explosives and/or sodium chlorite, the rate of $\mathrm{RDX}$ degradation increased. Additionally, a rise in reaction temperature significantly increased the rate of RDX degradation. Of the possible metabolites formed from this process, both nitrite and nitrate were identified. This method could provide a cost-effective altemative for treatment of explosives under environmentally safe conditions.

\section{Introduction}

The massive stockpiles of explosives and their contamination in water, soil and sediment around the world pose a serious threat to humankind, health and ecology (Spiegel et al. 1997; Jarvis et al. 1998; Hovatter et al. 1997). Currently, acceptable technologies or resources used to demilitarize aging stockpiles and clean up contaminated sites does not exist. It has been estimated that there are more than 10,000 sites around the world where explosive treatment technology is needed. The current stockpile of energetic materials requiring resource recovery or disposition (RRD) weighs 449,308 tons. Through 2001 , over 1.2 million tons will pass through or reside in the RRD account (Joint Ordnance Commands Group; 1995). A totally different but significantly similar challenge exists in cleaning up the sites where soil and ground water are contaminated with TNT, RDX, HMX, and other nitro-based explosives. In addition, unexploded ordnance (UXO) sites around the world also require a technology for disposal of explosives.

Some of the current technologies used to eliminate explosives are incineration, open buming and open detonation. The cost of incineration is beyond our means and resources and open buming and open detonation are environmentally unacceptable. There are many other techniques, however, currently being developed that degrade RDX in environmentally friendly ways. Anaerobic biodegradation of explosives has been reported using a number of different microoganisms (Huang, Chi-Yu 1998; Huang, Wenfeng et al. 1998; Nicklin et al. 1998; Coleman et al. 1998; Boopathy et al. 1998; Young et al. 1997; Hawari et al. 1997). In these cases, the first step in the process is the removal of nitrite, which is used as the primary nitrogen source for the microorganisms. However, the process is limited by growth rates of the microoganisms and the cost of maintaining sufficient populations for use in bioremediation. Also, phytoremediation techniques are currently in development to treat contaminated sediment and groundwater (Thompson, 1997; Best et al. 1997; Wolfe et al. 1998). These techniques use the redox activity of dehydragenases, reductases, and oxidases found in plants. Additionally, photolysis of RDX with UV, ozone, and peroxide has been reported (Bose et al. 1998). They report that approximately 50 percent of the organic nitrogen is converted to nitrate during the oxidation process, suggesting that the carbon and nitrogen within the ring structure of RDX are oxidized to organic byproducts.

We are reporting sodium chlorite based technology for destruction of explosives. It is environment-friendly and safe, offers potential economic benefits, and can be easily implemented over incineration, open buming, open detonation and other technologies available today. 


\section{Materials and Methods}

\section{Chemicals}

The chemicals used in this study were hexahydro-1,3,5-trinitro-1,3,5-triazine (RDX) (Chem Service, West Chester, PA) and sodium chlorite (Aldrich Chemical Company, Milwaukee, WI). HPLC grade methyl alcohol (Sigma Chemical Co., St. Louis, MO) was also used. Milli-Q water was used for all the experiments.

\section{Analytical Methods}

A Hewlett Packard (Palo Alto, CA) 1090L HPLC with a photodiode array UV-visible detector was used to identify and quantify the RDX in solution. The detector sampled at $230 \mathrm{~nm}$ and $254 \mathrm{~nm}$ with a reference at $550 \mathrm{~nm}$. Separation was performed using an Alltech Platinum C18 reverse phase column (250 $\mathrm{mm} \times 4.6 \mathrm{~mm})$ as well as an Alltech Platinum $\mathrm{C} 18$ guard column $\left(100 \AA, 5\right.$ micron) heated to $38^{\circ} \mathrm{C}$. The isocratic mobile phase consisted of 50 percent methanol and 50 percent Milli-Q water (Millipore Co., Bedford, MA) flowing at a rate of $1.0 \mathrm{ml}$ minute ${ }^{-1}$. The sample injection volume was $30 \mu \mathrm{l}$. A PC workstation with ChemStation software controlled the HPLC. Ion chromatography was used to analyze the RDX metabolites nitrate and nitrite.

\section{Experimental Methods}

All experiments involved the mixing of RDX solutions with sodium chlorite under varying experimental conditions. All reactions were performed at normal atmospheric pressure and under aqueous conditions. The effects of changes in sodium chlorite concentration, RDX concentration and temperature on RDX degradation were studied. The concentration of RDX was monitored by HPLC. Calibration curves using RDX standards were generated for each experiment and used to calculate the concentration of RDX in solution. Additionally, control samples, containing only the explosive and water, were prepared for each trial and subjected to the same environmental conditions as the experimental vials. The metabolites nitrite and nitrate, formed by the degradation of RDX by sodium chlorite treatment, were analyzed using ion chromatography.

A stock solution of $\mathrm{RDX}(1000 \mu \mathrm{g} / \mathrm{ml}$ in acetonitrile, with water added). was used in all the experiments. The appropriate amount of RDX stock solution was first added to the reaction vials $(2 \mathrm{~mL})$ containing water. Then, suitable amounts of sodium chlorite crystals were added directly to the RDX solutions. For experiments at varying temperatures, an environmentally controlled incubator (VWR Scientific Co., Philadelphia, PA) was used to bring up and maintain the desired temperatures of the reaction vials.

\section{Results}

To investigate the degradation of RDX by sodium chlorite, sodium chlorite crystals were added to the RDX solution in water at room temperature $\left(22-24^{\circ} \mathrm{O}\right)$. The degradation of RDX was monitored over 72 hours. Figure 1 shows the changes in concentration of $R D X$ in solution with and without sodium chlorite treatments. Furthermore, the concentration of RDX was decreased in samples where sodium chlorite was added. The concentration of RDX in the control without sodium chlorite treatment, containing only RDX and water, remained essentially unchanged over time.

We further investigated the effects of varying the initial concentration of the sodium chlorite on RDX degradation at room temperature $\left(22-24^{\circ} \mathrm{O}\right)$ under aqueous conditions. We found that the rate of RDX degradation was increased with increases in the concentration of sodium chlorite. Table 1 compares the rate 
of RDX degradation at various concentrations of sodium chlorite. The relative rate increase was slow between $0.57 \mathrm{M}$ and $1.14 \mathrm{M}$. At those high concentrations of sodium chlorite, the availability of RDX may be the rate-limiting factor because of higher RDX degradation rates. It may be worth noting here that the rate numbers were calculated based on changes in RDX concentration over a 1.5 hour time period. Thus, the estimated rate is an average rate but not an initial rate. Overall, the average rate of degradation of RDX increased with increase in sodium chlorite.

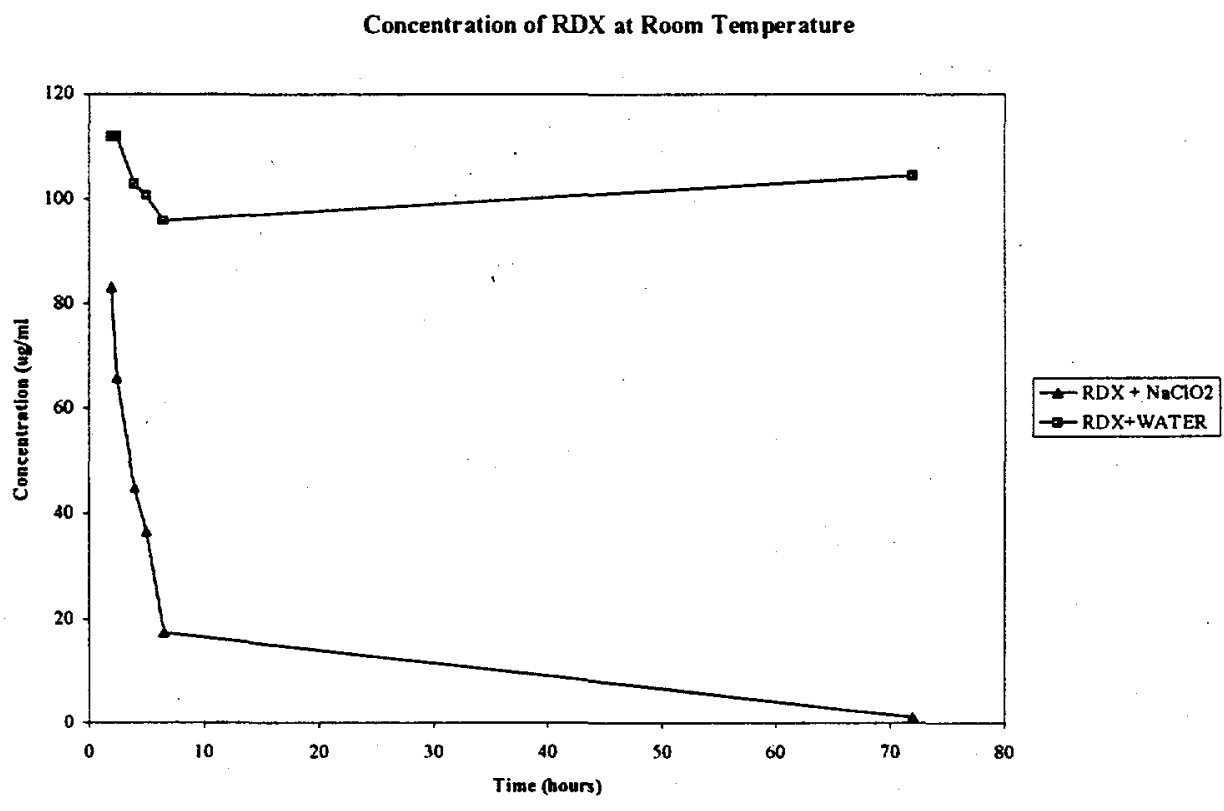

Figure 1: Kinetics of RDX degradation by sodium chlorite. Solutions contained final concentrations of $100 \mu \mathrm{g} \mathrm{ml}^{-1}$ of $\mathrm{RDX}$ and $100 \mathrm{mg} \mathrm{ml}^{-1} \mathrm{NaClO}_{2}$ in water $(\mathbf{A})$. The reaction was performed at room temperature $\left(22-24^{\circ} \mathrm{C}\right)$ and atmospheric pressure in a $2-\mathrm{ml}$ reaction vial. The control sample contained only $\mathrm{RDX}$ and water ( $\square$. The total volume of the reaction mixtures was $1 \mathrm{ml}$.

Table 1. Rates of RDX Degradation by Different Concentrations of $\mathrm{NaClO}_{2}$ at Room Temperature $\left(22-24^{\circ} \mathrm{C}\right)^{2}$

\begin{tabular}{c|c}
\hline $\mathrm{NaClO}_{2}$ Concentration (M) & $\begin{array}{c}\text { Average Rate } \\
\mathbf{m g} / \mathrm{L} / \mathbf{h r}\end{array}$ \\
\hline 0.07 & 3.54 \\
0.14 & 10.13 \\
0.28 & 17.4 \\
0.57 & 26 \\
1.14 & 32 \\
\hline
\end{tabular}

${ }^{2}$ Each sample contained final concentrations of $200 \mu \mathrm{g} \mathrm{ml}^{-1} \mathrm{RDX}$ and varying amounts of $\mathrm{NaClO}_{2}$ in water incubated at room temperature $\left(22-24^{\circ} \mathrm{C}\right)$ and atmospheric pressure. The total volume of the reaction mixtures was $1 \mathrm{ml}$.

Rates were calculated using the concentration of RDX remaining 1.5 hour after addition of the sodium chlorite. 
We also evaluated the effects of varying the initial RDX concentration on the rate of RDX degradation. While keeping the sodium chlorite concentration constant, we varied the amount of $\mathrm{RDX}$ in solution. The reactions were again performed at room temperature $\left(22-24^{\circ} \mathrm{C}\right)$ under aqueous conditions. Table 2 compares the amount of $R D X$ degradation at varying initial $R D X$ concentrations, with a fixed amount of sodium chlorite. As can be expected, the amount of RDX degraded increased with increases in the initial concentration of RDX. Over a three-hour period, the $10 \mu \mathrm{g} \mathrm{m}^{-1}$ sample degraded by $4.57 \mu \mathrm{g}$, compared to the $200 \mu \mathrm{g} \mathrm{ml}^{-1}$ sample which degraded by $130.73 \mu \mathrm{g}$ in the same time period.

Table 2. $\mathrm{RDX}$ degradation in 3 hours with $1.13 \mathrm{M} \mathrm{NaClO}_{2}$ and varying concentrations of $\mathrm{RDX}^{2}$

\begin{tabular}{c|c}
\hline \hline Concentration of RDX $(\mu \mathrm{g} / \mathrm{ml})$ & Amount Degraded $(\mu \mathrm{g})$ \\
\hline 10 & 4.57 \\
25 & 11.71 \\
50 & 25.57 \\
100 & 56.62 \\
150 & 90.64 \\
200 & 130.73 \\
control $^{\mathrm{b}}$ & 0.00 \\
\hline
\end{tabular}

${ }^{2}$ Each sample contained final concentrations of $100 \mathrm{mg} \mathrm{ml}^{-1}$ of $\mathrm{NaClO}_{2}$ and varying concentrations of RDX, and Milli- $\mathrm{Q}$ in water and incubated at room temperature (22$24^{\circ} \mathrm{C}$ and atmospheric pressure. The total volume of the reaciton mixtures was $1 \mathrm{ml}$. bThe control sample contained final concentrations of $100 \mu \mathrm{g} \mathrm{ml}^{-1} \mathrm{RDX}$ in water, no $\mathrm{NaClO}_{2}$ was used.

cThe amount degraded was calculated by subtracting the concentration of RDX remaining after three hours in the sodium chlorite solution from the intial concentration of RDX before sodium chlorite was added.

Using ion chromatography, sodium chlorite treated RDX samples were analyzed to determine the presence of nitrate and nitrite metabolites from RDX. Both nitrates and nitrites were present. The combined molar ratio of nitrate and nitrite to RDX was around 1.5. The sodium chlorite peaks on the chromatographs had retention times very close to those of nitrate and nitrite. This could have caused a masking effect on the metabolite peaks. At this time, a method to remove the sodium chlorite is being developed.

The degradation of RDX by sodium chlorite was further characterized by evaluating the effects of temperature on the rate of RDX degradation. Samples containing the same concentrations of RDX and sodium chlorite were incubated at different temperatures. The amount of RDX degradation was estimated based on changes in RDX concentration over a certain time period. As temperature increased, the extent of RDX degradation increased as well (Table 3). However, in control samples, the concentration of RDX remained the same at all temperatures.

The rates of RDX degradation at various temperatures were estimated based on changes in RDX concentration at certain time intervals. Because the rate rose significantly with small rises in temperature, it was necessary to make the rate calculations for the various samples using different time intervals. The time intervals used for calculating rates for the samples at $25^{\circ} \mathrm{C}, 35^{\circ} \mathrm{C}, 45^{\circ} \mathrm{C}$, and $55^{\circ} \mathrm{C}$ were $2,1,0.5$ and 0.5 hour respectively. Therefore, it must be noted that the initial rates could be much higher what is estimated here. The rate more than tripled with a 10-degree rise in temperature, increasing from $32 \mathrm{mg} / \mathrm{L} / \mathrm{hr}$ at $25^{\circ} \mathrm{C}$, to $110 \mathrm{mg} / \mathrm{L} / \mathrm{hr}$ at $35^{\circ} \mathrm{C}$. Figure 2 shows the increase in rate with increasing temperature. Because the reaction occurs so quickly at temperatures above $45^{\circ} \mathrm{C}$, it is likely that at $55^{\circ} \mathrm{C}$ the actual rate is greater than is calculated here. Control samples without sodium chlorite treatment were run for each temperature assessment and showed no significant change in concentration of RDX 
Table 3. Percent degradation of RDX with $1.13 \mathrm{M} \mathrm{NaClO}_{2}{ }^{2}$

\begin{tabular}{c|l}
\hline \hline Temperature (Celsius) & \multicolumn{1}{|c}{ After 2 Hour Incubation $^{\mathrm{b}}$} \\
\hline $22-24$ & $26 \%$ \\
35 & $91.40 \%$ \\
45 & $100 \%$ \\
55 & $100 \%$ \\
\hline
\end{tabular}

${ }^{2}$ Each sample contained final concentrations of $200 \mu \mathrm{g} \mathrm{ml} \mathrm{m}^{-1} \mathrm{RDX}$ and $100 \mathrm{mg} \mathrm{ml}^{-1}$ $\mathrm{NaClO}_{2}$ in water. The reactions were performed at room temperature $\left(22-24^{\circ} \mathrm{C}\right), 35^{\circ} \mathrm{C}$, $45^{\circ} \mathrm{C}$, and $55^{\circ} \mathrm{C}$ in $2-\mathrm{ml}$ reaction vials at atmospheric pressure. The total volume of the reaction mixtures was $1 \mathrm{ml}$.

${ }^{b}$ Calculations were made comparing the HPLC data from the baseline concentration of RDX before adding sodium chlorite to the remaining concentration after 2 hours of incubation in sodium chlorite solutions.

\section{Rate of RDX Degradation at Varying Temperatures}

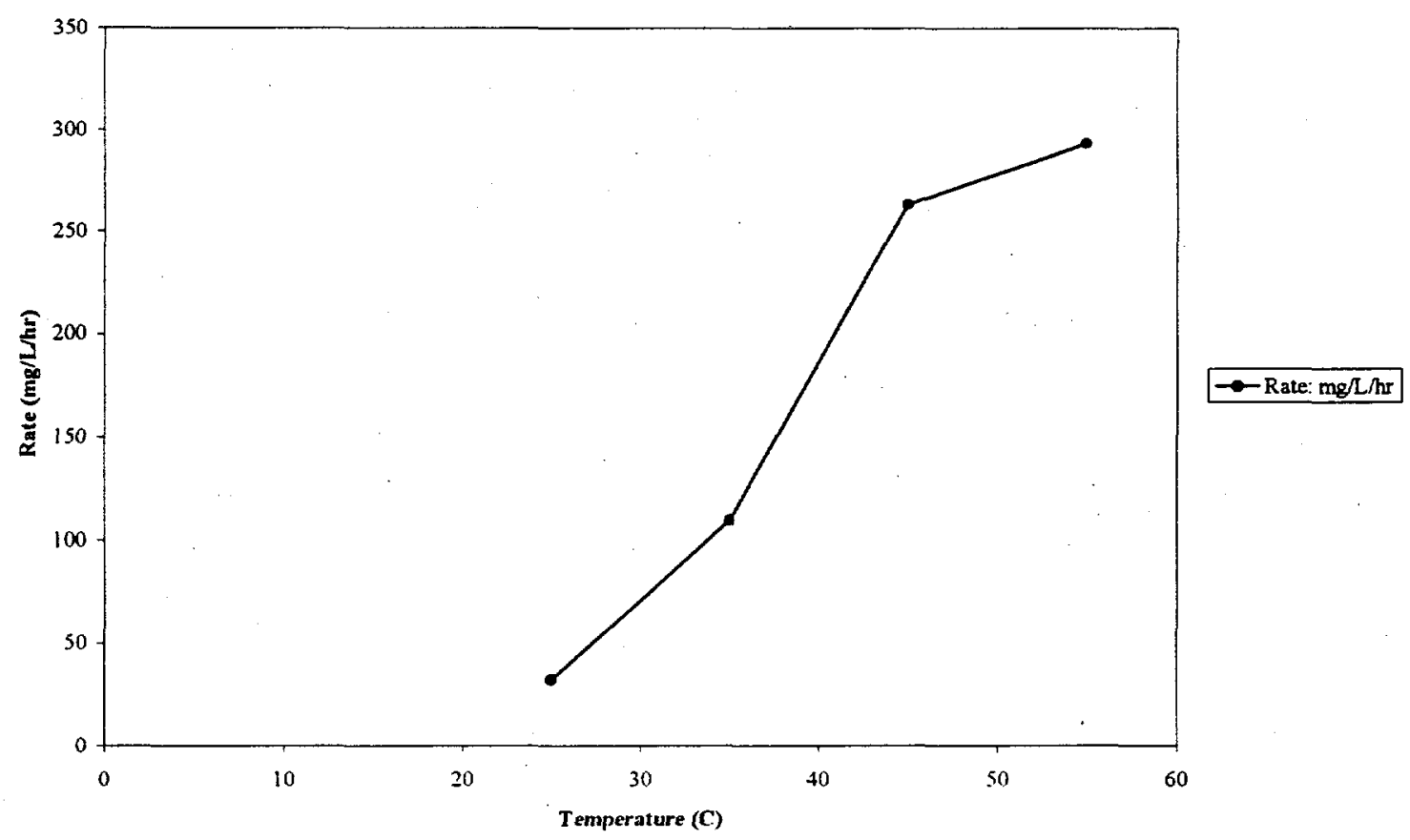

Figure 2: RDX degradation at varying temperatures. Solutions contained final concentrations of $200 \mu \mathrm{g} \mathrm{m}^{-1}$ of $\mathrm{RDX}$ and $100 \mathrm{mg} \mathrm{m}^{-1} \mathrm{NaClO}_{2}$ in water. The reactions were performed at room temperature $\left(22-24^{\circ} \mathrm{C}\right.$, $35^{\circ} \mathrm{C}, 45^{\circ} \mathrm{C}$, and $55^{\circ} \mathrm{C}$ in $2-\mathrm{ml}$ reaction vials at atmospheric pressure. The total volume of the reaction mixtures was $1 \mathrm{ml}$. 


\section{Discussion}

The toxicity of explosive RDX is eliminated as it is degraded through the oxidative power of sodium chlorite. The process was performed under mild conditions (without acid or base or organic solvents) and at room temperature $\left(22-24^{\circ} \mathrm{C}\right)$. Thus, the process is energy efficient and environmentally benign, whereas other current technologies require high temperature, organic solvents and expensive capital equipment.

We expect that chlorite technology will be an affordable and easily implemented method to destroy explosives with high public acceptance associated with it. Current technologies used to destroy explosives are limited to incineration, open burning and open detonation. Incineration is expensive and public acceptance is limited. Open buming and open detonation are environmentally unfriendly due to the potential release of air pollutants, and these methods also have poor public acceptance. Other technologies under development are processes involving molten salt, base hydrolysis, organic solvents (DMSO-dimethylsulphoxide solvent process) and supercritical water oxidation. These processes are relatively less cost-effective, either due to high temperatures needed for processing or the use of organic solvents. As a result, they pose a difficult design problem in building mobile systems at thousands of sites.

The transformation of TNT by microorganisms and plants has been reported. Microbial technology cannot be used directly for the destruction of explosive stockpiles as they cannot tolerate a high concentration of explosives. They have a relatively low efficiency of destruction at high concentrations of explosives, and therefore have slower kinetics. However, they could be used in combination with chlorite technology for a follow-up treatment of the explosives.

The sodium chlorite based process overcomes many of the limitations found in the current processes, while maintaining the silent features of bioprocessing. Chlorite is used as a cleaning agent and an antimicrobial agent in food processing, as well as many other applications. The primary attractive features of chlorite based processing are simplicity and speed. A mobile system can be designed without any major technical or cost hurdles. Chlorite solutions can be used to wash equipment and floors at sites where explosives are handled on a day-to-day basis. Finally, they can be sprayed in remote locations. This feature is very attractive for certain sites where contamination is present on the surfaces and there is a safety risk for human exposure. The chlorite technology does not release any air pollutant will meet the regulations of clean air act amendments, RCRA and FFCA.

Sodium chlorite is a well-known oxidizer and thus it may be useful in the destruction of a variety of other organic contaminants present in stockpiles. As nitro-compounds are used in dye; polymer, defense and agrochemical industries, the technology could even be useful in treatment of other industrial wastes. The applications of this technology could be useful in the treatment of explosive stockpiles, UXO and in the clean up of explosive contaminated groundwater, soil, and sediments. Other oxidizers or bleaching agents should be evaluated as agents in the destruction of energetic materials.

\section{Acknowledgements}

Our project is funded by the SERDP program of the U.S. Department of Defense.

\section{Nomenclature}

RDX---Hexahydro-1,3,5-trinitro-1,3,5-triazine

$\mathrm{NaClO}_{2}$---sodium chlorite 


\section{References}

Best, E.P., Sprecher, S.L., Fredrickson, H.L., Zappi, M.E., Larson, S.L. 1997. "Screening subnersed plant species for phytoremediation of explosives-contaminated groundwater from the Milan Army Ammunition Plant." Army Engineer Waterways Experiment Station, AD-A334 994/1/XAB.

Boopathy, R., Gurgas, M., Ullian, J., Manning, J.F. 1998. "Metabolism of explosive compounds by sulfate-reducing bacteria" Curr. Microbiol., 37(2):127-131.

Boopathy, R., Manning, J., Kulpa, C.F. 1998. "Biotransformation of explosives by anaerobic consortia in liquid culture and in soil slurry." Int. Biodeterior. Biodegrad., 41(1):67-74.

Bose, P., Glaze, W.H., Maddox, D.S. 1998a. "Degradation of RDX by various advanced oxidation processes: I. Reaction rates." Water Res., 32(4):997-1004.

Bose, P., Glaze, W.H., Maddox, D.S. 1998b. "Degradation of RDX by various advanced oxidation processes: II. Organic byproducts." Water Res., 32(4):1005-1018.

Coleman, N.V., Nelson, D.R., Duxbury, T. 1998. "Aerobic biodegradation of hexahydro-1,3,5-trinitro1,3,5-triazine (RDX) as a nitrogen source by a Rhodococcus sp., strain DN22." Soil Biol. Biochem., $30(8 / 9): 1158-1167$

Hawari, J., Greer, C.W, Jones, A.M., Sunahara, G.I, Shen, C.F., Guiot, S.R., Ampleman, G., Thiboutot, S. 1997. "Soil contaminated with explosives: a search for remediation technologies." Challenges Propellants Combust: 100 Years Nobel, ed. Kuo, Kenneth K, pp. 135-144. Int. Symp. Spec. Top. Chem. Propul, 4th Meeting, 1996. Begell House, New York.

Hovatter, P.S., Talmage, S.S., Opresko, D.M., Ross, R.H. 1997. "Ecotoxicity of nitroaromatics to aquatic and terrestrial species at army Superfund sites" ASTM Spec. Tech. Publ., $6^{\text {th }}$ volume, 117-129.

Huang, C. 1998. The anaerobic biodegradation of the high explosive octahydro-1,3,5,7-tetranitro1,3,5,7-tetrazocine (HMX) by and extremely thermophilic anaerobe Caldicellulosinuptor owensensis. Ph.D. Dissertation, University of California, Los Angeles.

Huang, W., Zhao, J., Huang, M. 1998. "Experimental research on TNT-RDX wastewater treatmentbiodegradation and adsorption." Hanneng Cailiao., 6(2):49-53.

Jarvis A.S., Mcfarland, V.A., Honeycutt, M.E. 1998. "Assessment of the effectiveness of composting for the reduction of toxicity and mutagenicity of explosive-contaminated soil." Ecotoxicol. Environ. Saf., 39(2):131-135.

Nicklin, S., Bruce, N.C., French, C.E., Travis, E.R., Basran, A. 1998. "Biodegradation of RDX explosives by cell-free enzymic extract from Rhodococcus rhodochrous 11 ." PCT Int. Appl., Patent No. WO 9807839 .

Spiegel, K., Welsch, T. 1997. "Monitoring degradation processes of explosives by HPLX analysis with UV-and amperometric detection." Fresenius' J. Anal. Chem. 357(3):33-337.

Thompson, P.L. 1997. "Phytoremediation of munitions (RDX, TNT) waste at the lowa Army Ammunition Plant with hybrid poplar trees." Diss. Abstr. Int., 58(8):4388

Wolfe, N.L., Carreira, L.H., Delgado, M.C. "Aquatic plant enzymes for bioremediation of soil, sludge, and waters" PCT Int. Appl., Patent No. WO 9423857. 
Young, D.M., Kitts, C.L., Unkefer, P.J., Ogden, K.L. 1997. "Biological breakdown of RDX in slurry reactors proceeds with multiple kinetically distinguishable paths." Biotechnol. Bioeng., 56(3):258267.

U. S. Army. "Explosives and Ammunition." Chapter 13 in AMC REG 385-100, Safety Manual, United States Army Materiel Command, Alexandria, Virginia.

U. S. Army. 1995. Joint Demilitarization Study, Number 323. Joint Ordnance Commands Group, Munitions Demil/Disposal Subgroup Washington D.C. 


$$
=
$$




\section{PATENT APPLICATION ABSTRACTS}

\section{Superoxide Patent US Patent File No. E-1655 A Method for Digesting a Nitro-Bearing Explosive Compound}

The present invention is a process wherein superoxide radicals are used to break down the explosive compounds. The process has an excellent reaction rate for degrading explosives, and operates at ambient temperature and atmospheric pressure in aqueous conditions. Because the superoxide molecules are small, much smaller than an enzyme molecule for example, they can penetrate the microstructure of plastic explosives faster. The superoxide generates reactive hydroxyl radicals, which can destroy other organic contaminants, if necessary, along with digesting the explosive nitro-bearing compound.

\section{Sodium Chlorite Patent US Patent File No. E-1730 Method of Digesting an Explosive Nitro Compound}

The present invention is a process wherein bleaching oxidants are used to digest explosive nitro compounds. The process has an excellent reaction rate for digesting explosives and operates under multivariate conditions. Reaction solutions may be aqueous, non-aqueous or a combination thereof, and can also be any $\mathrm{pH}$, but preferably have a $\mathrm{pH}$ between 2 and 9 . The temperature may be ambient as well as any temperature above which freezing of the solution would occur and below which any degradation of the bleaching oxidant would occur or below which any explosive reaction would be initiated. The pressure may be any pressure, but is preferably ambient or atmospheric, or a pressure above a vapor pressure of the aqueous solution to avoid boiling of the solution. Because the bleaching oxidant molecules are small, much smaller than an enzyme molecule for example, they can penetrate the microstructure of plastic explosives faster. The bleaching oxidants generate reactive hydroxyl radicals, which can destroy other organic contaminants, if. necessary, along with digesting the explosive nitro compound.

\section{Enzyme Patent File No. E-1717 Method of Reduction of Nitroaromatics by Enzymatic Reaction with Redox Enzymes}

The invention is a method for the controlled reduction of nitroaromatic compounds such as nitrobenzene and 2,4,6-trinitrotoluene by enzymatic reaction with redox enzymes, such as Oxyrase (Trademark of Oxyrase, Inc., Mansfield, Ohio). The redox enzyme loses its ability to catalyze the reduction in the presence of oxygen, which provides control of the process and allows the recovery of a partially reduced intermediate product. 
PNNL-12081

\section{Distribution}

No. of

Copies

\section{OFFSITE}

2 Dr. Robert Holst

Executive Director

SERDP Program Office

901 North Stuart Street

Room 301

Arlington VA 22203-1821

ONSITE

16 Pacific Northwest National Laboratory

R. E. Allen

$\mathrm{K} 8-14$

M. M. Shah (10)

P8-08

Technical files (5)

Dist.1 